\title{
SEIS ANOS DE EXPERIMENTAÇÃO DE ADUBAC,ĀO (N P K) EM VIDEIRA CULTIVAR NIAGARA ROSADA VEGETANDO EM UM SOLO PODZOLIZADO, INDAIATUBA, SP
}

\author{
MAURILO MONTEIRO TERRA \\ Pesquisador Cientifico, MS
}

Orientador: Prof. Dr. MOACYR DE O.C. DO BRASIL SOBRINHO

Tese apresentada à Escola Superior de Agricultura "Luiz de Queiroz", da Universidade de São Paulo, para obtenção do título de Doutor em Agronomia, Area de Concentração: Solos e Nutrição de Plantas.

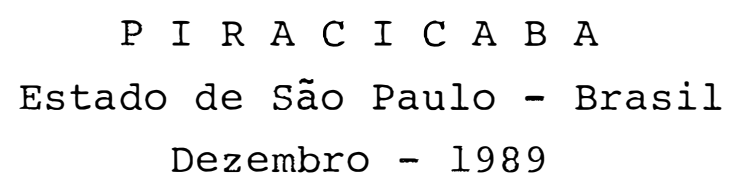




\section{Terra, Maurilo Monteiro}

T323s Seis anos de experimentação de adubação (NPK) em videira cultivar Niagara Rosada vegetando em um solo podzolizado, Indaiatuba, SP. Piracicaba, 1989. $158 \mathrm{p}$.

Tese - ESALQ

Bibliografia.

1. Solo podzólico - Adubação - Indaiatuba 2. Uva Adubação - Indaiatuba I. Escola Superior de Agricultụ ra Luiz de Queiroz, Piracicaba

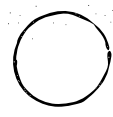

CDD 634.83 


\title{
SEIS ANOS DE EXPERIMENTAÇÃO DE ADUBAÇÃO (N P K) EM VIDEIRA
} CULTIVAR NIAGARA ROSADA VEGETANDO EM UM SOLO PODZOLIZADO, INDAIATUBA, SP

MAURILO MONTEIRO TERRA

\begin{abstract}
Aprovada em: 21.03.1990
Comissão Julgadora:

Prof. Dr. Moacyr de Oliveira C. do Brasil Sobrinho-ESALQ/USP Prof. Dr. Henrique Paulo Haag -ESALQ/USP

Prof. Dr. Jorge de Castro Kiehl -ESALQ/USP

Prof. Dr. Godofredo Cesar Vitti -ESALQ/USP

Dr. Mário ojima

-IAC/SAASP
\end{abstract}

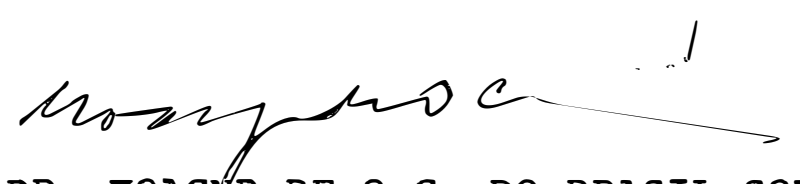

Prof. DR. MOACYR DE O.C. DO BRASIL SOBRINHO orientador 
HOMENAGEM

Instituto Agronômico de Campinas

Escola Superior de Agricultura "Luiz de Queiroz" Conselho Nacional de Desenvolvimento Cientificb e Tecnológico - CNPq. 
Ao meu pai Aracy, pelo incentivo constante à minha formação educacional e profissional,

DEDI CD

A minha esposa Sandra, aos meus filhos queridos Giuliano e Felipe, 


\section{AGRADECIMENTOS}

O autor expressa os seus agradecimentos:

- Ao Professor Doutor Moacyr de Oliveira Camponez do Brasil Sobrinho pela orientação, amparo e incentivo durante a realização e confecção do presente trabalho.

- Ao Sr. Airton Casarin, proprietário do Sítio Palmeiras, em Indaiatuba, SP, onde foi realizado o experimento.

- A Pesquisadora Científica Violeta Nagai pela colaboração e orientação na execução e discussão das anālises estátísticas.

- Ao meu particular amigo e colega Ivan José An.tunes Ribeiro pelo auxílio e estímulo à realização deste trabalho.

- Ao Engenheiro Agrônomo e amigo André Camargo Pereira da Silva, estagiário da Seção de Viticultura e nosso orientado, pe la colaboração na revisão de literatura.

- À Bibliotecāria Maria Lūcia Nery Dutra de Castro, do Instituto Agronômico, pela colaboração e orientação na elaboração das referências bibliográficas.

- A Secretária Sandra Aparecida Manoel pelos serviços de datilografia.

- Aos funcionārios da Seção de Viticultura, do Institū to Agronômico, Nereu Pedro dos Santos, Antonio Allé e Meire Correia da Silva Ferrari e a todos que direta ou indiretamente,/contribuiram para a realização deste trabalho. 


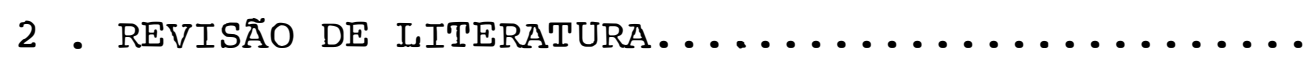

2.1 . Funções do nitrogênio................ 5

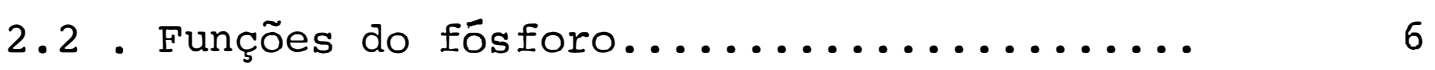

2.3 . Funções do potāssio................. 7

2.4 - Concentração de macronutrientes na folha. 8

2.5 . Doses de $\mathrm{N}, \mathrm{P}$ e $\mathrm{K}$ recomendadas.......... 11

2.6 - Resultados experimentais com aplicação

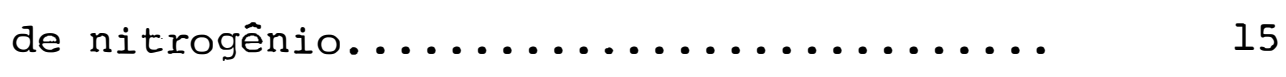

2.7 . Resultados experimentais com aplicação

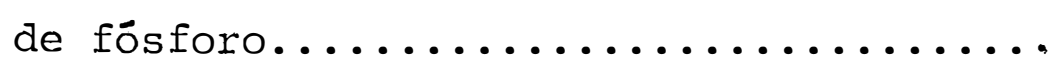

2.8 Resultados experimentais com aplicação

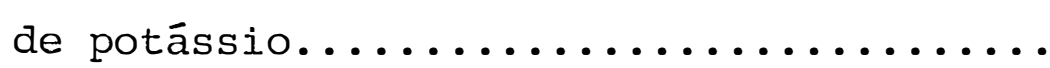

2.9 - Resultados experimentais com aplicação de nitrogênio, e/ou fósforo e/ou potāsüio 
3 . MATERIAL E MÉTOdOS.................... 37

3.1 . Cultivar estudado.............. 37

3.2 . Fertilizantes estudados............. 38

3.3 . Local do experimento................ 39

3.4 . Classificação do solo.............. 47

3.5 . Porta-enxerto e idade.............. 47

3.6 . Espaçamento.................. 47

3.7 . Sistema de condução.............. 47

3.8 . Poda.......................... 48

3.9 . Tratos culturais................ 48

3.10. Delineamento experimental........... 48

3.11. Modos e épocas de aplicação de fertilizantes,....................... 51

3.12. Modos e épocas de coleta de amostras de

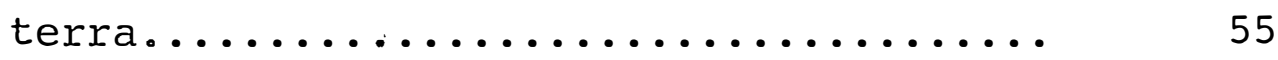

3.13. Modos e épocas de coleta de amostras de

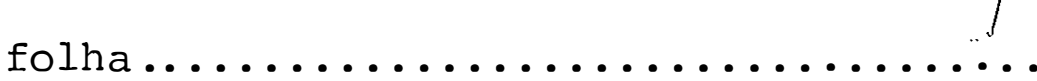

3.14. Maturação, colheita, número de cachos e peso médio de cacho............... 57

3.15. Anâlises quîmicas de terra e de folha.... 58

3.16. Anālises estatísticas............... 59 
4.1.1. Comparação entre as fontes de

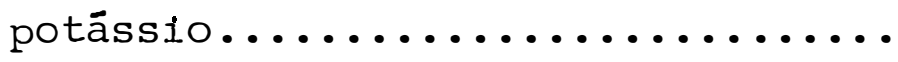

4.1.2. Comparação com a testemunha

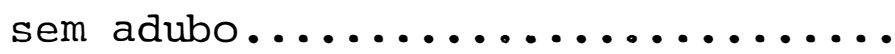

4:1.3. Análises de regressão...........

4.1.4. Dose econômica................

4.2. Resultados de peso médio de cacho......... 4.2.1. Comparação entre as fontes de

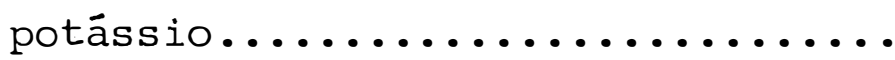

4.2.2. Comparação com a testemunha

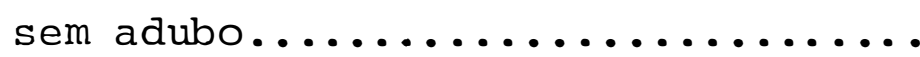

4.2.3. Análises de regressão.

4.3. Resultados de concentração de macronutrientes na matéria seca das folhas......

4.3.1.1. Comparação entre as fon tes de potássio. 
4.3.1.2. Comparação com a testẹ munha sem adubo..........

4.3.1.3. Análises de regressão.....

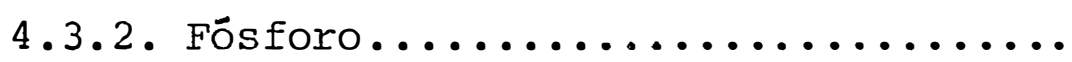

4.3.2.1. Comparação entre as fontes de potássio.......

4.3.2.2. Comparação com a teste munha sem adubo..........

4.3.2.3. Análises de regressão.....

4.3.3.1. Comparação entre as fontes de potássio........

$4 \cdot 3 \cdot 3 \cdot 2$. Comparação com a testẹ munha sem adubo..........

4.3.3.3. Análises de regressão..... 106

4.3.4. Cálcio...................... 108

4.3.4.1. Comparação entre as

fontes de potássio........

4.3.4.2. Comparação com a testẹ munha sem adubo.......... 
viii.

Página

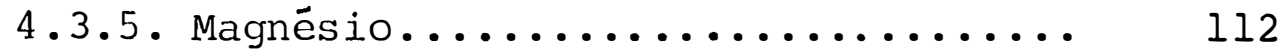

4.3.5.1. Comparação entre ! as

fontes de potássio........

114

4.3.5.2. Comparação com a testemunha sem adubo......... $\quad 114$

4.3.5.3. Anālises de regressão..... 117

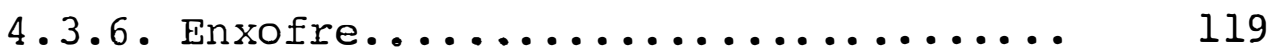

4.3.6.1. Comparação entre as fontes de potássio....... ! 119

4.3.6.2. Comparação com a teste munha sem adubo.......... 122

4.3.6.3. Análises de regressão.... 122

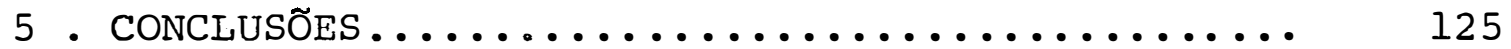

5.1. Produção............................ 125

5.2. Peso médio de cacho.................. 127

5.3. Concentração de macronutrientes na matéria seca das folhas................ 
ix.

Pāgina

7 . BIBLIOGRAFIA RECOMENDADA................... 144

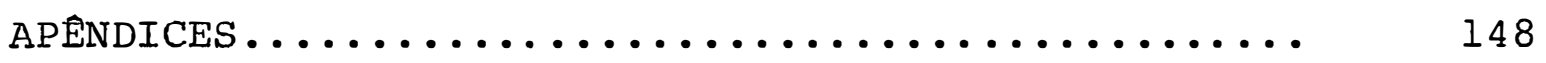




\section{SEIS ANOS DE EXPERIMENTAÇÃO DE ADUBAÇ̃̃O (N P K) EM VIDEIRA CULTIVAR NIAGARA ROSADA VEGETANDO EM UM SOLO PODZOLIZADO, INDAIATUBA, SP}

Autor: MAURILO MONTEIRO TERRA

Orientador : PROF. DR. MOACYR DE O.C. DO BRASIL SOBRINHO

\section{RESUMO}

Foi realizado um experimento durante 6 anos no município de Indaiatuba, Estado de são Paulo, com videiras do cultivar Niagara Rosada que estavam com 6 anos de idade. Anualmente, foram aplicadas 5 diferentes doses de $\mathrm{N}(30,60$, 90 , 120 e $150 \mathrm{~g} / \mathrm{planta})$ e de $\mathrm{P}_{2} \mathrm{O}_{5}$ e $\mathrm{K}_{2} \mathrm{O}(40,120,200,280$ e $360 \mathrm{~g} / \mathrm{planta),} \mathrm{em} \mathrm{vārias} \mathrm{combinações,} \mathrm{afim} \mathrm{de} \mathrm{determinar} \mathrm{os}$ níveis adequados de adubação $N$, $P$ e $K$ e verificar os acréscimos de produção, de peso de cacho e de concentração de macronutrientes na matēria seca das folhas, obtidos com às adubações nitrogenada, fosfatada e potāssica, em comparação com a testemunha sem adubo.

Avaliou-se também neste ensaio o comportamento de duas fontes de potássio, cloreto de potássio e sulfato duplo de potássio e magnésio, misturadas em diferentes porcenta gens. 
A fonte de potássio não influiu na produção, no peso médio do cacho e na concentração dos macronutrientes na matéria seca das folhas.

A produção e o peso do cacho da uva responderam às aplicações de diferentes combinações de doses de $\mathrm{N}$, $\mathrm{P}_{2} \mathrm{O}_{5}$ e $\mathrm{K}_{2} \mathrm{O}$ em relação à testemunha sem adubo. No decorrer dos anos, $_{p}$ as concentrações de $\mathrm{N}$ e $\mathrm{K}$ na matéria seca das folhas responderam gradativamente a estas adubações.

$\mathrm{Na}$ análise conjunta dos seis anos ${ }_{F}$ houve resposta de produção às adựações nitrogenadas e potássica, mas não houve resposta de peso do cacho para as adubações com nitrogênio, fósforo e potássio, verificadas através das equações de regressão. Considerando individualmente cada ano de ensaio, não houve efeito das adubações nitrogenada, fosfatada e potássica, nas concentrações de $\mathrm{N}$, Ca, Mg e S na matéria se ca das folhas.

As produções máximas de uva alcançadas no conjunto 1980-85, foram obtidas com a aplicação de $105 \mathrm{~g}$ de N/ pianta e de $276 \mathrm{~g}$ de $\mathrm{K}_{2} \mathrm{O} / \mathrm{planta}$.

As doses econômicas recomendadas no conjunto 1980-85, situaram-se nas faixas de 92 a $103 \mathrm{~g}$ de $\mathrm{N} / \mathrm{planta} \mathrm{e}$ de 202 a 261 g de $\mathrm{K}_{2} \mathrm{O} / \mathrm{planta.}$ 


\section{SIX YEARS OF N P K FERTILIZER EXPERIMENTATION WITH GRAPEVINE CULTIVAR NIAGARA ROSADA, GROWING IN A PODZOL SOIL, IN INDAIATUBA, SP}

Author: MAURIIO MONTEIRO TERRE: Adviser: PROF. DR. MOACYR DE O.C. DO BRASII SOBRINHO

\section{SUMMARY}

A field trial was carried up during a perioc of 6 years in Indaiatuba,SP, with grapevines of cultivar Niagara Rosada. By the time the trial was set up the grapevines were 6 year old. Five rates of $N(30,60,90,120$ and $150 \mathrm{~g} / \mathrm{plant})$ and $\mathrm{P}_{2} \mathrm{O}_{5}$ and $\mathrm{K}_{2} \mathrm{O}(40,120,200,280$ and $360 \mathrm{~g} /$ plant) were applied annually in different combinations, in order to determine the adequate $\mathrm{N}, \mathrm{P}$ and $\mathrm{K}$ fertilization levels and verify the increments in yield, bunch weight and macronutrient concentration in the dry matter of leaves.

Two sources of potassium, potassium chloride and double sulphate of potassium and magnesium, were also tested in mixtures of different proportions.

There was no effect of potassium source on yield, bunch weight and macronutrient concentration in the leaves. Yield and bunch weight showed response to the different rates of $\mathrm{N}, \mathrm{P}_{2} \mathrm{O}_{5}$ and $\mathrm{K}_{2} \mathrm{O}$. Gradually, along with time, the concentration of $\mathrm{N}$ and $\mathrm{K}$ in the leaves responded 
xiii.

to these fertilizations.

In the 6-year joint analysis, $\mathrm{N}$ and $\mathrm{K}$ fertilization increased yield, whereas no effect on bunch weight was observed for $\mathrm{N}_{\varepsilon} \mathrm{P}$ and $\mathrm{K}$ application. Considering each year individually, there was no effect of $N_{*}, P$ and $K$ fertili zation on the $\mathrm{N}_{\text {, }} \mathrm{Ca}_{\mathrm{p}} \mathrm{Mg}$ and $\mathrm{S}$ concentrations in the leaves. Maximum yields of grape during the period of 1980-85 were reached with $105 \mathrm{~g}$ of $\mathrm{N} / \mathrm{plant}$ and $276 \mathrm{~g}$ of $\mathrm{K}_{2} \mathrm{O} /$ plant.

Economical rates for the $1980-85$ period fell within the ranges of 92-103 $\mathrm{g}$ of $\mathrm{N} / \mathrm{plant}$ and 202-261 $\mathrm{g}$ of $\mathrm{K}_{2} \mathrm{O} / \mathrm{plant}$. 


\section{INTRODUCÃO}

A área cultivada com videiras no Brasil, segundo dados da Fundação Instituto Brasileiro de Geografia e Estatística - IBGE „ referentes ao ano de 1987, é de 59.076 ha. Nesta área são produzidas 557.414 t de uva, com uma produtividade média de $9.436 \mathrm{~kg} / \mathrm{ha}$, (ANUÁRIO ESTATÍSTICO DO BRASII, 1988). Estes números representam 0,102\% da área mundial ocupada pela videira e $0,38 \%$ da produção mundial (SITUATION de la viticulture dans le monde en 1986, 1987).

Os principais Estados produtores,

detendo 99,45\% da produção nacional são: Rio Grande do Sul, com área de 39.852 ha, produção de 351.380 t e rendimento médio de $8.817 \mathrm{~kg} / \mathrm{ha} ;$ São Paulo, com área de $9.084 \mathrm{ha}$, produção de 107.234 t e rendimento médio de $11.805 \mathrm{~kg} / \mathrm{ha} ;$ Santa Catarina, com área de 5.820 ha, produção de 60.000 t e rendimento médio de $10.309 \mathrm{~kg} / \mathrm{ha}$; Paraná, com área de $2.225 \mathrm{ha}$, produção de 24.600 t e rendimento médio de $11.065 \mathrm{~kg} / \mathrm{ha}$; Pernambuco, com área de 825 ha, produção de 11.180 t e rendimento médio de $13.552 \mathrm{~kg} / \mathrm{ha}$ (ANUARIO ESTATISTICO DO BRASIL, 1988).

A viticultura paulista representa um expressivo segmento da atividade agrícola no Estado. O valor da sua 
produção ocupa o 170 lugar entre os produtos de origem vege tal, sendo mais importante que todas as outras frutas de clima temperado juntas. Por outro lado, o cultivo da videira é de exploração tipicamente familiar e minifundiāria, sendo as uvas produzidas em pequenas propriedades de até 10 hectares. A mão de obra é constituída pela família do produtor e/ou meeiros, sendo,portanto, atividade fixadora do homem à terra.

o Estado de são Paulo é o principal produtor de uvas para mesa do Brasil, bastante distanciado das demais unidades da federação. Entretanto, toda sua produção está cal cada em praticamente dois cultivares: Niagara Rosada, produto ra de uvas rústicas, com mais de 34 milhões de plantas, e Itá lia, produtora de uvas finas, com cerca de 1,3 milhões de plantas (PIRES \& TERRA, 1987a).

A viticultura de maior express̃ão neste Estado continua sendo o cultivo de uvas rústicas para mesa, predominando os cultivares americanos. O 'Niagara Rosada' constitui, ainda hoje, perto de $85 \%$ da uva rústica para mesa do mercado paulista.

O cultivo desta uva rústica está amplamente di fundido nó Estado de São Paulo, sendo que a região dos municí pios de Jundiaí, Louveira, Itupeva, Vinhedo, Jarinf, Morungaba, Itatiba e Valinhos, mantém a liderança na produção do 'Niagara Rosada', com mais de 24 milhões de plantas.

o clima dessa região, por apresentar inverno com temperaturas baixas, impede o escalonamento da poda, e com isso a safra anual principal dá-se no mês de janeiro, época 
em que os preços caem a níveis baixos.

Digna de nota é a expansão do plantio da videi ra 'Niagara Rosada" no município de Indaiatuba, que atualmente conta com mais de 4 milhöes de plantas, alcançando o segundo lugar entre os municipios paulistas produtores deste cultivar (PIRES \& TERRA, 1987 a). Este município apresenta um microclima diferente da região tradicional produtora de uvas rústicas para mesa ${ }_{p}$ com temperaturas mais elevadas tanto no inverno quanto na primavera e no verão. Desta forma, apresenta a vantagem da maturação mais precoce, proporcionando melhor remuneração ao produtor nos entrepostos de comercialização por ocasião da colheita, que é realizada em fins de novem bro a meados de dezembro.

Embora seja importante a cultura de uva no Bra sil e o cultivo de uva rústica para mesa no Estado de são Pau 10, existe pequena quantidade de trabalhos experimentais refe rentes à adubação e à nutrição mineral, necessitando portanto de estudos básicos em casas de vegetação e estudos práticos em condições de campo.

Sabe-se também que os aumentos frequentes nos preços dos fertilizantes e a utilização inadequada e/ou iñdiscriminada dos mesmos, têm elevado constantemente o custo de produção e/ou reduzido a produção, diminuindo assim a renda líquida dos viticultores.

Os objetivos deste estudo foram:

a) determinar as doses adequadas de adubação com nitrogênio , fósforo e potássio. 
b) verificar os acréscimos de produção, de peso de cacho e de concentração de macronutrientes na folha, obtidos com as adubações nitrogenada, fosfatada e potássica.

c) avaliar o efeito das fontes de potássio, cloreto de potássio e sulfato duplo de potássio e magnésio, aplicadas nas seguintes porcentagens: 100:0; 75:25; 50:50; 25:75 e 0:100, do nivel 3 utilizado. 


\section{REVISÃO DE LITERATURA}

2.1. Funções do nitrogênio

o nitrogênio tem como função primāria manter ou promover o crescimento necessário da planta (CHRISTENSEN et alii, 1978). E componente das proteínas, essenciais para formação dos protoplastos; é constituinte da clorofila, aminoācí dos e nucleotídeos (WEAVER, 1976 e MILLER, 1986).

o nitrogênio é o elemento que tem maior ...'influência na produção, brotação e formação de folhas, determi nando o tamanho e compactação dos cachos da videira. (PHILLIPINE COUNCIL FOR AGRICULTURAL RESEARCH, 1976 e PEACOCK . et alii, 19.82) .

Conforme NEGRINI (1988), o nitrogênio determina o crescimento vegetativo da planta, sendo elemento essencial na fase de crescimento. Sua absorção, segundo CHRISTENSEN et alii (1978) e CHAUVET \& REYNIER (1984), não é feita de maneira uniforme, possuindo três fases críticas, a saber: durante o crescimento ativo dos ramos produtivos, no florescimento e durante o aumento dos frutos.

A planta da videira absorve o nitrogênio funda 
mentalmente na, forma de $\mathrm{NO}_{3}{ }^{-}$, e em menor quantidade na forma de $\mathrm{NH}_{4}^{+}$(TERRA \& PIRES, 1987). Como nos compostos orgânicos, o nitrogênio, segundo MALAVOLTA et alii (1974), se acha em formas reduzidas, devendo $\circ \mathrm{NO}_{3}{ }^{-}$ser transformado em $\mathrm{NH}_{4}^{+}$antes de sua incorporação em aminoácidos e proteínas.

Devido à grande mobilidade deste elemento dentro da planta, uma deficiência terá seus primeiros sintomas aparecendo nos órgãos mais velhos da videira (MILIÉr, 1986 e TERRA \& PIRES, 1987).

2.2. Funções do fós foro

O fósforo, segundo NEGRINI (1988), possui nume rosas funções na planta, fazendo parte das nucleoproteínas, que são importantes no processo de multiplicação celular, e de várias enzimas, que são utilizadas em diversas funções bio químicas.

A maior parte do fósforo na planta é enrontrada nas partes de crescimento rápido, como regiões meristemáti cas, sementes e frutos (WEAVER, 1976). Pode ser considerado como regulador do desenvolvimento da planta, sendo neciessário em pequenas quantidades (CHAUVET \& REYNIER, 1984).

Por este elemento ser encontrado em regiões me ristemāticas, é responsável pela formação de um forte e profundo sistema radicular, alēm de regular o amadurecimento de ramos e frutos (PHILLIPINE COUNCIL FOR AGRICULTURAL RESEARCH, 
1976).

E absorvido pela planta essencialmente como $\mathrm{H}_{2} \mathrm{PO}_{4}{ }^{-}$; sofrendo transformações bastante rāpidas logo depois da absorção; não sofrendo redução dentro da planta e permanecendo no estado de oxidação que é absorvido (MALAVOLTA et alii, 1974).

Apresenta boa mobilidade na planta, logo os primeiros sintomas de deficiência começam a aparecer nos órgãos mais velhos da videaira (MILLER, 1986 e TERRA l \& PIRES, 1987).

2.3. Funções do potássio

o potāssio é importante para a planta, pois é. o elemento responsável pela abertura e fechamento dos estômatos (WEAVER, 1976 e MILLER, 1986). Alēm da participação nesse processo, é importante tambēm na formação do açúcar, na sinte se de proteínas e na divisão celular (CHRISTENSEN et alii, 1978 e NEGRINI, 1988). Migra dos tecidos velhos para jovens e pode-se mover das folhas para os frutos na fase de maturação; isto significa que um bom suprimento deste elemento beneficia não só o fruto, mas tambēm o mosto da uva (PHILLIPINE councIL FOR AGRICULTURAL RESEARCH, 1976).

E absorvido na forma de $\mathrm{K}^{+}$, sendo altamente mó vel na planta (MALAVOLTA et alii, 1974 e TERRA \& PIRES, 1987). Segundo FREGONI (1985), existem vārios fatores que afetam a 
absorção de potāssio pela planta, tais como: solo, clima, por ta-enxerto, irrigação, etc.

Os sintomas de deficiência, devido à sua alta mobilidade, manifestam-se primeiro nas folhas velhas (MALAVOL TA et alii, 1974 e TERRA \& PIRES, 1987). Uma deficiência gran de de potássio diminui o número de raĩzes e consequlentemente ocasiona diminuição no diâmetro do tronco e ramos, diminuindo sensivelmente a produção e a qualidade dos frutos ' (HUGUET, 1978) .

2:4. Concentração de macronutrientes na folha

Um dos mëtodos utilizados para se determinar o estado nutricional de uma planta è atravēs da anālise foliar. Esta anālise pode representar um Indice dos nutrientes disponíveis para a videira. O princípio básico da análise foliar conforme URETA (1981), baseia-se na lei dos fatores limitantes, segundo a qual sob baixo nível nutricional existe uma resposta à fertilização. Baseado nesta teoria, pode-se afirmar que existe um nível crítico para cada nutriente, sendo que acima deste nível, um aumento de nutriente pode traduzirse em aumento de produção, e abaixo, a planta poderia estar em condições de deficiência.

GALLO \& OLIVEIRA (1950) estudaram a influência da época de amostragem, do porta-enxerto e da presença de cachos nos ramos, sobre a concentração dos principais nuitrien- 
tes nas folhas de videira. Constataram que o teor de $\mathrm{N}$ variou de 3,00 a 4,10\%; $\mathrm{P}$ de 0,205 a 0,495\%; K de 1,19 a 2,00\%; Ca de 0,91 a $1,22 \%$ e o de Mg de 0,165 a $0,230 \%$

Em estudo comparativo de porta-enxerto e de va riedades através de seus efeitos na composição das folhas de videira, GALLO \& RIBAS (1962) encontraram para o cultivar Nia gara Rosada, enxertado sobre 'Ripária do Traviū', 3,40\% de N; $0,30 \%$ de $\mathrm{P} ; 1,80 \%$ de $\mathrm{K}, 0,77 \%$ de $\mathrm{Ca}$ e 0,19\% de Mg ha folha.

HERNANDO \& MENDIOLA (1965) determinaram os teores de nitrogênio, fōsforo, potássio, cálcio, magnésio e enxofre em folhas de videira, verificando que estes variavam de $1,71-3,91 \%$ de $\mathrm{N}$; 0,33-0,60\% de $\mathrm{P} ; 0,24-1,43 \%$ de $\mathrm{K}, \quad 1,48-$ 4,80\% de Ca, 0,33-1,06\% de $\mathrm{Mg}$ e 1,47-1,73\% de S.

Estudando a composição foliar do cultivar seibel 2, HIROCE et alii (1970) encontraram os seguintes teores médios de alguns nutrientes nas folhas colhidas durante o flo rescimento: $3,44-4,76 \%$ de $\mathrm{N}, 0,325-0,392 \%$ de $\mathrm{P}, 1,27-1,49 \%$ de K; 1,30-1,91\% de Ca e 0,24-0,30\% de Mg.

CUMMINGS et alii (1973), em experimento durante três anos com Vitis rotundifolia concluíram que as -concentrações de $\mathrm{N}, \mathrm{P}, \mathrm{K}, \mathrm{Ca}$ e $\mathrm{Mg}$ na folha variavam muito de ano pạ ra ano. As variações encontradas foram: 1,50-2,60\% de $\mathrm{N}$; $0,125-0,165 \%$ de $\mathrm{P} ; 0,60-1,40 \%$ de $\mathrm{K} ; 0,75-1,10 \%$ de Ca ể 0,24$0,29 \%$ de $\mathrm{Mg}$.

PEREIRA et alii (1976) compararam mudas de värios porta-enxertos quanto ao desenvolvimento inicial, exigên cia e capacidade de extração de nutrientes, e encontraram a 
seguinte variação de nutrientes nas folhas: 2,51-2,69\% de $\mathrm{N}$; $0,271-0,373 \%$ de $\mathrm{P} ; 1,81-1,33 \%$ de $\mathrm{K} ; 1,39-1,90 \%$ de de $\mathrm{Ca}$ e $0,18-0,23 \% \mathrm{de} \mathrm{Mg}$.

CHRISTENSEN et alii (1978) determinaram uma tabela de valores para o cultivar Thompson Seedless, através da análise foliar:

Avaliação

$\mathrm{NO}_{3}{ }^{-}$

(ppm)
$\mathrm{P}$

(\%)

$<0,10$

$0,10-0,15$

0,15
$\mathrm{K}$

(\%) deficiente

questionável

adequado

$$
\begin{array}{r}
<350 \\
350-500 \\
500-1200
\end{array}
$$

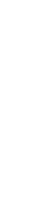

mais do que

necessārio $\quad 1200$

excessivo 2000

possibilidade de toxidez 3000

Conduzindo ensaio com videiras do cultivar Nia gara Rosada, com o objetivo de obter o acúmulo de nutrientes durante um ciclo vegetativo, DECHEN (1979) encontrou as seguintes variações ros teores de alguns nutrientes nas folhas: 2,51-4,04\% de $\mathrm{N} ; 0,63-1,22 \%$ de $\mathrm{P} ; 2,14-3,07 \%$ de $\mathrm{K} ; 0,67-1,95 \%$ de $\mathrm{Ca} ; 0,24-0,32 \%$ de $\mathrm{Mg}$ e 0,24-0,41\% de $\mathrm{S}$. 
de macronutrientes no pecíolo e limbo da 6a. folha, a partir do ápice dos ramos da videira 'Niagara Rosada' e observaram a existência de variações nos teores existentes:

\begin{tabular}{lrl}
\hline & peciolo & limbo \\
\hline $\mathrm{N}$ & $1,71 \%$ & $4,87 \%$ \\
$\mathrm{P}$ & $0,63 \%$ & $0,62 \%$ \\
$\mathrm{~K}$ & $7,12 \%$ & $3,29 \%$ \\
$\mathrm{Ca}$ & $1,24 \%$ & $1,65 \%$ \\
$\mathrm{Mg}$ & $0,45 \%$ & $0,32 \%$ \\
$\mathrm{~S}$ & $0,16 \%$ & $0,29 \%$ \\
\hline
\end{tabular}

TERRA (1983) em estudo sobre carências de macronutrientes afetando o desenvolvimento de videira do cultivar Niagara Rosada, determinou as seguintes concentrações de nutrientes nas folhas em plantas normais: $3,35 \%$ de $\mathrm{N}$; $0,582 \%$ de $\mathrm{P} ; 1,37 \%$ de $\mathrm{K} ; 1,25 \%$ de Ca e 0,270\% de S.

HIROCE et alii (1989) em estudos sobre o esta do nutricional de videira 'Niagara Rosada', encontraram as se guintes variações nos teores de nutrientes nas folhas: 2,76$4,68 \%$ de $N ; 0,26-1,23 \%$ de $P ; 1,07-3,06 \%$ de $K ; 0,77-2,68 \%$ de $\mathrm{Ca} ; 0,19-0,54 \%$ de $\mathrm{Mg}$ e $0,16-0,47 \%$ de $\mathrm{S}$.

2,5, Doses de $\mathrm{N}, \mathrm{P}_{2} \mathrm{O}_{5}$ e $\mathrm{K}_{2} \mathrm{O}$ recomendadas

GOBBATO (1940) afirmou que, dos elementos in- 
dispensáveis à vida da parreira, os que mais preocupam ao ví ticultor são o nitrogênio, o potássio, o fósforo e o cálcio que, normalmente são escassos no solo, sendo que a quantidade destes absorvida pela planta é variāvel, dependendo do clima, local, idade da planta . Como adubação de restituição, re comendava uma adubação trienal nas seguintes doses: 150 a 250 kg de salitre do Chile ou de nitrato de cálcio, 200 a 300 kg de superfosfato e 150 a $300 \mathrm{~kg}$ de sulfato de potássio, por hectare.

PAIVA NETO (1941) ressaltou que existe a necessidade de se fazer duas adubações, sendo a primeira na ëpo ca do plantio, denominada de adubação corretiva, para adequar o solo à planta, para elevar o pH para aproximadamente 6,0 e para ajustar um bom teor de matēria orgânica. Já a segunda, denominada de resti.tuição, visa recompor o solo por causa dos elementos retirados pelas colheitas, sendo que esta adubação deveria ter $99 \mathrm{~kg}$ de $\mathrm{N} ; 4 \mathrm{lg}$ de $\mathrm{P}_{2} \mathrm{O}_{5}$ e $50 \mathrm{~kg}$ de $\mathrm{K}_{2} \mathrm{O}$ por hectare e por ano.

MALAVOLTA (1959). recomendou para a videira uma adubação de produção a ser realizada anualmente, nas seguintes doses: $200 \mathrm{~g} / \mathrm{planta}$ de urëia, $500 \mathrm{~g} / \mathrm{planta}$ de superfosfato simples e $150 \mathrm{~g} / \mathrm{planta}$ de cloreto de potássio ou 180 g/planta de sulfato de potássio.

NOGUEIRA (1965) afirmou que se deve procurar uma adubação mais barata, desde que seja tecnicamente aconselhável. Recomenda uma adubação mínima por planta de 10 ḷg de esterco de curral, $400 \mathrm{~g}$ de nitrocálcio, $300 \mathrm{~g}$ de fosforita 
de Olinda e $150 \mathrm{~g}$ de cloreto de potássio.

WINKLER (1965) comentou que a videira não è uma

planta tão exigente como algumas outras espēcies hortícolas em relação à necessidade de nutrientes. O nitrogênio e o potássio são considerados como elementos mais extraídos , alēm do fósforo, e as quantidades adequadas destes elementos a serem aplicadas são 45 a $78 \mathrm{~kg} / \mathrm{ha}$ de $\mathrm{N}, 280$ a $340 \mathrm{~kg} / \mathrm{ha}$ de $\mathrm{P}_{2} \mathrm{O}_{5}$ e 450 a $670 \mathrm{~kg} / \mathrm{ha}$ de $\mathrm{K}_{2} \mathrm{O}$, na região da Califórnìa.

INGLEZ DE SOUSA (1969) relatou que todos os vinhedos do Brasil poderiam produzir mais se fossem adequadamente adubados. A dose de cada adubo simples por planta e por ano indicada è a seguinte: $240 \mathrm{~g}$ de sulfato de amônio, $300 \mathrm{~g}$ de superfosfato e $100 \mathrm{~g}$ de cloreto de potāssio.

PEREIRA (.19.72) recomendou para a videira em produção as variações nas doses N, P e K: 40 a 100 g/planta de N, 90 a 270 g/planta de $\mathrm{P}_{2} \mathrm{O}_{5}$ e 120 a $300 \mathrm{~g} /$ planta de $\mathrm{K}_{2} \mathrm{O}$.

SANTOS NETO (1973) recomendou para a videira, na adubação $\mathrm{N}, \mathrm{P}$ e $\mathrm{K}$ de manutenção, realizada ano a ano, as seguintes variações nas doses por planta: 25 a $50 \mathrm{~g}$ de $\mathrm{N}$, 50 a $200 \mathrm{~g}$ de $\mathrm{P}_{2} \mathrm{O}_{5}$ e 75 a 250 g de $\mathrm{K}_{2} \mathrm{O}$.

De acordo com a ASSOCIAÇÃO NACIONAL PARA DIFUSÃo DE AdUBOS (1975), a adubação de produção N, P'e K, feita parceladamente em cobertura, anualmente, em g/pē,; deveria ter as seguintes doses de nutrientes: 100 de $\mathrm{N}, 100$ de $\mathrm{P}_{2} \mathrm{O}_{5}$ e 100 a 200 de $\mathrm{K}_{2} \mathrm{O}$.

De acordo com CAMPINAS 
uma adubação de restituição para a videira feita anualmente, deveria conter as seguintes variações nas doses de $N, P$ e K por planta: 20 a $60 \mathrm{~g}$ de $\mathrm{N}, 60$ a $300 \mathrm{~g}$ de $\mathrm{P}_{2} \mathrm{O}_{5}$ e 60 a $240 \mathrm{~g}$ de $\mathrm{K}_{2} \mathrm{O}$.

DECHEN (1980) recomendou aplicar o adubo em sulcos laterais distantes $50 \mathrm{~cm}$ da planta e a $30 \mathrm{~cm}$ de profundidade, parcelando-se a aplicação do seguinte modo; $50 \%$ an tes ou na poda, 30\% na fase de chumbinho e $20 \%$ na fase de meia baga. A adubação deve ter $100-120 \mathrm{~kg}$ de $\mathrm{N}, 120-1500 \mathrm{~kg}$ de $\mathrm{P}_{2} \mathrm{O}_{5}$ e 120-1200 kg de $\mathrm{K}_{2} \mathrm{O}$ por ha e por ano.

MALAVOLTA (1980). sugere que a videira reti ra em um ano, para produzir $10 \mathrm{t} / \mathrm{ha}$ de frutos, $70 \mathrm{~kg}$ de nitrogênio, $9 \mathrm{~kg}$ de fósforo e $80 \mathrm{~kg}$ de potāssio. Para suprir esta retirada MALAVOLTA (1981), sugere 100-300 kg de $\mathrm{N}, 300-$ $1500 \mathrm{~kg}$ de $\mathrm{P}_{2} \mathrm{O}_{5}$ e $300-1200 \mathrm{~kg}$ de $\mathrm{K}_{2} \mathrm{O}$.

COMMISSION ROMANDE DES FUMURES, SOUS-COMMISSION VITICOLE (1983), relatou que a videira durante o período de um ano exporta 40 a $100 \mathrm{~kg}$ de nitrogênio, 10 a $40 \mathrm{~kg}$ de fósforo e 50 a $100 \mathrm{~kg}$ de potássio por hectare. A adubação de restituição deve ser feita por $0-100 \mathrm{~kg}$ de $\mathrm{N}, 30-60 \mathrm{~kg}$ de $\mathrm{P}_{2} \mathrm{O}_{5}$ e 100-160 kg de $\mathrm{K}_{2} \mathrm{O}$ por ha.

TERRA (19.85): recomenda que / a adubação de manutenção para a videira deveria ser cons tituída de $40 \mathrm{~g}$ de $\mathrm{N}, 30$ a $120 \mathrm{~g}$ de $\mathrm{P}_{2} \mathrm{O}_{5}$, e 20 a $80 \mathrm{~g}$ de $\mathrm{K}_{2} \mathrm{O}$ por planta, quando se tratava de uvas rústicas para mesa, vinho e suco. Quando a adubação fosse realizada para uvas finas para mesa e passa, dever-se-ia aplicar $60 \mathrm{~g}$ de $\mathrm{N}, 50 \mathrm{a}$ 
$200 \mathrm{~g}$ de $\mathrm{P}_{2} \mathrm{O}_{5}$ e 30 a $120 \mathrm{~g}$ de $\mathrm{K}_{2} \mathrm{O}$ por planta. JUNQUEIRA (1986) sugere que a adubação da videira deveria ser feita de acordo com a análise de solo. Pa ra videiras destinadas a vinho e rústicas para mesa, dever se-ia aplicar 200-300 $\mathrm{g}$ de $\mathrm{N} ; 300-500 \mathrm{~g}$ de $\mathrm{P}_{2} \mathrm{O}_{5}$ e 100-200 g de $\mathrm{K}_{2} \mathrm{O}$ por planta, nas formas de sulfato de amônio, farinha de ossos e cloreto de potássio.

TERRA, (1985) sugere... aplicar por planta, $40 \mathrm{~g}$ de $\mathrm{N}, 60$ a $120 \mathrm{~g} \mathrm{P}_{2} \mathrm{O}_{5}$ e $40 \mathrm{~g}$ de $\mathrm{K}_{2} \mathrm{O}$, quando se tratava de uvas rústicas para mesa.

NEGRINI (1988) recomenda para suprir as reti radas anuais de $\mathrm{N}, \mathrm{P}$ eK, as seguintes doses que forneceriam es tes elementos em quantidades teoricamente ideais: 60 a $80 \mathrm{~kg} /$ ha de $\mathrm{N}, 80-100 \mathrm{~kg} / \mathrm{ha}$ de $\mathrm{P}_{2} \mathrm{O}_{5}$ e 150-170 kg/ha de $\mathrm{K}_{2} \mathrm{O}$.

\section{6", Resultados experimentais com aplicação de nitrogênio}

Em experimentos com diferentes doses de nitrogênio,EL-SHOURBAGY \& ISMAIL (1961) aplicaram 90, 120 e 150 gramas/planta/ano, e verificaram que a dose de $120 \mathrm{~g}$ aumentou significativamente o número de cachos e o peso da produção por planta. A aplicação de $150 \mathrm{~g}$ de nitrogênio aumentou o número de gemas que se desenvolveram produzindo brotos, porém com produção menor.

ISMAIL et alii (1964), em sua pesquisa, aplica 
ram em vinhedos do cultivar Gharibi, nitrogênio em quatro doses diferentes $(30,60,90$ e $120 \mathrm{~g} / \mathrm{planta})$. Altas doses de nitrogênio aumentaram as doses de nitrato nos tecidos dos cachos. As análises de $\mathrm{P}$ e $\mathrm{K}$ mostraram que as plantas estavam bem nutritas destes elementos. Os dados mostraram que a dose $90 \mathrm{~g} / \mathrm{planta}$ de nitrogênio pode ser utilizada com limitações em programas de fertilidade, pois obtiveram bagas gran des com este nível de nitrogênio.

CHADHA \& SINGH (1971), avaliando experimentos com plantas de 'Thompson Seedless' e 'Kandhari', aplicaram ni trogênio nas doses de 250, 500, 750 e 1000 g/planta, em dois ciclos. A maior dose de nitrogênio resultou em um máximo cres cimento de ramos, número de cachos, tamanho de baga, e produção. Quando se aumentaram os níveis de nitrogênio houve uma maturação precoce, aumento no teor de nitrogênio nos pecíolos e nas folhas, e diminuição no teor de sólidos solūveis das bạ gas. No segundo ano do ensaio, as maiores produções -" obtidas foram $8,22 \mathrm{~kg} / \mathrm{planta}$ para o cultivar Thompson Seedless e $15,58 \mathrm{~kg} / \mathrm{planta}$ para o 'Kandhari'.

HABEEB et alii (1976), em ensaio com diferentes doses de nitrogênio para plantas do cultivar Itälia, aplí caram 30-70 g/planta em intervalos de $1-3$ anos, com 70 ou 90 g/planta aplicados anualmente em diferentes épocas do ano. Constataram que a diferença do número de cachos/planta foi pe quena entre cada tratamento. A melhor época de aplicação foi em fevereiro e a melhor dose de $70 \mathrm{~g}$ de $\mathrm{N}$.

TULIN \& MOROZOV (1976), conduzindo três anos 
de ensaio, aplicaram o nitrogênio no final de março nas doses de 40, 60 ou $100 \mathrm{~kg} / \mathrm{ha}$, em sulcos a $25 \mathrm{~cm}$ de profundidade, em ambos os lados da rua do vinhedo, que era adubado regularmen te com N, $\mathrm{P}_{2} \mathrm{O}_{5}$ e $\mathrm{K}_{2} \mathrm{O}(30,40$ e $40 \mathrm{~kg} / \mathrm{ha})$. O tratamento com ni trogênio na dose de $60 \mathrm{~kg} / \mathrm{ha}$ aumentou o peso de cacho, a produção e o lucro líquido. As diferentes doses de nitrogênio não tiveram efeito no teor de açúcar do mosto.

QUISPE (1971), em ensaio com plantas do cultivar Itália, com mais de vinte anos de idade, plantadas em péfranco, no espaçamento $1,00 \times 0,80 \mathrm{~m}$ ( 12.500 plantas/ha), tes tou três doses de nitrogênio 8,16 e 24 g/planta $(100,200$ e $300 \mathrm{~kg} / \mathrm{ha})$, na forma de sulfato de amônio. Foram feitos três tipos de aplicações: no sulco a cada $20 \mathrm{~cm}$, a lanço e ao pé da planta. Metade do nitrogênio foi aplicado em novembro e me tade em janeiro, irrigando-se a cada 15 dias e no verão, a ca da 10 dias. Os resultados obtidos mostraram uma produção mēdia de $17.650 \mathrm{~kg} / \mathrm{h} a$ com a aplicação de $200 \mathrm{~kg} / \mathrm{ha}$ ao pé da planta. O melhor peso de cacho foi de 425,80 gramas, obtido com $100 \mathrm{~kg} / \mathrm{ha}$ de $\mathrm{N}$ aplicados ao pé da planta. O melhor rendimento foi de $16.870 \mathrm{~kg} / \mathrm{ha}$ usando-se $300 \mathrm{~kg} / \mathrm{ha}$ de nitrogênio. Em relação ao local de aplicação não houve diferença significativa.

CHAUHAN et alii (1983), conduzindo ensaio entre os anos de 1977 e 1979, aplicaram doses de nitrogênio variando de 100 a $300 \mathrm{~g} / \mathrm{planta}$. A testemunha proporcionou produção de $10,7 \mathrm{~kg} / \mathrm{planta}$, enquanto a dose de $300 \mathrm{~g} / \mathrm{planta}$ de $\mathrm{N}$ proporcionou 13,38 kg/planta. Porém, a dose econômica recomenda- 
da foi de $150 \mathrm{~g} /$ planta de $\mathrm{N}$, que resultou numa produção de $12,70 \mathrm{~kg} / \mathrm{planta}$.

RETAMALES \& RAZETO (1985) estabeleceram um en saio com 'Thompson Seedless' de 9 anos de idade, conduzidos no sistema de pérgola 3,5 x 3,5 m ( 816 plantas/ha), onde aplicaram 3 doses de nitrogênio na forma de uréia 0,110 e $440 \mathrm{~kg} / \mathrm{ha}(0,135$ e $540 \mathrm{~g} / \mathrm{planta})$, aplicados a lanço e incorporados em seguida. Constataram que no solo o teor/ de $\mathrm{N}$ aumentou conforme a dose aumentava. Na planta, ocorreu um aumento do crescimento vegetativo com maior emissão de brotos. Com relação à produção e ${ }^{\circ}$ Brix não houve diferenças significa tivas entre os tratamentos. Concluíram que altas doses de ni trogênio causavam um elevado crescimento vegetativo, sem aumento da produção.

LAVIN \& VALENZUELA (1986 a) estudaram o efeito de diferentes doses de nitrogênio com diferentes fontes. Testaram salitre do Chile, uréia e nitrato de amônio, nas do ses de 45, 90 e $180 \mathrm{~g} /$ planta $(37,5,75,0$ e $150 \mathrm{~kg} / \mathrm{ha})$. A apli cação foi feita em sulcos laterais a $40 \mathrm{~cm}$ da planta e a 20$25 \mathrm{~cm}$ de profundidade. As plantas estavam dispostas em espaçamento de $3,0 \times 4,0 \mathrm{~m}$ (833 plantas/ha).

Dos parâmetros analisados, verificou-se quanto à produção que o uso do nitrato de amônio foi superior ao salitre do Chile e a uréia. O peso dos ramos podados e o

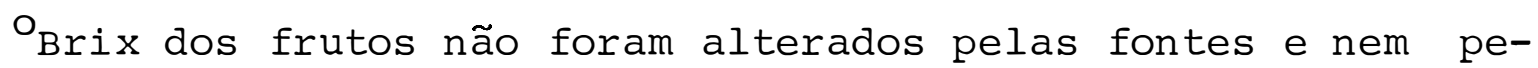
las cooses. Concluỉram que não houve resposta 'significativa 
dos adubos devido à falta de umidade, limitando a disponibilidade de nitrogênio para absorção. Neste trabalho, o nitrogênio aplicado na dose de $37,5 \mathrm{~kg} / \mathrm{ha}$ na forma de nitrato de amônio foi suficiente para produzir $36 \mathrm{t} / \mathrm{ha}$ ou $43 \mathrm{~kg} / \mathrm{planta}$ de uva, em média.

Os mesmos autores LAVIN \& VALENZUELA (1986 b), aplicaram três doses de nitrogênio em plantas do cultivar Pe dro Jimenez para verificar se ocorreria alteração nos! teores de N, P e K das folhas no florescimento e na maturação dos frutos. As doses utilizadas foram 45,90 e $180 \mathrm{~g} / \mathrm{planta.}$ Os resultados mostraram que os teores de nitrogênio não foram modificados, o que significa que as doses menores foram sufi cientes. O fósforo permaneceu inalterado e com o potássio ocorreu uma pequena queda nos teores deste elemento quando se aplicou doses maiores de N.

AHMED et alii (1988), utilizando o cultivar Red Roomy, testaram o efeito de diferentes doses de nitrogênio (sulfato de amônio, nitrato de amônio, nitrato de cálcio e uréia), variando de 75 a $175 \mathrm{~g} / \mathrm{planta}$. Todas as fontes uti lizadas aumentaram a produção, o número e peso de cachos, o peso de 100 bagas, o diâmetro e comprimento das bagas, e a acidez total, porém, a máxima produção com boa qualidade do fruto foi obtida com a dose de $150 \mathrm{~g} / \mathrm{planta}$ de $\mathrm{N}$, ' $\mathrm{na}$ forma de sulfato de amônio.

MAATOUK et alii (1988) testaram diferentes do ses e fontes de nitrogênio no crescimento vegetativo e compo sição foliar da videira 'Red Roomy'. As fontes utilizadas fo 
ram sulfato de amônio, nitrato de amônio, uréia e nitrato de cálcio, e as doses variaram de 75, 100, 125 e $175^{\prime} \mathrm{g} / \mathrm{planta}$. Ve rificaram que o sulfato de amōnio aumentou o teor de nitrogênio e diminuiu.o teor de potássio na folha.

WOLF \& POOL (1988) estudaram o efeito de três níveis de nitrogênio no crescimento e produção de videira do cultivar Chardonnay. O adubo utilizado foi o nitrato de amônio nas doses de 0,39 e $84 \mathrm{~kg} / \mathrm{ha}$ de $\mathrm{N}$, aplicadas dois meses antes do florescimento. A dose $84 \mathrm{~kg} / \mathrm{ha}$ foi colocada no solo de dois modos: aplicação unica aos dois meses antes do florescimento e aplicação parcelada $56 \mathrm{~kg} / \mathrm{ha}$ dois meses antes do florescimento e $28 \mathrm{~kg} / \mathrm{ha}$ logo após o florescimento. Em relação ao peso dos ramos, não houve diferença da aplicação entre as doses. A produção não aumentou com a aplicação do N; as elevadas doses che garam a produzir menos que o tratamento controle devido ao ele vado crescimento vegetativo. O peso de cachos mostrou uma tendência de aumentar com o aumento das doses.

2.7. Resultados experimentais com aplicação de fósforo

PIZA JR \& NEPTUNE (1966), utilizando superfosfa to com fósforo marcado, na quantidade de $80 \mathrm{~g} / \mathrm{planta}$, observaram o melhor modo de aplicação e sua absorção pela planta. Foram utilizados dois modos de aplicação: no primeiro o adubo foi colocado em cobertura numa faixa de $15 \mathrm{~cm}$ de largura, distante $30 \mathrm{~cm}$ do tronco; e no segundo, colocado no 
fundo de valetas abertas lateralmente às linhas da videira, com $30 \mathrm{~cm}$ de largura, distantes $40 \mathrm{~cm}$ dos troncos. das plantas. Verificaram que a absorção do fósforo aplicado em cobertura se deu de modo mais rápido do que quando colocado em sulco. Constataram que os teores de nitrogênio nas folhas diminuiram no final do ensaiọ, e que a porcentagem de fósforo proveniente do adubo foi sempre crescente, mostrando que a utilização do fósforo do adubo continua mesmo no final do ciclo vegetativo.

BALCAR et alii (1970) estudaram a eficiência da absorção de fósforo dos cultivares Pinot Blanc e Harria ge, quando foi aplicado em diferentes profundidades e distân cias da planta. As plantas do cultivar Pinot Blanc, com 2 anos de idade, eram conduzidos em espaldeira alta, no espaçamento de $3 \times 2 \mathrm{~m}$. Aplicou-se o fósforo a 10 e $30 \mathrm{~cm}$ de profundidade, e a 30, 60 e $90 \mathrm{~cm}$ de distância da planta. 0 melhor aproveitamento do fósforo ocorreu na distância de $60 \mathrm{~cm}$ e a $20 \mathrm{~cm}$ de profundidade, devido às raízes possuírem peque no tamanho, com desenvolvimento pleno. O cultivar Harriage era conduzido em espaldeira baixa, no espaçamento de 2 x lm, plantas velhas, com 25 anos de idade. Nestas plantas, o fósforo foi aplicado a 10-40 cm de profundidade, e a 25 e 100 cm de distância. Verificaram que o melhor aproveitamento ocorreu quando se aplicou a $100 \mathrm{~cm}$ de distância e a $20 \mathrm{~cm}$ de profundidade, caracterizando bem a idade da planta que possui raízes bem desenvolvidas, estando distanciadas do tronco. 
SCHALLER (1988), em experimentos conduzidos por vários anos, em quatro locais diferentes, verificou que a adu bação com $120 \mathrm{~kg} / \mathrm{ha}$ de $\mathrm{P}_{2} \mathrm{O}_{5}$, aumentou a produção de 0,2 a 1,7\%, e a qualidade dos frutos de 1;,2 a 3,2\% na média, dependendo da localidade. Apesar dos resultadas positivos, os efei tos não foram significativos, pois o controle produziu mais que os tratamentos com fósforo. A anālise foliar mostrou que nem sempre os teores de fósforo foram alterados.

2,8, Resultados experimentais com aplicação de potássio

CHRISTENSEN (1964) aplicou potássio na dose çé $2.250 \mathrm{~g} / \mathrm{planta}$ em vinhedo de 'Thompson Seedless' e verificou que esta adubação aumentou a produção em 31\%, o peso dos cachos em 24\%, e o peso das bagas em $10 \%$

$$
\text { PEROV et alii (1973), em experimentos de } 6
$$

anos, com vários cultivares de videira, em diferentes tipos de solo, verificaram que o potássio era fator limitante e a aplicação de $90 \mathrm{~kg} / \mathrm{ha}$, proporcionou 40\% a mais de produção do que o controle, e 14 e $8 \%$ a mais do que quando se aplicou $\mathrm{N}$ e $\mathrm{P}_{2} \mathrm{O}_{5}$ respectivamente, na mesma proporção. Verificaram também que a melhor fonte de potássio foi o cloreto.

CLINE \& BRADT (1980) adubaram videiras 'Concord' com sulfato, cloreto e nitrato de potássio nas doses 232 ou $465 \mathrm{~kg}$ por hectare de $\mathrm{k}_{2} \theta$. Verificaram que, não houve redução na produção, na qualidade do fruto e no vigor das 
plantas com as altas doses de cloreto de potássio. As plantas que foram adubadas com nitrato de potássio sofreram pequena diminuição na produção, foram menos vigorosas, e o teor de potássio nos pecíolos foi menor do que quando se aplicou cloreto ou sulfato de potássio.

2.9, Resultados experimentais com aplicação de nitrogênio, e/oư fósforo e/ou potássio

LARSEN et alii (1959) instalaram ensaio com o cultivar Concord, tratados com diferentes níveis qe NPK, para verificar a ação na produção e teor de nutrientes no pecío 10. Por cinco anos adubaram com iv $(45$ e $90 \mathrm{~kg} / \mathrm{ha}), \mathrm{P}_{2} \mathrm{O}_{5}(0$ e $90 \mathrm{~kg} / \mathrm{ha})$ e $\mathrm{K}_{2} \mathrm{O}(\mathrm{e}$ e $135 \mathrm{~kg} / \mathrm{ha})$, em diferentes combinações. Verificaram que não ocorreu nenhuma diferença significativa entre os tratamentos, exceto naquele que tinham aplicado 90,90 eo, onde o nível de potássio foi menor que nos outros tratamentos. Concluíram que altas produções poderiam sermanti das com doses menores de nitrogênio do que eram aplicados, in clusive podendo-se manter boas produções em vinhedos férteis, sem aplicações anuais de potássio. O sulfato e o cloreto de potássio comportaram-se da mesma forma como fontes de potás sio, e a alta ãose de potássio poderia causar deficiência de magnésio.

FREGONI \& ZIONI (1969), pesquisando vinhedos do cultivar Barbera, localizados em solo fértil ligesiramente 
calcário e bem drenado, aplicaram em cada lote $200 \mathrm{~kg} / \mathrm{ha}$ de esterco de curral em anos alternados, e os seguintes tratamen tos: $300 \mathrm{~g} / \mathrm{planta}$ de superfosfato mais $200 \mathrm{~g} / \mathrm{planta}$ de sulfato de potássio no outono, e $200 \mathrm{~g} / \mathrm{planta}$ de nitrato de amônio no fim do inverno; outro tratamento igual ao anterior só que o potāssio foi aplicado no fim do inverno; e 300 g/planta de NPK (11-22-16) no fim do inverno. Verificaram depois de cinco anos que os efeitos dos diferentes tratamentos não diferiram significativamente entre si, mas causaram na média um aumen to na produção de $26 \%$ sobre o controle, que não havia recebi do adubação. Verificaram tambēm que os tratamentos não afetaram a concentração de açūcar do mosto.

NIJJAR \& RAM (1969) conäuziram um ens'aio em vinhedos do cultivar Anab-e-Shahi, com 3 anos de idade. Utili zaram três níveis de $\mathrm{N}$ e $\mathrm{P}_{2} \mathrm{O}_{5}(450,900$ e 350 gramas por plan ta), em várias combinações. O melhor resultado em termos de produção e qualidade deu-se com 900 g/planta de $\mathrm{N}$ e 900-1350 $\mathrm{g} / \mathrm{planta}$ de $\mathrm{P}_{2} \mathrm{O}_{5}$. O teor de fósforo nos pecíolos e folhas aumentava quando se fornecia baixas doses de nitrogênio, mas di minuía quando o nitrogênio era aplicado em altas doses, independente da dose de $\mathrm{P}_{2} \mathrm{O}_{5}$ aplicada. As diferentes doses de $\mathrm{P}_{2} \mathrm{O}_{5}$ não afetaram os níveis de nitrogênio existentes.

$$
\text { ALANASOV (1970) conduzindo ensaio durante }
$$

três anos com o cultivar Siroba-Melniska, obteve melhores resultados com $250 \mathrm{~kg} / \mathrm{ha}$ de nitrato de amônio, $400 \mathrm{~kg} / \mathrm{ha}$ de superfosfato, $200 \mathrm{~kg} / \mathrm{ha}$ de sulfato de potássio e $800 \mathrm{~kg} / \mathrm{ha}$ de esterco de curral. Este tratamento aumentou a proquução em 
$21,5 \%$ em relação ao controle. O nitrato de amônio aplicado isoladamente a $500 \mathrm{~kg} / \mathrm{ha}$ proporcionou as maiores produçoẽs, porēm, as uvas ficaram com baixa concentração de açūcar e al ta acidez.

NIJENSOHN et alii (1970) realizaram um experi mento com sulfato de amônio a $400 \mathrm{~kg} / \mathrm{ha}$, superfosfato triplo a $800 \mathrm{~kg} / \mathrm{ha}$ e sulfato de potássio a $400 \mathrm{~kg} / \mathrm{ha}$, combinados em NK, NP, PK, NPK e controle, em plantas dos cultivares Criolla e Cereza, espaçadas 3,5 x 3,5 m (816 plantas/ha). Após a colheita, concluíram que o fósforo foi o único elemento que causou um aumento significativo na produção PK-137\%, NPK 151\%, considerando o controle como 100\%, com produções de $21.440,23.631$ e $15.650 \mathrm{~kg} / \mathrm{ha}$, respectivamente. O nitrogênio e o potássio na ausência de fósforo não tiveram efeito na produção de uva e no teor de açúcar. A maior produção resultante da adubação não afetou a concentração de açúcar clo suco de uva, nem o vigor das plantas, constatado pelo peso dos ramos podados.

POPA \& IONESCU (1970) obtiveram O"melhor cres cimento de plantas, a maior produção e a melhor qualidade dos frutos, com a aplicação de 40 t/ha de esterco de currál, mais $150 \mathrm{~kg}$ de $\mathrm{N}, 225 \mathrm{~kg}$ de $\mathrm{P}_{2} \mathrm{O}_{5}$ e $75 \mathrm{~kg}$ de $\mathrm{K}_{2} \mathrm{O}$ por hectare, incorporados a 30 ou $60 \mathrm{~cm}$ de profundidade.

SERPUHOVITINA (1970), conduzindo ensaio com quatro aplicações anuais de NPK (90:120:90 kg/ha), em 16 cultivares com produções instāveis, conseguiu aumentar o núniero de brotos e aumentar a produção. 
IANNINI (1972), em ensaio com dois cultivares de videira plantados numa densidade de 1.350 plantas/ha, adu bou com $\mathrm{N}, \mathrm{P}_{2} \mathrm{O}_{5}$ e $\mathrm{K}_{2} \mathrm{O}$ a 80-80-300 kg/ha, e notou que não hou ve aumento da produção dos dois cultivares.

KOROBKO (1972), conduzindo ensaio com adubos minerais visando aumentar o crescimento das plantas e a produção, e melhorar a qualidade dos frutos, concluiu que os me lhores resultados foram obtidos com o tratamento $90 \mathrm{~kg} / \mathrm{ha}$ de nitrogênio, $160 \mathrm{~kg} / \mathrm{ha}$ de $\mathrm{P}_{2} \mathrm{O}_{5}$ e $90 \mathrm{~kg} / \mathrm{ha}$ de $\mathrm{K}_{2} \mathrm{O}$.

MUZYCHENKO (1972) realizou experimentação em solo de pradaria, com o cultivar Pinot Gris, com aplícações em sulco de $\mathrm{N}, \mathrm{P}_{2} \mathrm{O}_{5}$ e $\mathrm{K}_{2} \mathrm{O}$ nas doses de 100,150 e $100 \mathrm{~kg} / \mathrm{ha}$, no outono, por três anos consecutivos, e verificou que esta adubação mostrou um aumento de $38,6 \%$ na produção e um incremento no teor de sólidos solúveis.

DYUZHEV et alii (1973) verificaram que a apli cação antual de $\mathrm{N}, \mathrm{P}_{2} \mathrm{O}_{5}$ e $\mathrm{K}_{2} \mathrm{O}$ na dose $100 \mathrm{~kg} / \mathrm{ha}$ em solos irri ğados, aumentou em 1,15 t/ha a produção do cultivar Riesling, durante três anos, Em solos não irrigados, a aplicação de $\mathrm{P}_{2} \mathrm{O}_{5}$ e $\mathrm{K}_{2} \mathrm{O}$ nas doses 100 ou $150 \mathrm{~kg} / \mathrm{ha}$, uma vez cada 2-3 arros e $50 \mathrm{~kg} / \mathrm{ha}$ de $\mathrm{N}$ todo ano, elevou o teor de NPK na folha e au mentou a produção do cultivar Chasselas no terceiro ano em $2,25-2,50$ t/ha.

IONCHEV \& MINEVA (1973), em vinhedos do culti var Saperavi, espaçados 1,6 1 1,0 m (6.250 planta/ha), em terreno com ligeiro declive, realizaram ensaios com diferentes doses de NPK, em diferentes combinações, variando de 80 
a $240 \mathrm{~kg} / \mathrm{ha}$. As combinações NPK que proporcionaram maior pro dução por hectare e maior peso dos cachos foram 160-160-80, $160-160-160$ e $160-160-240 \mathrm{~kg} / \mathrm{ha}$.

KOROBKO (1973) realizou ensaio com o cultivar Riesling, em terreno irrigado com diferentes doses de NPK, em vārias combinações. As produções máximas foram obtidas em vinhedos cujas folhas mostravam uma concentração de NPK igual a $5,9,1,0$ e $3,1 \%$, respectivamente. A dose que pro moveu a maior concentração foliar de NPK foi $90 \mathrm{~kg} / \mathrm{ha}$ de $\mathrm{N}$, $160 \mathrm{~kg} / \mathrm{ha}$ de $\mathrm{P}_{2} \mathrm{O}_{5}$ e $20 \mathrm{~kg} / \mathrm{ha} \cdot \mathrm{de} \mathrm{K}_{2} \mathrm{O}$.

LICUL (1973) testou o efeito do NPK na prodụ ção e na qualidade dos frutos do cultivar Teran Erni, durante quatro anos em duas localidades. As doses utilizadas variaram de 80 a $160 \mathrm{~kg} / \mathrm{ha}$ de $\mathrm{N}, 40$ a $240 \mathrm{~kg} / \mathrm{ha}$ de $\mathrm{P}_{2} \mathrm{O}_{5}$ e 50 a $300 \mathrm{~kg} / \mathrm{ha}$ de $\mathrm{K}_{2} \mathrm{O}$. Verificou que o efeito na qualidade dos frutos foi pequeno. O menor custo foi conseguido com 750 $\mathrm{kg} / \mathrm{ha}$ de NPK $((80: 40: 50)$ \& proporcionando a segunda maior média de produção.

POMOHACI et alii (1973) realizaram um ensaio durante 2 anos com doses de N, P e K variando de 0 a 200 kg/ha, com quatro cultivares enxertados em 'Ripária' e 'Kober $5 \mathrm{BB}^{\prime}$. Houve pequena diferença entre os cultivares e porta-enxertos, porém a melhor produção foi obtida com N, $\mathrm{P}_{2} \mathrm{O}_{5}$ e $\mathrm{K}_{2} \mathrm{O}$ nas doses 150:150:150 kg/ha.

VELICHKO ( 1974 a) conduzindo ensaio com videiras do cultivar Aligoté e Merlot, aplicou diferentes níveis 
de $\mathrm{N}_{2} \mathrm{P}_{2} \mathrm{O}_{5}$ e $\mathrm{K}_{2} \mathrm{O}: 50,100$ e $150 \mathrm{~kg} / \mathrm{ha}$ de cada nutriente. Veri ficou que a maior produção e melhor qualidade dos frutos foi obtida com vinhedos que receberam $100 \mathrm{~kg} / \mathrm{ha}$ de cada nutriente. Realizou também outro ensaio com os mesmos cultivares visando a aplicação ideal, efetiva e mais econômica dos fertilizantes. A dose ideal e econômica foi conseguida com a aplicação de $100 \mathrm{~kg} / \mathrm{ha}$ de cada nutriente.

ALIEV (1975) testou o efeito de adubos minerais na produção de vinhedos não irrigados. Aplicou diferentes doses de NPK em diversas combinações, variando de 60 a $240 \mathrm{~kg} / \mathrm{ha}$. Os melhores resultados obtidos foram com $90 \mathrm{~kg} / \mathrm{ha}$ de $\mathrm{P}_{2} \mathrm{O}_{5}$ mais $120 \mathrm{~kg} / \mathrm{ha}$ de $\mathrm{K}_{2} \mathrm{O}$ aplicados no final do outono, adicionando-se $90 \mathrm{~kg} / \mathrm{ha}$ de $\mathrm{N}$ no início da primavera.

AVRAMOV et alii (1975) testaram os efeitos do potássio e do nitrogênio na produção e no crescimento da videira do cultivar Merlot. Aplicaram duas doses diferentes, e a que melhor resultado deu em matēria de produção e crescimen to foi $180 \mathrm{~kg} / \mathrm{ha}$ de $\mathrm{K}_{2} \mathrm{O}$ mais $180 \mathrm{~kg} / \mathrm{ha}$ de $\mathrm{N}$.

SERPUKHOVITINA (1975) procurou determinar O efeito e o método de aplicação de fertilizantes na produção e qualidade da uva. Os tratamentos ütilizados foram: NPK (90: $120: 90 \mathrm{~kg} / \mathrm{ha}$ ) aplicados a $15-20 \mathrm{~cm}$ de profundidade; NPK na mesma dose aplicados a 30-50 cm de profundidade; e o último cultivado sem nenhum fertilizante. O melhor resultado foi obtido com o tratamento NPK (90:120:90 kg/ha) aplicados a 30$50 \mathrm{~cm}$ de profundidade.

ARTAMOVA (1976) com o cultivar Taiti Rozovyi, 
aplicou nitrogênio a 30 e $120 \mathrm{~kg} / \mathrm{ha} ; \mathrm{P}_{2} \mathrm{O}_{5}$ a 30 e $120 \mathrm{~kg} / \mathrm{ha}$ e $\mathrm{K}_{2} \mathrm{O}$ a 45 e $90 \mathrm{~kg} / \mathrm{ha}$, em vārias combinaçōes. Os f fertilizantes foram aplicados em faixas, a 50-60 cm de profundidade. A maior média de produção em cinco anos foi de 7,2 t/ha, obtida de plantas que receberam NPK a $30: 120: 45 \mathrm{~kg} / \mathrm{ha}$, aumentando a pro dução em relação ao controle em 34\%. O teor de açūcares dos frutos não foi afetado pelas diferentes adubações.

BUKATAR \& BABUSHKIN (1976) realizaram ensaios

de 3 anos com fertilizantes NPK, aplicados nas entrelinhas em 1,2 e 3 sulcos e em cobertura. Os melhores resultados obtidos com relação à produção e retorno econômico foram conseguidos com os fertilizantes aplicados em 2 sulcos.

GEORGIEVA (1976), em ensaio com fertilizantes, aplicou $N_{*}$ P e $\mathrm{K}$ separadamente, na dose $300 \mathrm{~kg} / \mathrm{ha}$ de cada ou uma combinação NPK com 500:300:300 kg/ha. A aplicação de N, P e $\mathrm{K}$ separadamente proporcionou produções de 4.800 a $6.260 \mathrm{~kg} /$ ha, e à combinação dos três, $7.810 \mathrm{~kg} / \mathrm{ha}$. o potássio promoveu a maior produção e a melhor qualidade dos frutos, mas a aplicação de NPK mostrou-se mais benéfica.

HABEED et alii (1976) estudaram o comportamento do cultivar Itālia diante de doses de $\mathrm{P}_{2} \mathrm{O}_{5}$ de 5,5 ou $11 \mathrm{~g} /$ planta e $\mathrm{K}_{2} \mathrm{O}$ a 0,50 ou $75 \mathrm{~g} / \mathrm{planta,} \mathrm{aplicados} \mathrm{separadamente}$ em vārios intervalos, ou em conjunto em altas doses, em inter valos de quatro anos. Notaram que houve num ano pouca variação com $75 \mathrm{~g} / \mathrm{planta}$ de $\mathrm{K}_{2} \mathrm{O}$; por outro lado, no ano seguinte a dose $50 \mathrm{~g} / \mathrm{planta}$ de $\mathrm{K}_{2} \mathrm{O}$ superou a anterior. A melhor dose de $\mathrm{P}_{2} \mathrm{O}_{5}$ foi de $5,5 \mathrm{~g} / \mathrm{planta}$. 
IONEV (1976), utilizando o cultivar Cabernet Sauvignon, enxertado em Rupestris du Lot, no espaçamento de $3,2 \mathrm{~m}$ entre ruas e $0,5,1,0$ e $1,5 \mathrm{~m}$ entre plantas ' 6.250 , 3.125 e 2.083 plantas/ha), aplicou três doses de $\mathrm{N}_{2} \mathrm{P}_{2} \mathrm{O}_{5}$ e $\mathrm{K}_{2} \mathrm{O} \cdot(60,120$ e $180 \mathrm{~kg} / \mathrm{ha})$. Os vinhedos que estavam espaçados $3,2 \times 1,5 \mathrm{~m}$ proporcionaram as maiores produções por hec tare quando foram aplicados $120 \mathrm{~kg} / \mathrm{ha}$ de cada nutriente.

TAKHMAZOV \& ASKENDEROV (1976) estudaram dois

cultivares de videira, testando a aplicação de NP em diferen tes doses: 60 a $240 \mathrm{~kg} / \mathrm{ha}$ de $\mathrm{N}$ no outono e 60 a $180 \mathrm{~kg} / \mathrm{ha}$ de $\mathrm{P}_{2} \mathrm{O}_{5}$ na primavera. Os cultivares Bayan Shirei e Rkatsiteli proporcionaram os maiores retornos econômicos com as doses de $\mathrm{N}$ e $\mathrm{P}_{2} \mathrm{O}_{5}, 90: 90$ e 180:90 kg/ha, respectivamente.

KHUDAVERDOV et alii (1977) realizaram tra-

balhos com videiras dos cultivares Senso e Riesling, aplican do diferentes doses e combinações de NPK em kg/ha. Notaram que nestes cultivares as melhores produções foram :obtidas com as doses 120:120:120 para o cultivar Senso e 90:90:90 pạ ra o cultivar Resling.

SOLDATOVA \& EPSHTEIN (1977), em estudos sobre efeito dos fertilizantes em vinhedos com baixa produtividade, verificaram que aplicando-se o fertilizante a 50-60 cm de profundidade houve um aumento do peso da baga e do cacho, do crescimento dos brotos, do crescimento das raízes e da produtividade.

SANGHAVI \& NIJJAR (1978) realizaram um ensaio durante 2 anos com o cultivar Himrod aplicando-se doses 
de $\mathrm{N}\left(0,4\right.$ e 1,2 kg/planta ) e $\mathrm{P}_{2} \mathrm{O}_{5}$ e $\mathrm{K}_{2} \mathrm{O}(0,8$ e $1,2 \mathrm{~kg} / \mathrm{plan}-$ ta), em vārias combinações. Verificaram que as maiorès prodụ ções foram obtidas com N, P e K $(0,4-1,2-0,8 \mathrm{~kg} / \mathrm{planta})$.

VERMA \& NIJJAR (1978), pesquisando um ensaio com o cultivar Perlette conduzido no espaçamento $2,5 \mathrm{x} 2,5 \mathrm{~m}$ (1.600 plantas/ha). aplicaram cinco doses de N, P e K em diferentes combinações. A dose $\mathrm{N}_{5} \mathrm{P}_{3} \mathrm{~K}_{3}(1,17 \mathrm{~kg}$ de $\mathrm{N}+1,50 \mathrm{~kg}$ de $\mathrm{P}_{2} \mathrm{O}_{5}+1,00 \mathrm{~kg}$ de $\mathrm{K}_{2} \mathrm{O}$ por planta), proporcionou $\mathrm{O}$ maior crescimento vegetativo da planta, porēm, com baixa produção. A maior produção foi obtìda com a dose $\mathrm{N}_{2}{ }^{\mathrm{P}}{ }_{2} \mathrm{~K}_{2} \quad(0,5 \mathrm{~kg}$ de $\mathrm{N}+1,00 \mathrm{~kg}$ de $\mathrm{P}_{2} \mathrm{O}_{5}$ e $0,5 \mathrm{~kg}$ de $\mathrm{K}_{2} \mathrm{O}$ por planta). Apesar destes valores, concluíram que a dose que proporcionava o melhor desenvolvimento vegetativo com boa produção foi O $\mathrm{N}_{3} \mathrm{P}_{3} \mathrm{~K}_{3}\left(0_{0}, 75 \mathrm{~kg}\right.$ de $\mathrm{N}+1,50 \mathrm{~kg}$ de $\mathrm{P}_{2} \mathrm{O}_{5} \circ 1_{,} 00 \mathrm{~kg}$ de $\mathrm{K}_{2} 0$ por planta).

RASSKAZOVA (1979) realizou um ensaio para determinar 0 espaçamento de videiras que melhor proporcio nasse a utilização dos nutrientes. Conclứram que videiras plantadas a uma densidade de 1.600 plantas/ha utilizavam o nutriente aplicado com 2,5 vezes mais eficiência do que videiras com densidade de 4.000 plantas/ha.

HAESELER et alii (1980), em ensaio com o cultivar Concord, aplicaram fósforo anualmente nas doses dé 50 e $150 \mathrm{~kg} / \mathrm{ha}$ de $\mathrm{P}_{2} \mathrm{O}_{5}$ - durante 8 anos, em combinação com o nitrogênio ( $\mathrm{NP}$ e $\mathrm{NP}_{3}$ ) ou nitrogênio e potássio ( $\mathrm{NPK}$ ou $\mathrm{NP}_{3} \mathrm{~K}$ ), onde $\mathrm{P}=50 \mathrm{~kg} / \mathrm{ha}$ e $\mathrm{P}_{3}=150 \mathrm{~kg} / \mathrm{ha}$. Concluiram que a produ- 
ção, número de cachos/planta, peso dos cachos e peso das ba gas foram aumentados com $N K$, $N P K$ e $\mathrm{NP}_{3} \mathrm{~K}$. O NPK e $\mathrm{NP}_{3} \mathrm{~K}$ foram mais efetivos do que NKe $N$, $N P$ e $\mathrm{NP}_{3}$ não causaram nenhum efeito. $0{ }^{\circ}$ Brix não foi afetado com os diferentes tratamentos de adubação. O fósforo do solo aumentou quando se aplicou $150 \mathrm{~kg} / \mathrm{ha}$ de superfosfato. O potássio do solo aumentou quando se aplicou $95 \mathrm{~kg} / \mathrm{ha}$ de cloreto de potássio, e a extra ção de potássio do solo pela planta diminuiu quando se aplicou $\mathrm{P}_{3}$ combinado com $\mathrm{K}$.

BELOV et alii (1983) realizaram ensaio com plantas do cultivar Fetyaska Belaya, conduzidas no espaçamen to de $2,25 \times 1,5 \mathrm{~m}\left(2.960\right.$ plantas/ha), aplicando-se $\mathrm{N}, \mathrm{P}_{2} \mathrm{O}_{5}$ e $\mathrm{K}_{2} \mathrm{O}$ nas entrelinhas, anualmente, na primavera, em doses variando de 60 a $240 \mathrm{~kg} / \mathrm{ha}$ de cada nutriente, a uma profundi dade de 20 a $40 \mathrm{~cm}$. Embora a dose 240:240:240 tenha proporcionado a maior produção $(4,84 \mathrm{t} / \mathrm{ha})$, a dose 90:90:90, promoveu uma produção muito próxima $(4,67$ t/ha). Não foi notada diferença no teor de açūcar nos frutos entre as diferentes doses aplicadas.

REZNIK (1983) aplicou $\mathrm{N}, \mathrm{P}_{2} \mathrm{O}_{5}$ e $\mathrm{K}_{2} \mathrm{O}$ em plan tas do cultivar Fetyaska Belaya, em doses variando de 60:60: 60 a 240:240:240 kg/ha. Constatou que altas doses de NPK diminuem o crescimento das raízes, principalmente aquelas situadas entre 0-20 cm de profundidade, enquanto doses mais baixas estimulam o crescimento.

GIORGESSI et alii (1984), em ensaio de adubação com N, P, K nas doses de 100 e 200 kg/ha, aplicados na 
primavera, em sulco, concluîram que não houve diferença significativa na produção por planta, no peso médio do cacho e no teor de sólidos solūveis totais ( ${ }_{\text {Brix }}$, devido à pouca disponibilidade de água.

PEROVIC (1984) realizou ensaio com o cultivar Vranac enxertado em R-99 durante três anos, com diferentes doses de $\mathrm{N} \cdot(90,140$ ou $190 \mathrm{~kg} / \mathrm{ha}), \mathrm{P}_{2} \mathrm{O}_{5}(80,130$ ou $180 \mathrm{~kg} / \mathrm{ha})$ e $\mathrm{K}_{2} \mathrm{O}(120,190$ ou $260 \mathrm{~kg} / \mathrm{ha})$, em vārias combina ções. O nitrogênio a 140 e $190 \mathrm{~kg} / \mathrm{ha}$ reduziu a produção. Aumentando-se a dose de $\mathrm{N}$, os teores de NPK na folha foram levemente afetados, havendo diminuição do teor de magnésio e aumento do de cálcio. Não houve influência na produção com as doses de $\mathrm{P}_{2} \mathrm{O}_{5}$. Aumentando-se a dose de $\mathrm{K}_{2} \mathrm{O}$ de 120 para $190 \mathrm{~kg} / \mathrm{ha}$ aumentou-se a produção, não havendo resposta quando se aplicou $260 \mathrm{~kg} / \mathrm{ha}$ deste elemento.

BICER \& OZEL (1986) em ensaio com o cultivar Tarsus Beyazin aplicaram $\mathrm{N}$ e $\mathrm{P}_{2} \mathrm{O}_{5}$ nas doses variando de 40 a $120 \mathrm{~kg} / \mathrm{ha}$, na forma de sulfato de amônio e superfosfato triplo. A dose maior de nitrogênio aumentou a produção. A dose ideal foi de $80 \mathrm{~kg}$ de $\mathrm{N}$ e $100 \mathrm{~kg}$ de $\mathrm{P}_{2} \mathrm{O}_{5}$ por hectare.

BRAR \& BINDRA (1986), realizaram ensaio visan do a determinação do efeito da densidade de plantio no crescimento, na produção, na qualidade dos frutos e no teor de nutrientes da folha. Verificaram que o crescimento das plantas, medido pelo diâmetro do tronco e peso dos ramos poda dos foram, maiores no espaçamento de $3,0 \times 3,0 \mathrm{~m}$. A maior pro dução por planta ocorreu no espaçamento 3,0 x 3,0 m com 2,65 
kg. A qualidade dos cachos foi melhor quando as plantas esta vam espaçadas $3,0 \times 3,0 \mathrm{~m}$, com cachos pesando $230 \mathrm{~g}$, sendo

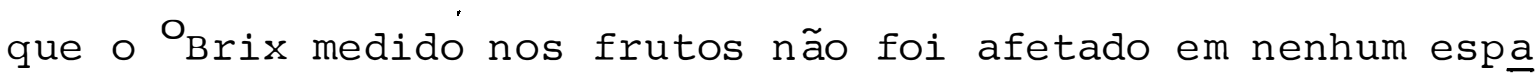
çamento. Os teores de N, P, K na folha foram maiores no espaçamento $3,0 \times 3,0 \mathrm{~m}$, e decrescia quando se aumentava o adensamento.

LIXANDRU et alii (1986) conduziram experimen to de 1981 a 1985, verificando que $100 \mathrm{~kg}$ de $\mathrm{N}$, mais $40 \mathrm{~kg}$ de $\mathrm{P}_{2} \mathrm{O}_{5}$ e mais $102-150 \mathrm{~kg}$ de $\mathrm{K}_{2} \mathrm{O} / \mathrm{ha}$, foi o melhor tratamento para o cultivar Frincusã.

MAHORKAR et alii (1986), em três anos de experimentação com vinhedos de 'Thompson Seedless', com seis anos de idade, avaliaram o efeito de diferentes doses e combinações de N, P e K quanto à produção. Concluíram que o melhor tratamento foi N, P e K 180-180-80 g/planta, aplicados anualmente e, que proporcionou produção de 2,83 kg/planta; enquanto o controle produziu somente $1,77 \mathrm{~kg} / \mathrm{planta}$.

ARUTYUNYAN (1987), para determinar a dose econômica de fertilizante, testou värias combinações de $\mathrm{N}$, P, K em plantas dos cultivares Rkatsiteli e Mskhali, espaçados $2,5 \times 1,5 \mathrm{~m}$ (2.666 plantas/ha). Verificou que altas doses de NPK nem sempre aumentaram as produções comphraradas com o controle e com as doses mais baixas; na média, a cose de $100 \mathrm{~kg} / \mathrm{hà} \mathrm{die} \mathrm{cada} \mathrm{nutriente} \mathrm{foi} \mathrm{economicamen-}$ te mais efetiva.

NEILSEN et alii (1987) testaram o efeito do NPK na produção e composição de frutos, de plantas espaçadas 
$4,0 \times 2,0 \mathrm{~m}(1.250 \mathrm{plantas} / \mathrm{ha})$. As fontes e doses utilizadas foram nitrato de amônio $(50,150$ e 300 kg/ha); superfosfato triplo (0 e $90 \mathrm{~kg} / \mathrm{ha}$ ) e cloreto de potássio (0 e 500 $\mathrm{kg} / \mathrm{ha}$ ). Verificaram que a produção aumentou com doses crescentes de nitrogênio; o peso dos cachos mostrou a ocorrência de uma interação NXP, para melhor crescimento. A melhor dose de nitrogênio ficou entre 50 e $150 \mathrm{~kg} / \mathrm{ha}$; o fósforo isolado não aumentou o peso dos cachos; e o potássio isolado não aumentou nem a proclução e nem o peso dos cachos.

SHASKOV et alii (1987), em experimentos com o cultivar Aligotë, testaram diferentes níveis de N, P e K durante quatro anos. Concluíram que o volume de massa verde, qualidade dos frutos e produção estão diretamente relacionados com a aplicação de fertilizantes. Os melhores resultados foram obtidos quando se aplicaram $\mathrm{N}_{2} \mathrm{P}_{2} \mathrm{O}_{5}$ e $\mathrm{K}_{2} \mathrm{O}$ njas doses 120-180-120 a $240 \mathrm{~kg} / \mathrm{ha}$, respectivamente.

CONRADIE \& SAAYMAN (1988) realizaram ensaio com plantas do cultivar Chenin Blanc, espaçadas de $3,05 \times 1,52 \mathrm{~m}(2,157 \mathrm{plantas} / \mathrm{ha})$, para testar o efeito de diferentes doses de $\mathrm{N}(16,56$ e $96 \mathrm{~kg} / \mathrm{ha})$, de $\mathrm{P}_{2} \mathrm{O}_{5}(0,9$ e 18 $\mathrm{kg} / \mathrm{ha})$ e de $\mathrm{K}_{2} \mathrm{O}(0,45$ e $90 \mathrm{~kg} / \mathrm{ha})$, em diferentes combinações. Utilizaram como fontes os fertilizantes nitrato de amônio, superfosfato e sulfato de potássio. Verificaram que o nitrogênio aumentou a produção e a brotação, mas reduziu ligeiramente o pH do solo da superfície, tanto mais quanto maior a dose aplicada. Concluíram que a videira necessita de $40 \mathrm{~kg} /$ ha de $\mathrm{N}$ para produzir 13 t/ha de uva. O fósforo e o potássio 
tiveram um efeito positivo na produção, e as doses ideais aplicadas anualmente de $\mathrm{P}_{2} \mathrm{O}_{5}$ e $\mathrm{K}_{2} \mathrm{O}$ determinadas foram $9 \mathrm{~kg} /$ ha e $40 \mathrm{~kg} / \mathrm{ha}$, respectivamente. 


\section{MATERIAL E METODOS}

3.1. Cultivar estudado

A videira 'Niagara', de bagas brandas e arredondadas, originou-se do cruzamento em que participaram as espécies Vitis labrusca L. e Vitis vinéfera L.. Foi introduzi da no Brasil em 1894 e, a partir de 1910, começou a ser difundida pelos Estados brasileiros, principalmente no Estado de São Paulo. Em princípios de 1933, no distrito de Louveira, município de Jundiaí, Estado de são Paulo, foram observadas algumas mutações somãticas de 'Niagara', originando a Niagara Rosada (INGLEZ DE SOUSA, 1959).

o cultivar Niagara Rosada possui vigor médio, ciclo curto, boa resistência às doenças, exigindo de 5 a 12 pulverizações com fungicidas durante um ciclo e mediana prodū tividade. Os cachos são de tamanho médio, compactos e cilín drico-cônicos. As bagas são médias, globosas, de cor rosada intensa, sabor foxado, textura fundente, apresentando pequena aderência ao pedicelo. o defeito do cultivar é a ${ }^{\vdots}$ baixa resistência à cönservação e ao transporte (INGLEZ DE SOUSA, 1969). 


\section{3,2, Fertilizantes estudados}

Segundo HIROCE (1980), o tipo de adubo deve ser escolhido depois de se saber o tipo de solo, pois assim os adubos serão utilizados com maior eficiência. Por exemplo: em solo de reação neutra a alcalina, o fósforo deve ser aplicado na forma de superfosfato, e nos solos ligeiramente ácidos, na forma de escórias básicas ou fosfatos tipo básicos. o potássio pode ser aplicado tanto na forma de cloreto ou de sulfato, mas se ocorrer carência de magnésio, deve-se prefe rir os adubos potássicos que contenham magnésio. No caso do nitrogênio, a forma nítrica é mais eficaz em solos ácidos, e o sulfato de amônio é muito melhor em solos alcalinos. Em regiões úmidas e nas de inverno seco, a uréia e/ou o nitrato de amônio são melhores pois são menos lixiviados e mais facilmen te absorvidos pela planta.

Para a realização deste trabalho foram utiliza dos cinco níveis de nitrogênio, cinco níveis de fósforo e cin co níveis de potássio, usando-se como fontes de nutrientes a uréia, o superfosfato triplo e o cloreto de potássio, ...respectivamente. Utilizaram-se também porcentagens diferentes de sulfato duplo de potássio e magnésio em substituição ao clore to de potássio, quando empregadas doses correspondentes a 200 gramas por planta de $\mathrm{K}_{2} \mathrm{O}$.

Segundo MALAVOLTA \& NEPTUNE (1983) , a uréia possui $45 \%$ de $\mathrm{N}$, sendo solúvel em água, e, como a maioria dos adubos nitrogenados,tem a tendência de abaixar $\circ \mathrm{pH}$ do solo; 
pode-se perder por volatilização, particularmente nas adubações em cobertura.

O superfosfato triplo contém $42-46 \%$ de $\mathrm{P}_{2} \mathrm{O}_{5}$ to tal, sendo solúvel em água; o cloreto de potássio possui $60 \%$ de $\mathrm{K}_{2} \mathrm{O} ;$ e o sulfato duplo de potássio e magnésio contém $20-$ 22\% de $\mathrm{K}_{2} \mathrm{O}, 18-19 \%$ de MgO e 22-23\% de S (MALAVOLTA, 1981).

o uso da uréia e do superfosfato triplo como fontes de nutrientes neste trabalho, se deveu também à sua crescente produção nacional e de importação em relação aos outros congêneres, conforme dados apresentados na Tabela 1 .

\section{3, Irocall do experimento}

o experimento foi realizado no Sítio. Palmei ras, propriedade de Airton Casarin, localizado no Bairro das Videiras, município de Indaiatuba, Estado de São Paulo, situa do a $23^{\circ} 05^{\prime}$ de latitude sul e a $47^{\circ} 13^{\prime}$ de longitude oeste e 630 m de altitude média.

A região, do ponto de vista climático, apresen ta-se, de acordo com o sistema proposto por KÖeppen, classifi cada como Cwa (SETZER, 1966): Os balanços hídricos do local, segundo THORNTHWAITE \& MATHER (1955), nos anos de 1980 a 1985, são apresentados nas Tabelas 2 a 7 . 
Tabela 1. Evolução da produção nacional e de impor/tação dos principais fertilizantes nitrogenados e fosfatados, em $t$ de $\mathrm{N}$ e $t$ de $\mathrm{P}_{2} \mathrm{O}_{5}$

\begin{tabular}{|c|c|c|c|c|}
\hline Fertlizantes & 1980 & 1982 & 1984 & 1986 \\
\hline & \multicolumn{3}{|c|}{ Nitrogenados } & \\
\hline \multicolumn{5}{|c|}{ Nitrato de amônio } \\
\hline Nacional & 73.590 & 80.394 & 63.414 & 59.903 \\
\hline \multicolumn{5}{|l|}{ Nitrocálcio } \\
\hline Nacional & 27.420 & 22.647 & 40.218 & 42.971 \\
\hline \multicolumn{5}{|c|}{ Sulfato de amônio } \\
\hline Nacional & 41.762 & 37.716 & 35.561 & 27.879 \\
\hline Importado & 170.613 & 131.457 & 121.206 & 168.103 \\
\hline \multicolumn{5}{|l|}{ Uréia } \\
\hline Nacional & 86.150 & 157.961 & 383.659 & 404.733 \\
\hline \multirow[t]{2}{*}{ Importado } & 255.123 & 86.306 & 1.350 & 76.439 \\
\hline & \multicolumn{3}{|c|}{$\underline{\text { Fosfatados }}$} & $\therefore$ \\
\hline \multicolumn{5}{|c|}{ Fosfato de monoamônio } \\
\hline Nacional & 253.064 & 236.042 & 255.246 & 277.904 \\
\hline Importado & 2.190 & - & - & 8.097 \\
\hline \multicolumn{5}{|c|}{ Fosfato de diamônio } \\
\hline Nacional & 156.678 & 89.514 & 83.896 & 87.314 \\
\hline Importado & 202.814 & 39.083 & 43.0 .39 & 53.264 \\
\hline \multicolumn{5}{|c|}{ Superfosfato simples } \\
\hline Nacional & 332.0 .77 & 228.807 & 403.062 & 419.640 \\
\hline Importado & 21.706 & 9.504 & 1.840 & 4.088 \\
\hline \multicolumn{5}{|c|}{ Superfosfato triplo } \\
\hline Nacional & 487.798 & 253.862 & 329.184 & 306.612 \\
\hline Importado. & 1.34 .0 .98 & 23.976 & 25.898 & 80.839 \\
\hline
\end{tabular}


Tabela 2. Balanço hídrico para o município de Indaiatuba, SP, em 1980 .

\begin{tabular}{|c|c|c|c|c|c|c|}
\hline Mês & $\begin{array}{l}\text { Temp. } \\
\text { Oे }_{\mathrm{C}}\end{array}$ & $\begin{array}{l}\mathrm{EP} \\
\mathrm{mm}\end{array}$ & $\begin{array}{l}\mathrm{P} \\
\mathrm{mm}\end{array}$ & $\begin{array}{l}\mathrm{ER} \\
\mathrm{mm}\end{array}$ & $\begin{array}{l}\mathrm{DEF} \\
\mathrm{mm}\end{array}$ & $\begin{array}{l}\text { EXC } \\
\mathrm{mm}\end{array}$ \\
\hline Jan. & 22,7 & 108 & 166 & 108 & 0 & 58 \\
\hline Fev. & 23,7 & 103 & 175 & 103 & 0 & 72 \\
\hline Mar. & 24,9 & 123 & 94 & 120 & 3 & 0. \\
\hline Abr. & 22,5 & 89 & 130 & 89 & 0 & 15 \\
\hline Maio & 20,8 & 77 & 10 & 63 & 14 & 0 \\
\hline Jun. & 17,8 & 48 & 86 & 48 & 0 & 0 \\
\hline Jul. & 19,4 & 61 & 4 & 45 & 16 & 0 \\
\hline Ago. & 20,2 & 73 & 41 & 57 & 16 & 0 \\
\hline Set. & 19,5 & 66 & 52 & 57 & 9 & 0 \\
\hline out. & 22,4 & 101 & 48 & 65 & 36 & 0 \\
\hline Nov. & 23,2 & 10.9 & 105 & 106 & 0 & 0 \\
\hline Dez. & 2.4 .2 & 12.3 & .39 .3 & 123 & 0 & 175 \\
\hline Ano & 21,7 & 1.0 .81 . & $1 . .30 .4$ & 9.84 & 94 & 320 \\
\hline
\end{tabular}

Fonte: Instituto Agronômico - Seção de Climatologia Agrícola. 
Tabela 3. Balanço hídrico para o município de Indaiatuba, SP, em 1981 .

\begin{tabular}{llrrrrr}
\hline Mês & $\begin{array}{l}\text { Temp. } \\
\text { OC }\end{array}$ & $\begin{array}{l}\mathrm{EP} \\
\mathrm{mm}\end{array}$ & $\begin{array}{l}\mathrm{P} \\
\mathrm{mm}\end{array}$ & $\begin{array}{l}\mathrm{ER} \\
\mathrm{mm}\end{array}$ & $\begin{array}{l}\mathrm{DEF} \\
\mathrm{mm}\end{array}$ & $\begin{array}{r}\text { EXC } \\
\mathrm{mm}\end{array}$ \\
\hline Jan. & 24,2 & 129 & 231 & 129 & 0 & 102 \\
Fev. & 25,2 & 118 & 63 & 105 & 13 & 0 \\
Mar. & 24,4 & 116 & 149 & 116 & 0 & 0 \\
Abr. & 21,8 & 86 & 26 & 70 & 16 & 0 \\
Maio & 20,9 & 77 & 20 & 46 & 31 & 0 \\
Jun. & 17,1 & 43 & 84 & 43 & 0 & 0 \\
Jul. & 16,4 & 42 & 13 & 30 & 12 & 0 \\
Ago. & 19,7 & 65 & 11 & 35 & 30 & 0 \\
Set. & 22,5 & 93 & 5 & 27 & 66 & 0 \\
Out. & 20,8 & 88 & 101 & 88 & 0 & 0 \\
Nov. & 23,7 & 112 & 332 & 112 & 0 & 129 \\
Dez. & 23,0 & 116 & 118 & 116 & 0 & 2 \\
\hline Ano & 21,6 & 1.085 & 1.153 & 917 & 168 & 233 \\
\hline
\end{tabular}

Fonte: Instituto Agronômico - Seção de Climatologia Agrícola. 
Tabela 4. Balanço hỉdrico para o município de Indaiatuba, SP, em 1982 .

\begin{tabular}{llrrrrr}
\hline Mês & $\begin{array}{l}\text { Temp } \\
{ }^{2} \mathrm{C}\end{array}$ & $\begin{array}{l}\text { EP } \\
\mathrm{mm}\end{array}$ & $\begin{array}{l}\mathrm{P} \\
\mathrm{mm}\end{array}$ & $\begin{array}{l}\text { ER } \\
\mathrm{mm}\end{array}$ & $\begin{array}{c}\text { DEF } \\
\mathrm{mm}\end{array}$ & $\begin{array}{r}\text { ExC } \\
\text { mm }\end{array}$ \\
\hline Jan. & 22,7 & 108 & 291 & 108 & 0 & 183 \\
Fev. & 24,9 & 118 & 113 & 118 & 0 & 0 \\
Mar. & 23,2 & 107 & 161 & 107 & 0 & 49 \\
Abr. & 20,7 & 78 & 121 & 78 & 0 & 43 \\
Maio & 18,7 & 54 & 93 & 54 & 0 & 39 \\
Jun. & 19,3 & 59 & 233 & 59 & 0 & 174 \\
Jul. & 19,0 & 56 & 39 & 56 & 0 & 0 \\
Ago. & 19,8 & 68 & 21 & 55 & 13 & 0 \\
Set. & 20,8 & 81 & 12 & 44 & 37 & 0 \\
Out. & 22,1 & 98 & 227 & 98 & 0 & 46 \\
Nov. & 24,1 & 115 & 209 & 115 & 0 & 94 \\
Dez. & 22,3 & 109 & 407 & 109 & 0 & 298 \\
\hline Ano & 21,5 & 1.051 & 1.927 & 1.001 & 50 & 926 \\
\hline
\end{tabular}

Fonte: Instituto Agronômico - Seção de Climatologia Agrícola. 
Tabela 5. Balanço hídrico para o município de Indaiatuba, SP, em 1983.

\begin{tabular}{llrlrrr}
\hline Mês & $\begin{array}{l}\text { Temp. } \\
\text { OC }\end{array}$ & $\begin{array}{l}\text { EP } \\
\text { mm }\end{array}$ & $\begin{array}{l}\text { P } \\
\text { mm }\end{array}$ & $\begin{array}{l}\text { ER } \\
\text { mm }\end{array}$ & $\begin{array}{l}\text { DEF } \\
\text { mm }\end{array}$ & $\begin{array}{l}\text { EXC } \\
\text { mm }\end{array}$ \\
\hline Jan. & 23,7 & 115 & 269 & 115 & 0 & 154 \\
Fev. & 24,4 & 103 & 256 & 103 & 0 & 153 \\
Mar. & 22,8 & 104 & 191 & 104 & 0 & 87 \\
Abr. & 22,2 & 86 & 158 & 86 & 0 & 72 \\
Maio & 20,7 & 77 & 168 & 77 & 0 & 91 \\
Jun. & 18,3 & 48 & 249 & 48 & 0 & 201 \\
Jul. & 19,3 & 61 & 19 & 56 & 5 & 0 \\
Ago. & 19,5 & 65 & 5 & 39 & 26 & 0 \\
Set. & 18,9 & 60 & 271 & 60 & 0 & 141 \\
Out. & 21,5 & 91 & 139 & 91 & 0 & 48 \\
Nov. & 22,9 & 109 & 133 & 109 & 0 & 24 \\
Dez. & $23,3$. & 119 & 191 & 119. & 0 & 72 \\
\hline Ano & 21,5 & 1.038 & 2.049 & 1.00 .7 & 31 & 1.043 \\
\hline \hline
\end{tabular}

Fonte: Instituto Agronômico - Seção de Climatologia Agrícola. 
Tabela 6. Baianço hỉarico para o município de Indaiatuba, SF, eni 1984.

\begin{tabular}{|c|c|c|c|c|c|c|}
\hline Mês & $\begin{array}{l}\text { Temp. } \\
{ }_{C}\end{array}$ & $\begin{array}{l}\mathrm{EP} \\
\mathrm{mm}\end{array}$ & $\begin{array}{l}\mathrm{P} \\
\mathrm{mm}\end{array}$ & $\begin{array}{l}\mathrm{ER} \\
\mathrm{Mm}\end{array}$ & $\begin{array}{l}\mathrm{DEF} \\
\mathrm{mm}\end{array}$ & $\begin{array}{l}\mathrm{EXC} \\
\mathrm{mm}\end{array}$ \\
\hline Jan. & 25,0 & 136 & 205 & 136 & 0 & 69 \\
\hline Fev. & 26,3 & 130 & 12 & 89 & 41 & 0 \\
\hline Mar. & 24,3 & 116 & $7 i$ & 86 & 30 & 0 \\
\hline Abr. & 21,9 & 86 & 88 & 86 & $\mathrm{C}$ & 0 \\
\hline Maio & 21,5 & 80 & 68 & 71 & 9 & ci \\
\hline Jun. & 19,6 & 59 & 0 & 12 & 47 & 0 \\
\hline Jul. & 20,1 & 64 & 6 & 13 & 51 & 0 \\
\hline Ago. & 19,1 & 59 & 108 & 59 & 0 & 0 \\
\hline set. & 19,7 & 66 & 85 & 66 & 0 & 0 \\
\hline out. & 23,5 & 111 & 28 & 68 & 43 & 0 \\
\hline Nov. & 23,6 & 112 & 128 & 112 & 0 & 0 \\
\hline Dez. & 23,0 & 116 & 227 & 116 & 0 & 43 \\
\hline Ano & 22,3 & 1.135 & 1.026 & 914 & 221 & 112 \\
\hline
\end{tabular}

Fonte: Instituto Ag̣ronômico - Seção de Climatologia Agrícola. 
Tabela 7. Balanço hîdrico para o municỉpio de Indaiatuba, SP, em 1985 .

\begin{tabular}{llrrrrr}
\hline Mês & $\begin{array}{l}\text { Temp. } \\
\mathrm{O}_{\mathrm{C}}\end{array}$ & $\begin{array}{l}\text { EP } \\
\mathrm{mm}\end{array}$ & \multicolumn{1}{l}{$\begin{array}{l}\mathrm{P} \\
\mathrm{mm}\end{array}$} & $\begin{array}{l}\text { ER } \\
\mathrm{mm}\end{array}$ & $\begin{array}{l}\text { DEF } \\
\mathrm{mm}\end{array}$ & $\begin{array}{l}\text { EXC } \\
\mathrm{mm}\end{array}$ \\
\hline Jan. & 23,4 & 118 & 187 & 118 & 0 & 69 \\
Fev. & 24,8 & 118 & 144 & 118 & 0 & 26 \\
Mar. & 23,9 & 110 & 176 & 110 & 0 & 66 \\
Abr. & 22,6 & 89 & 43 & 83 & 6 & 0 \\
Maio & 19,5 & 63 & 102 & 63 & 0 & 0 \\
Jun. & 16,8 & 40 & 19 & 39 & 1 & 0 \\
Jul. & 17,4 & 47 & 3 & 34 & 13 & 0 \\
Ago. & 20,5 & 73 & 5 & 37 & 36 & 0 \\
Set. & 21,1 & 81 & 68 & 71 & 10 & 0 \\
Out. & 23,5 & 111 & 35 & 52 & 59 & 0 \\
Nov. & 24,1 & 115 & 107 & 109 & 6 & 0 \\
Dez. & 24,2 & 123 & 131 & 123 & 0 & 0 \\
\hline Ano & 21,8 & 1.088 & 1.020 & 957 & 125 & 161 \\
\hline \hline
\end{tabular}

Fonte: Instituto Agronômico - Seção de Climatologia Agrícola. 


\section{4, Cllassificação do solo}

o solo onde foi instalado o experimento clas-. sifica-se como Solo Podzolizado com Cascalhos (CENTRO NACIO NAL DE ENSINO E PESQUISAS AGRONÔMICAS, 1960).

3,5. Porta-enxerto e idade

As videiras em estudo, quando da instalação do experimento, estavam com'seis anos de idade e enxertadas sobre o porta-enxerto 'Ripária do Traviū'. (106-8 mgt) (VIALA \& VERMOREL, 1909).

\section{3,6, Espaçamento}

As videiras encontravam-se plantadas no espaçamento de 2,00 $\mathrm{m}$ nas entrelinhas e 1,00 m entre plantas.

\section{3,7, Sistexna de condução}

o vinhedo experimental estava sendo conduzi do no sistema de cordão esporonado simples ou unilateral ( espaldeira), com três fios de arame. 


\subsection{Poda}

As podas de produção realizadas nas vicieiras do lote experimental foram curtas, deixando-se seis esporões por cordão esporonado, e duas gemas por ramo produtivo. As podas foram feitas anualmente, no período de 1980 a 1985, no dia 17 de julho.

Imediatamente após a poảa de produção foi aplicada calciocianamida a $20 \%$, na forma de pincelamento no ramo todo, com o intuíto de estimular e uniformizar a brotaÇão, segundo TERRA et alii (1982) .

\section{9, Tratos culturais}

Os demais tratos culturais, como tratamento de inverno, tratamento fitossanitārio, amarração dos brotos, desnetamento, desbrota, foram realizados de acordo com a recomendação de PIRES \& TERRA (1987).

\subsection{Delineamento essperimental}

O delineamento experimental de tratamentos foi o fatorial fracionado $(1 / 5)\left(5^{3}\right)$ proposto por CONAGIN \& JORGE (1977), com 2 repetições. Além dos 25 tratamentos que compõem o fatorial, foram estudados 5 tratamentos extras pa- 
ra avaliar fontes diferentes de potássio e comportamento da testemunha sem adubo.

Cada uma das 60 parcelas era constítuída de 6 plantas, considerando-se úteis apenas as 4 plantas centrais. Para cada linha existiam 2 linhas de bordadura.

A Figura 1 mostra o esquema do lote experimen tal.

A escolha dos 5 diferentes níveis de $\mathrm{N}, \mathrm{P}_{2} \mathrm{O}_{5}$ e $\mathrm{K}_{2} \mathrm{O}$, foi baseada em recomendações gerais de adubação (GOBBATO, 1940 ; PAIVA NETO, 1941; MALAVOLTA, 1959; NOGUEIRA, 1965; WINKLER, 1965; INGLEZ DE SOUSA, 1969; PEREIRA, 19.72; SANTOS NETO, 1973; ASSOCIAÇÃO NACIONAL PARA DIFUSÃO DE ADUBOS, 1975; CAMPINAS, 1977; DECHEN, 1980 e MALAVOLTA, 1980) e em resultados experimentais obtidos no exterior por ELSHOURBACY \& ISMAIL, 1961; ISMAIL et alii, 1964; NIJJAR \& RAM, 1969; NIJENSOHN et alii, 1970; POPA \& IONESCU, 1970 ; CHADHA \& SINGH, 1971; IANNINI, 1972; IONCHEV \& MINEVA, 1973; LICUL, 1973; POMOHACI et alii, 1973; VELICHKO, 1974 ; ALIEV, 1975; AVRAMOV et alii, 1975; SERPUKHOVITINA, 1975; GEORGIEVA, 1976; HABEED et alii, 1976; IONEV, 1976; TAKHAMAZOV \& ASKENDEROV, 1976; KHUDAVERDOV et alii, 1977; SANGHAVI \& NIJJAR, 1978; VERMA \& NIJJAR, 1978 e HAESELER et alii, 1980 .

Os níveis de adubação utilizados nesta pesqui sa foram os seguintes: $\mathrm{N}: 30,60,90,120$ e 150 gramas por planta; $\mathrm{P}_{2} \mathrm{O}_{5}: 40,120,200,280$ e 360 gramas por planta; e 


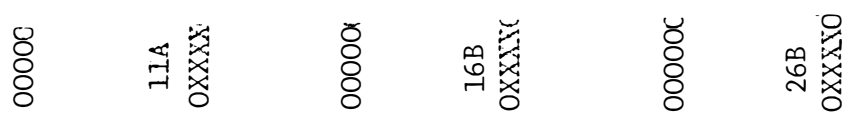

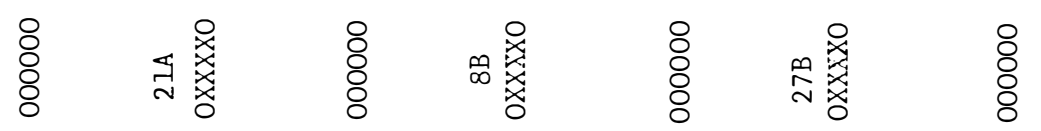

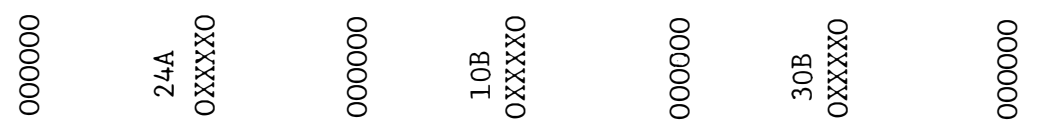

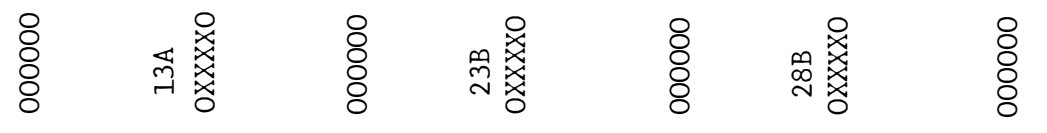

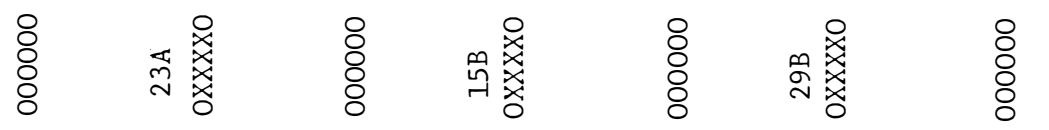

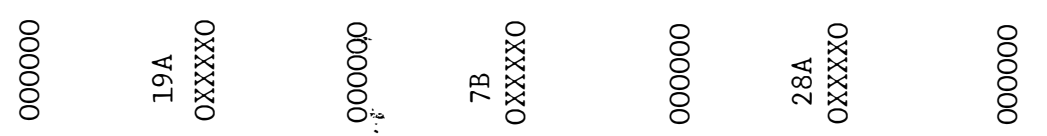

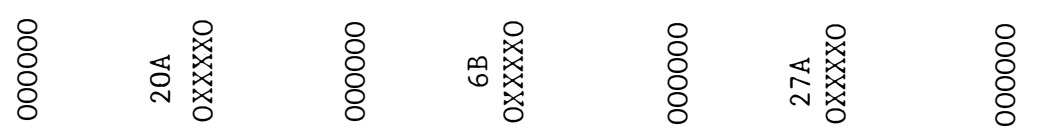

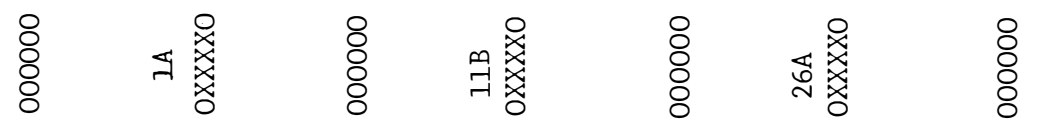

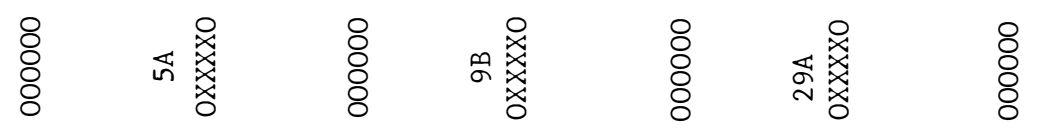

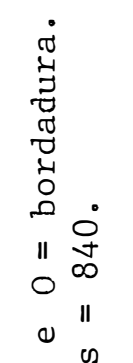

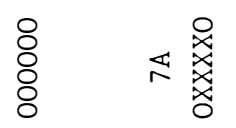

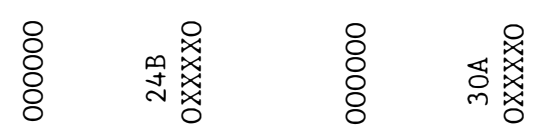

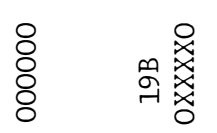

高暧

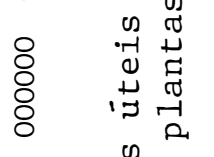

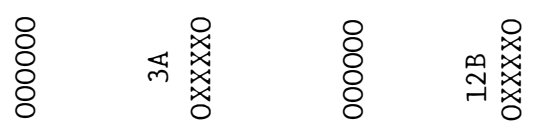

高 踥

害 靁

ํㅗㅇ

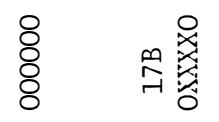

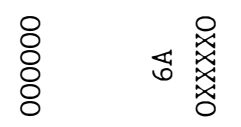

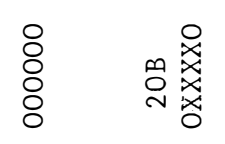

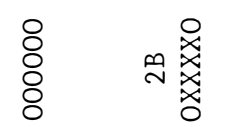

:

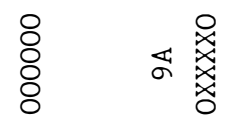

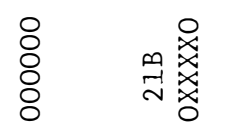

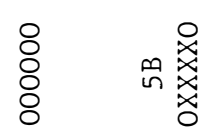

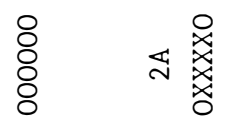

亩 商

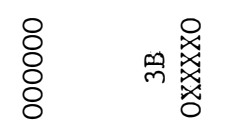

\&

高尔善

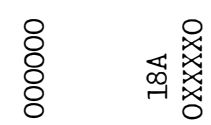

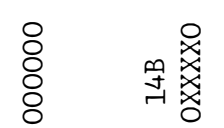

衷要爱

影

옹 变

รั

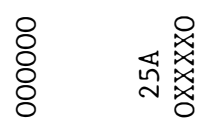

害暧

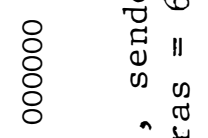

高翣

案

象愛 
$\mathrm{K}_{2} \mathrm{O}: 40,120,200,280$ e 360 gramas por planta。

Na Tabela 8, figuram os diferentes tratamentos estudados.

A correspondência entre as quantidades dos nutrientes $\mathrm{IJ}_{2} \mathrm{P}_{2} \mathrm{O}_{5}$ e $\mathrm{K}_{2} \mathrm{O}$, e as quantidades "dos fertilizantes, uréia, superfosfato triplo e cloreto de potássio e magnésio, respectivamente, encuntram-se na rabela 9.

Os cinco tratamentos extras foram os seguintes:

a. Tratamento 26: tes temunha sem adubo

b. Tratamento 27: $\mathrm{N}_{3} \mathrm{P}_{3} \mathrm{~K}_{3}$, usando-se como fontes de nutrientes uréia, superfosfato triplo e sulfato duplo de potássio e magnēssio..

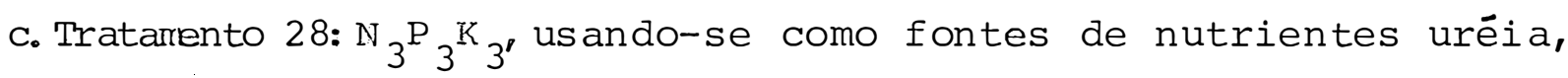
superfosfato triplo e mistura de cloreto de potássio com sul fato duplo de potássio e magnésio, na porcentagem 50:50.

d. Tratamento 29: $\mathrm{N}_{3} \mathrm{P}_{3} \mathrm{~K}_{3}$, usando-se como fontes de nutrientes uréia, superfosfato triplo e mistura de cloreto de potåssio e magnẹ sio, na porcentagem de 25:75.

e. Tratamento 30: $\mathrm{N}_{3} \mathrm{P}_{3} \mathrm{~K}_{3}$, us ando-se como fontes de nutrientes uréia, superfosfato triplo e mistura de cloreto de potássio com sul fato duplo de potássio e magnésio, na porcentagem 75:25.

\subsection{Modos e épocas de aplicação dos fertilizantes}

Segundo URETA (1981), a aplicação de nutrientes em excesso pode provocar desequilibrios nutricionais, ou facilitar o desenvolvimento de doenças na videira, que podem limitar o crescimento e a produção da planta.

Um balanço equilibrado de nutrientes è necessā- 
Tabela 8. Tratamentos estudados em delineamento $(1 / 5)\left(5^{3}\right)$, e tratamentos extras, em ensaio de adubação N, P e K conduzido de 1980 a 1985 , em Indaiatuba, SP

\begin{tabular}{|c|c|c|c|}
\hline \multirow{2}{*}{ Tratamentos } & \multicolumn{3}{|c|}{ Quantidade dos nutrientes } \\
\hline & $\mathrm{N}$ & $\mathrm{P} 205$ & $\mathrm{~K}_{2} 0$ \\
\hline 1. $\mathrm{N}_{1} \mathrm{P}_{1} \mathrm{~K}_{1}$ & 30 & 40 & 40 \\
\hline 2. $\mathrm{N}_{2} \mathrm{P}_{2} \mathrm{~K}_{2}$ & 60 & 120 & 120 \\
\hline 3. $\mathrm{N}_{3} \mathrm{P}_{3} \mathrm{~K}_{3}$ & 90 & 200 & 200 \\
\hline 4. $\mathrm{N}_{4} \mathrm{P}_{4} \mathrm{~K}_{4}$ & 120 & 280 & 280 \\
\hline 5. $\mathrm{N}_{5} \mathrm{P}_{5} \mathrm{~K}_{5}$ & 150 & 360 & 360 \\
\hline 6. $\mathrm{N}_{2} \mathrm{P}_{4} \mathrm{~K}_{5}$ & 60 & 280 & 360 \\
\hline 7. $\mathrm{N}_{3} \mathrm{P}_{5} \mathrm{~K}_{1}$ & 90 & 360 & 40 \\
\hline 8. $\mathrm{N}_{4} \mathrm{P}_{1} \mathrm{~K}_{2}$ & 120 & 40 & 120 \\
\hline 9. $\mathrm{N}_{5} \mathrm{P}_{2} \mathrm{~K}_{3}$ & 150 & 120 & 200 \\
\hline 10. $\mathrm{N}_{1} \mathrm{P}_{3} \mathrm{~K}_{4}$ & 30 & 200 & 280 \\
\hline 11. $\mathrm{N}_{3} \mathrm{P}_{2} \mathrm{~K}_{4}$ & 90 & 120 & 280 \\
\hline 12. $\mathrm{N}_{4} \mathrm{P}_{3} \mathrm{~K}_{5}$ & 120 & 200 & 360 \\
\hline 13. $\mathrm{N}_{5} \mathrm{P}_{4} \mathrm{~K}_{1}$ & 150 & 280 & 40 \\
\hline 14. $\mathrm{N}_{1} \mathrm{P}_{5} \mathrm{~K}_{2}$ & 30 & 360 & 120 \\
\hline 15. $\mathrm{N}_{2} \mathrm{P}_{1} \mathrm{~K}_{3}$ & 60 & 40 & 200 \\
\hline 16. $\mathrm{N}_{4} \mathrm{P}_{5} \mathrm{~K}_{3}$ & 120 & 360 & 200 \\
\hline 17. $\mathrm{N}_{5} \mathrm{P}_{1} \mathrm{~K}_{4}$ & 150 & 40 & 280 \\
\hline 18. $\mathrm{N}_{1} \mathrm{P}_{2} \mathrm{~K}_{5}$ & 30 & 120 & 360 \\
\hline 19. $\mathrm{N}_{2} \mathrm{P}_{3} \mathrm{~K}_{1}$ & 60 & 200 & 40 \\
\hline 20. $\mathrm{N}_{3} \mathrm{P}_{4} \mathrm{~K}_{2}$ & 90 & 280 & 120 \\
\hline 21. $\quad \mathrm{N}_{5} \mathrm{P}_{3} \mathrm{~K}_{2}$ & 150 & 200 & 120 \\
\hline 22. $\mathrm{N}_{1} \mathrm{P}_{4} \mathrm{~K}_{3}$ & 30 & 280 & 200 \\
\hline 23. $\mathrm{N}_{2} \mathrm{P}_{5} \mathrm{~K}_{4}$ & 60 & 360 & 280 \\
\hline 24. $\mathrm{N}_{3} \mathrm{P}_{1} \mathrm{~K}_{5}$ & 90 & 40 & 360 \\
\hline 25. $\mathrm{N}_{4} \mathrm{P}_{2} \mathrm{~K}_{1}$ & 120 & 120 & 40 \\
\hline 26. $\mathrm{N}_{0} \mathrm{P}_{0} \mathrm{~K}_{0}(1)$ & 0 & 0 & 0 \\
\hline 27. $\mathrm{N}_{3} \mathrm{P}_{3} \mathrm{~K}_{3(1)}$ & 90 & 200 & $200 *$ \\
\hline 28. $\mathrm{N}_{3} \mathrm{P}_{3} \mathrm{~K}_{3}(1)$ & 90 & 200 & $200 *$ \\
\hline 29. $\mathrm{N}_{3} \mathrm{P}_{3} \mathrm{~K}_{3}(1)$ & 90 & 200 & $200 *$ \\
\hline 30. $\mathrm{N}_{3} \mathrm{P}_{3} \mathrm{~K}_{3}(1)$ & 90 & 200 & $200 *$ \\
\hline
\end{tabular}

${ }^{(1)}$ Tratamentos extras. *: Provenientes de duas fontes de $\mathrm{K}_{2} \mathrm{O}$. 
Tabela 9. Fontes de nutrientes estudadas com correspondentes quantidades, em gramas por planta, em ensaio de adubação N, P e K, conduzido em Indaiatuba, SP, período de 1980 a 1985

\begin{tabular}{|c|c|c|c|c|}
\hline \multirow[b]{2}{*}{ № Tratamentos } & \multicolumn{4}{|c|}{ Quantidade dos fertilizantes } \\
\hline & Uréia & $\begin{array}{l}\text { Superfosfato } \\
\text { triplo }\end{array}$ & $\begin{array}{l}\text { cloreto de } \\
\text { potássio }\end{array}$ & $\begin{array}{l}\text { Sul fato duplo de } \\
\text { potássio e magnésio }\end{array}$ \\
\hline & \multicolumn{4}{|c|}{$\mathrm{g} / \mathrm{planta}$} \\
\hline 1 & 67 & 95 & 67 & - \\
\hline 2 & 133 & 286 & 200 & - \\
\hline 3 & 200 & 476 & 333 & - \\
\hline 4 & 267 & 667 & 467 & - \\
\hline 5 & 333 & 857 & 600 & - \\
\hline 6 & 133 & 667 & 600 & - \\
\hline 7 & 200 & 857 & 67 & - \\
\hline 8 & 267 & 95 & 200 & - \\
\hline 9 & 333 & 286 & 333 & - \\
\hline 10 & 67 & 476 & 467 & - \\
\hline 11 & 200 & 286 & 467 & - \\
\hline 12 & 267 & 476 & 600 & - \\
\hline 13 & 333 & 667 & 67 & $-i$ \\
\hline 14 & 67 & 857 & 200 & - \\
\hline 15 & 133 & 95 & 333 & - \\
\hline 16 & 267 & 857 & 333 & - \\
\hline 17 & 333 & 95 & 467 & - \\
\hline 18 & 67 & 286 & 600 & - \\
\hline 19 & 133 & 476 & 67 & - \\
\hline 20 & 200 & 667 & 200 & - \\
\hline 21 & 333 & 476 & 200 & - \\
\hline 22 & 67 & 667 & 333 & - \\
\hline 23 & 133 & 857 & 467 & - \\
\hline 24 & 200 & 95 & 600 & - \\
\hline 25 & 267 & 286 & 67 & - \\
\hline 26 & 0 & 0 & 0 & - \\
\hline 27 & 200 & 476 & - & 909 \\
\hline 28 & 200 & 476 & 167 & 455 \\
\hline 29 & 200 & 476 & 83 & 682 \\
\hline 30 & 200 & 476 & 250 & 227 \\
\hline
\end{tabular}


rio para um crescimento vigoroso, uma alta produção ou uma boa qualidade dos frutos (PHILLIPINE COUNCIL FOR AGRICULTURAL RESEARCH， 1976) 。

A colocação do adubo no solo varia muito, mas em geral é aplicado em sulco distante de 30 a $60 \mathrm{~cm}$ da planta, e a $20 \mathrm{~cm}$ de profundidade. O nitrogênio, que poderá ser parcelado, é aplicado em cobertura no início do crescimento vegetativo (PHILLIPINE COUNCIL FOR AGRICULTURAL RESEARCH, 1976 e NEGRINI, 1988)。

RODRIGUES \& KIEHL (1986), avaliaram as perdas de amônia por volatilização após aplicação de uréía em labora tório e em casa de vegetação com amostras de um solo Podzólico Vermelho-Amarelo (PV) e de um Latossolo Vermelho- Amarelo distrófico (LVd). A uréia foi aplicada em doses equivalentes a 120,180 e $240 \mathrm{~kg} / \mathrm{ha}$ de $\mathrm{N}$ e à superfície do solo, misturada à camada 0-2 cm e à camada 0-5 cm, e localzada a $5 \mathrm{~cm}$ de profundidade. Concluíram que as perdas por volatilização foram tanto mais baixas quanto menor foi a dose de uréia e maior a profundidade de aplicação, isto é, as aplicações a 0-5 $\mathrm{cm}$ e a $5 \mathrm{~cm}$ de profundidade permitiram melhor controle da volatilização, principalmente no solo PV onde as perdas puderam ser eliminadas com a localização do fertilzante a $5 \mathrm{~cm}$ de profundidade.

Para a realização deste experimento, os fertilizantes fosfatados e potássicos foram aplicados em ; sulcos abertos ao lado das linhas úteis, medindo $30 \mathrm{~cm}$ de largura, 
$20 \mathrm{~cm}$ de profundidade e distantes $80 \mathrm{~cm}$ das plantas, com base em trabalhos de PIZA JR \& NEPTUNE (1966) e BALCAR et alii (1970). Após a aplicạ̣ão destes fertilizantes nos sulcos, eram bem misturados com a terra de superfície e cobertos com esta terra. Depois desta operação era feita a cobertura morta com capim em toda a rua.

Os fertilizantes fosfatados e potāssicos foram aplicados, anualmente, em meados de junho, no período compreendido entre 1980 e 1985.

O fertilizante nitrogenado, nas diferentes doses, foi aplicado em sulcos estreitos abertos ao lado da linha ütil na rua sem cobertura morta, a $5 \mathrm{~cm}$ de profundidade e distantes $25 \mathrm{~cm}$ das plantas. Apōs a aplicação da uréia nos suleos, era feita a cobertura com terra de superrície.

As aplicações nitrogenadas foram feitạ três vezes ao ano, parceladamente e em doses iguais, durante os anos de 1980 a 1985; a primeira, logo após a poda, a segunda quando os frutos estavam na fase de "chumbinho" e a terceira quando os frutos estavam na fase de "meia-baga".

\subsection{2, Modos e épocas de coleta de amostras de terra}

Antes da instalação do experimento, em 22 de abril de 1980, foram coletadas 20 amostras simples de terra do lote experimental, na profundidade de 0 a $20 \mathrm{~cm}$, utilizando-se de um trado tipo holandes.Estas 20 amostras forammuito bem 
misturadas, e da mistura tirou-se umáninica: amostra composta que foi colocada num recipiente de papelão ap̣opriado, e após identificação foi enviada ao laboratório da Seção de Fertiıidade do Solo e Nutrição de Plantas do Instituto Agronômico, em Campinas, para a execução das anālises químicas.

As principais características quimicas desse solo são apresentadas na Tabela 10 .

Tabela 10. Resultados das anālises químicas da amostra de terra do lote experimental conduzido em Indaia tuba, SP. Ano de 1980 (RAIJ \& ZULLO, 1977).

\begin{tabular}{ccccccc}
\hline Amostra no & M.O. & $\mathrm{pH}$ & $\mathrm{Al}^{3+}$ & $\mathrm{Ca}{ }^{2+}, \mathrm{Mg}$ & $\mathrm{K}$ & $\mathrm{P}$ \\
\hline & $\circ$ & $\left(\mathrm{H}_{2} \mathrm{O}\right)$ & $-\mathrm{e} . \mathrm{mg} / 100 \mathrm{ml}$ de T.F.S.A.- & $-\mathrm{ug} / \mathrm{ml}$ de T.F.S.A. \\
1 & 2,9 & 6,2 & 0,0 & $4,6, \ldots, 8$ & 40 & 7 \\
\hline
\end{tabular}

Os valores encontrados para o fôsforo e potássio se situam na classe de teor considerado baixo.

A partir de 1981, foram retiradas anualmente duas amostras de terra por parcela, na profundidade de 0 a $20 \mathrm{~cm}$. As amostras de terra das parcelas correspondentes a um mesmo tratamento nas duas repetições eram muito bem misturadas e depois colocadas num recipiente de papelão apropriado. Estas amostras, após identificadas, tambēm eram enviadas ao mesmo laboratório do Instituto Agronōmico. As referidas amostras foram coletadas em meados de abril de cada ano, isto é, de 1981 a 1985. 
3.13. Modos e épocas de coleta de amostras de folha

Foram coletadas anualmente, amostras de $6^{\text {as }}$ fo lhas, correspondentes à primeira folha madura a pàrtir do ápice dos ramos, em nümero de dez por planta, à época de florescimento, de acordo com GALLO \& OLIVEIRA (1960) e GALLO \& RIBAS (1962). Após a coleta, estas amostras eram acondicionadas em sacos de papel e depois de identificadas, enviadas ao laboratório da Seção de Fertilidade do solo e Nutrição de Plantas do Instituto Agronômico, em Campinas, para a execução das anālises químicas.

As amostras de folhas foram coletadas normalmente entre 25 de setembro a 5 de outubro de cada ano, de 1980 a 1985, dependendo das condições climáticas ocorridas nesses anos.

3.14. Maturação, colheita, número de cachos e peso médio de cacho

MUZYCHENKO (1972), realizando experimentäção com aplicações de NPK, verificou que houve um incremento no teor de sólidos solúveis totais dos frutos ( ${ }^{\circ}$ Brix).

No entanto, FREGONI \& ZIONI (1969); NIJENSOHN et alii (1970); ARTAMOVA (1976); HAESELER et alii (1980); BELOV et alii (1983) e GIORGESSI et alii (1984), testando doses e fontes de NPK; TULIN \& MOROZOV (1976); RETAMALES \& RA- 
ZETO (1985) e LAVIN \& VALENZUELA (1986a), pesquisando diferentes doses e fontes de $\mathrm{N}$; e BRAR \& BRINDA (1986), estudando os efeitos da densidade de plantio, concluíram que ${ }^{\circ}{ }^{\circ}$ Brix dos frutos não foi afetado nessas pesquisas realizadas.

As colheitas foram executadas uma ünica vez por ano, no mês de dezembro, quando as bagas haviam atingido o ponto de maturação característico para o cultivar Niagara Rosada, que é de $14^{\circ}$ Brix segundo PEREIRA (1982). O teor de sólidos solūveis ( $\mathrm{Brix}$ ) foi medido através de um refratômetro manual com escala de medição de 0 a $45 \%$.

Completado o ciclo da cultura, com os frutos perfeitamente maduros, efetuaram-se, anualmente, as colheitas dos cachos de todas as parcelas separadamente, os quais foram pesados usando-se uma balança automática com capacidade para 20 quilos e sub-divisões de 20 gramas. Por ocasião da colheita anual erarn contados os números de cachos por parce la.

o peso médio de cacho por parcela foi calculado pela razão entre a produção e o número de cachos.

3.15. Análises químicas de terra e de folha

As determinações químicas das terras amostradas dos diferentes tratamentos nos anos de 1980, 1981 e 1982, foram realizadas seguindo os métodos de análise para fins de 
fertilidade descritos por RAIJ \& ZULLO (1977). As determinações químicas nos anos de 1983, 1984 e 1985, foram realizadas seguindo os métodos de análise para fins de fertilidade des critos por RAIJ \& QUAGGIO (1983).

As determinações químicas realizadas nas folhas amostradas das diferentes parcelas, em relação aos macronutrientes nitrogênio, fósforo, potássio, cálcio, magnésio e enxofre, foram executadas de acordo com BATAGLIA "I et alii (1983) .

\subsection{Análises estatísticas}

Foram feitas análises estatísticas dos dados referentes à produção por parcela, ao peso médio de cacho e aos macronutrientes extraídos das folhas.

Inicialmente foram realizadas as análises estą tísticas com o modelo para blocos ao acaso. As comparações en tre as médias dos tratamentos correspondentes ao nível $\mathrm{N}_{3} \mathrm{P}_{3} \mathrm{~K}_{3}$, com duas fontes de potássio, cloreto de potássio, incluido no delineamento, e sulfato duplo de potássio e magnésio, mistura de cloreto de potássio com sulfato duplo de potássio e magnésio na porcentagem 75:25, mistura de clóreto de potássio com sulfato duplo de potássio e magnésio na porcenta gem 50:50 e mistura de cloreto de potássio e magnésio na porcentagem 25:75, foram feitas pelo teste de Duncan, ao nível de 5\%, calculado segundo PIMENTEL GOMES (1982). 
60.

As comparações dos tratamentos em relação à testemunha sem adubo foram realizadas pelo teste de Dunnett, ao nível de 5\%.

Os tratamentos que compõem o fatorial $\left(\frac{1)}{5}\left(5^{3}\right)\right.$ foram estudados primeiramente atravēs de um modelo pollinomial quadrātico com 10 parâmetros, conforme CONAGIN \& JORGE (1977), a saber:

$$
\begin{gathered}
Y_{i j k} \leq b_{0} \xi_{0}+b_{1 i} \xi_{1 i}+b_{1 j} \xi_{1 j}+b_{1 k} \xi_{1 k}+b_{2 i} \xi_{2 j}+b_{2 j} \xi_{2 j}+b_{2 k} \xi_{2 k}+ \\
b_{1 i 1 j} \xi_{1 i 1 j}+b_{1 i 1 k} \xi_{1 i 1 k}+b_{1 j 1 k} \xi_{1 j 1 k}+\xi_{i j k}
\end{gathered}
$$

onde os $\xi_{i j k}$ são variáveis aleatórias independentes normalmente distribuĩdas, com mēdia zero e variância $\sigma^{2}$,

$$
\xi_{1 i t}=-3+x_{i . t} \text { e } \xi_{2 i t}=7-6 x_{i t}+x^{2} \text { it }, t=1, \ldots, 5 .
$$

A seguix, o estudo foi feito através do modelo quadrātico com 3 parâmetros para cada nutriente. Após a verificação da existência de ponto māximo, a anālise econômica foi executada considerando-se diferentes relações de preços de fertilizantes e de uva. 


\title{
4. RESULTADOS E DISCUSSÃO
}

\author{
4.1, Resultados de produção
}

4.1.1. Comparação entre as fontes de potássio

Os resultados das médias de produção de uva 'Niagara Rosada' em kg/parcela e os resultados parciais das análises da variância, de 1980 a 1985, e no conjunto 198085, encontram-se na Tabela 11.

Nesta Tabela, verifica-se que não houve diferença significativa do tratamento $\mathrm{N}_{3} \mathrm{P}_{3} \mathrm{~K}_{3}$ do delinẹamento, usando-se como fonte de potássio o cloreto de potássio, em comparação com os tratamentos $\mathrm{N}_{3} \mathrm{P}_{3} \mathrm{~K}_{3}$ : mistura de duas fontes de potássio (cloreto de potássio e sulfato duplo de notássio e magnésio), aplicadas, respectivamente, nas porcentagens $75: 25 ; 50: 50$; 25:75 e 0:100, do nível 3 utilizado, isto ë, $200 \mathrm{~g}$ de $\mathrm{K}_{2} \mathrm{O}$ por planta, nas análises individuais por ano ou no conjunto dos 6 anos, com exceção do ano agrícola 1983/84. Neste ano a mistura $75 \%$ de cloreto de potássio $+25 \%$ de sulfá to duplo de potássio e magnésio foi superior estatística- 


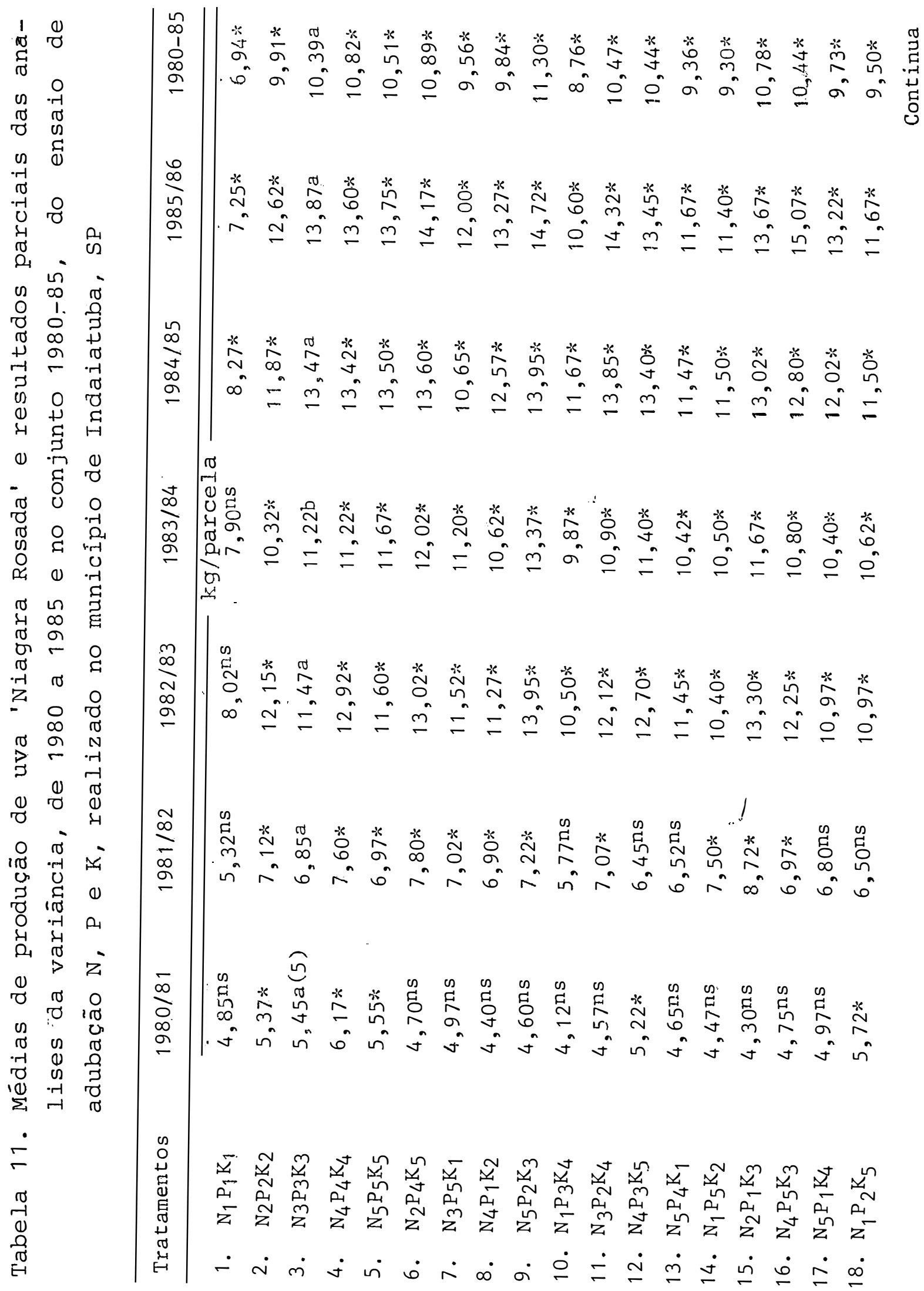




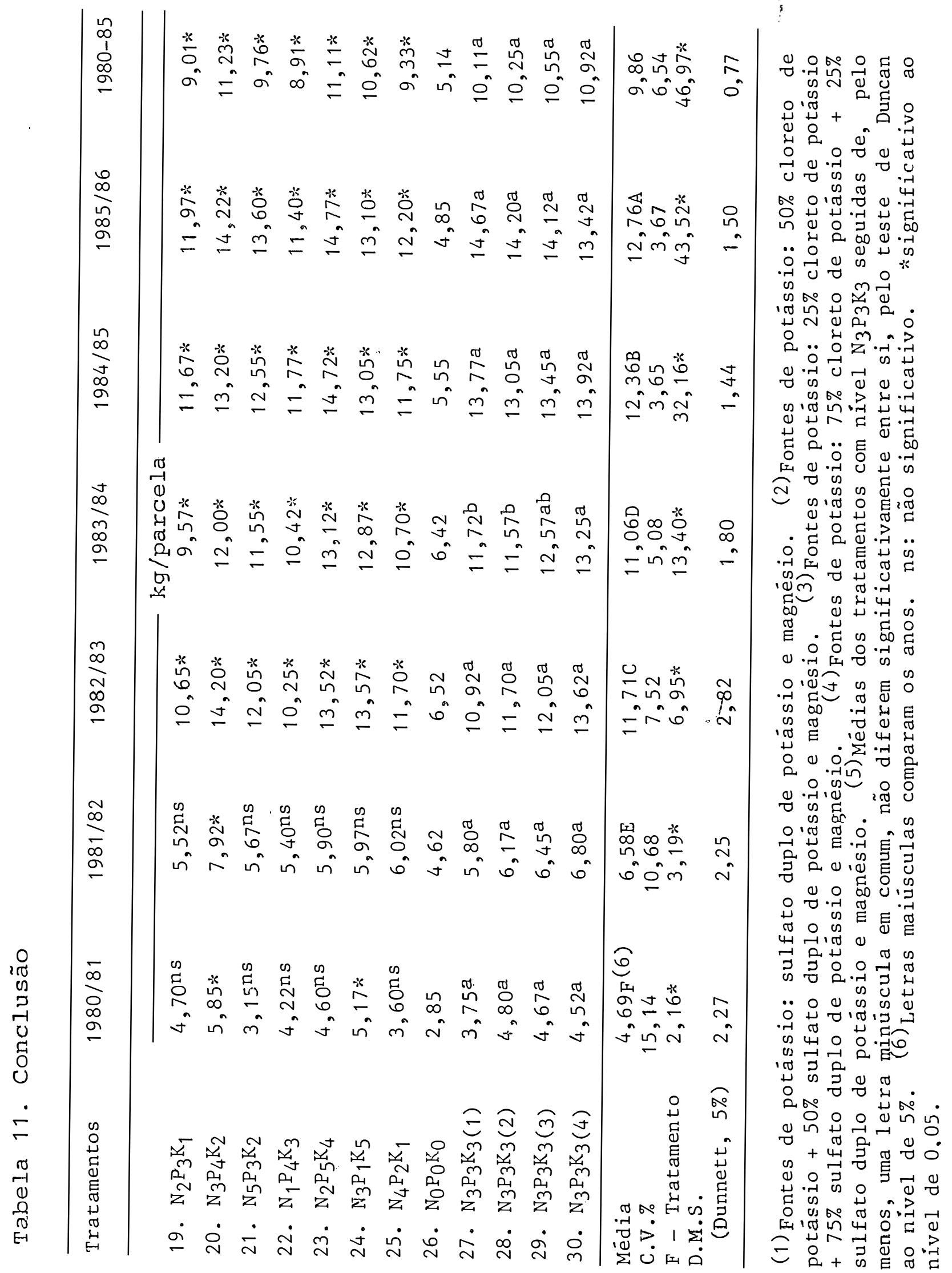


mente ao tratamento $\mathrm{N}_{3} \mathrm{P}_{3} \mathrm{~K}_{3}$ do delineamento.

Os resultados indicam que o cloreto de potássio e o sulfato duplo de potássio e magnésio comportaram-se de forma semelhante como fontes de potássio, com referência à produção, concordando com os resultados verificados por LARSEN et alii (1959) e por CLINE \& BRADT (1980).

4,1.2, Comparação com a testemunha sem adubo

A Tabela 11 mostra que, nos primeiros anos de produção alguns trațamentos com adubo não diferiram da teste munha; no entanto, a partir de 1982/83 houve efeito dạs dife rentes doses de adubação em relação à testemunha. A única exceção foi observada em relação à dose $\mathrm{N}_{1} \mathrm{P}_{1} \mathrm{~K}_{1}$ nos anos $1982 / 83$ e $1983 / 84$.

Finalmente, nos anos 1984/85, 1985/86 e no conjunto dos 6 anos, a totalidade dos tratamentos apresentou produção estatísticamente superior à testemunha.

Estes resultados indicam que, à medida que os fertilizantes foram sendo aplicados às videiras nas diferentes doses, deve ter havido um acúmulo gradativo dos nutrientes no solo, resultando em respostas positivas em relação à testemunha sem adubo.

No conjunto 1980-85, observa-se que todos os tratamentos estudados proporcionaram acréscimos significativos de produção às videiras, quando comparados com o contro- 
le.

O efeito da interação tratamento $x$ anos mostrou-se significativo estatísticamente.

Os resultados obtidos neste trabalho estão de acordo com os observados por FREGONI \& ZIONI (1969), ALANASOV (1970), PEROV et alii (1973), ARTAMOVA (1976), CHAUHAN et alii (1983) e MAHORKAR et alii (1986), que em ensaios de adubação N, P e K encontraram valores de produção significatị vamente superiores à testemunha sem adubo.

Diversos autores (CHRISTENSEN, 1964; POPA \& IONESCU, 1970; SERPUHOVITINA, 1970; KOROBKO, 1972; MUSYCHENKO, 1972; DYUZHEV et alii, 1973; GEORGIEVA, 1976; LIXANDRU et alii, 1986; ARUTUNYAN, 1987; NIELSEN et alii, 1987 ; SHASKOV et alii, 1987; AHMED et alii, 1988 e CONRADIE E SAAYMAN, 1989), estudando diferentes doses de N, P e K, verificaram que, aumentando-se a dose de um ou mais destes nutrien tes, havia um acréscimo significativo na producão.

IANNINI (1972), GIORGESSI et alii (1984) e SCHALLER (1988) observaram que, aumentando-se a quantidade de N, P e K, havia um incremento na produção, porém, não signifi cativamente; enquanto que RETAMALES \& RAZETO (1985) e WOLF \& POOL (1988), estudando diferentes níveis de nitrogēnio, verificaram que não houve diferença estatística dos níveis pesqui sados em relação à testemunha sem adubo. 


\subsubsection{Análises de regressão}

As estimativas dos coeficientes das equações de regressão, dos coeficientes de determinação múltipla e os valores dos testes $\notin$ e F para regressão, obtidos nas ánālises dos dados de produção de uva 'Niagara Rosada' de 1980 a 1985, e no conjunto 1980-85, encontram-se na Tabela 12.

Na referida Tabela, verifica-se inicialmente que não houve interações significativas entre os nutrientes $\mathrm{N}, \mathrm{P}$ e $\mathrm{K}$, em todos os anos considerados individualmente ou no conjunto dos 6 anos.

Observa-se também na Tabela 12, que a partir do ano agrícola $82 / 83$ foi havendo uma resposta linear às adubações nitrogenada e potássica, continuando atē o último ano do ensaio. Na anālise conjunta dos 6 anos houve também efeito linear às aplicações de nitrogênio e potássio. A partir de 1984/85 houve resposta quadrätica para estes dois elementos, ocorrendo o mesmo no conjunto dos 6 anos.

Quanto ao fósforo, não houve respo,stas significativas comparando com os níveis mais adequados em todos os anos individualmente ou no conjunto dos 6 anos, com exceção do ano 1985/86, onde a resposta foi linear.

Estes resultados indicam ser suficiente uma aplicação fosfatada a n u a l com o nível mais baixo de $\mathrm{P}_{2} \mathrm{O}_{5}$, para manutenção ou restituição do nutriente na planta.

As curvas de respostas de produção para doses crescentes de N, P e K, nos anos 1983/84, 1984/85, 1985/86 e 


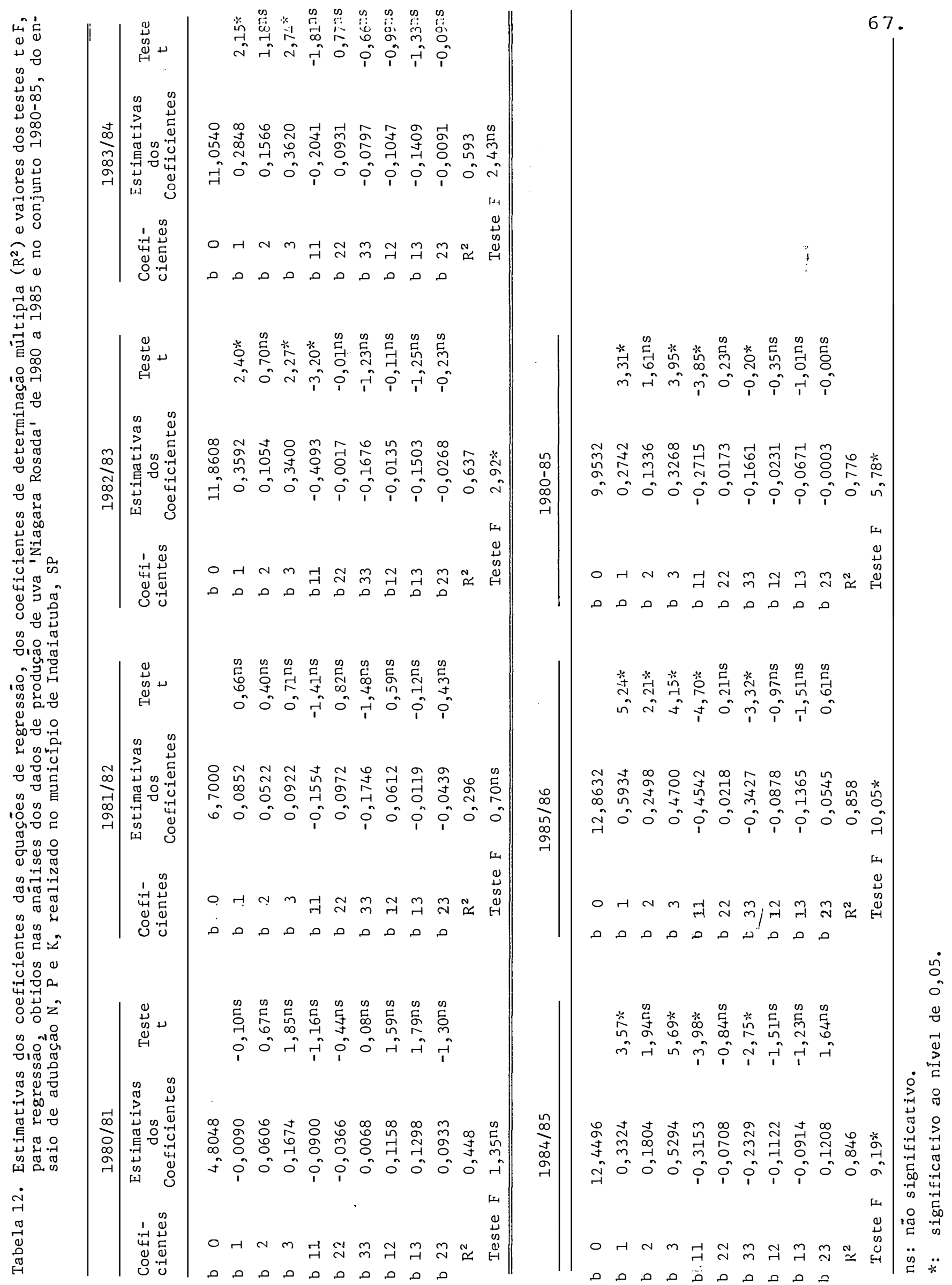


no conjunto 1980-85, considerando os níveis $\mathrm{N}_{\mathrm{O}} \mathrm{P}_{\mathrm{O}} \mathrm{K}_{\mathrm{O}}, \mathrm{N}_{1} \mathrm{P}_{2} \mathrm{~K}_{2}$, $\mathrm{N}_{3} \mathrm{P}_{3} \mathrm{~K}_{3}, \mathrm{~N}_{4} \mathrm{P}_{4} \mathrm{~K}_{4}$ e $\mathrm{N}_{5} \mathrm{P}_{5} \mathrm{~K}_{5}$, encontram-se nas Figuras $2,3,4$ e 5 .

A Figura 2 mostra que no ano 1983/84 ocorreu um acréscimo de produção das videiras com a adição crescente dos fertilizantes $N_{\theta} P$ e $\mathrm{K}$ 。

Nos anos 1984/85 e 1985/86, nota-se nas Figuras 3 e 4 que houve um acréscimo crescente da produção das plantas até o nível $\mathrm{N}_{3} \mathrm{P}_{3} \mathrm{~K}_{3}$, com pequena diminuição nos níveis $\mathrm{N}_{4} \mathrm{P}_{4} \mathrm{~K}_{4}$ e $\mathrm{N}_{5} \mathrm{P}_{5} \mathrm{~K}_{5}$ 。

Analisando-se conjuntamente os 6 anos, podese observar (Figura 5) que ocorreu um acréscimo crescente da produção das videiras até o nível $\mathrm{N}_{4} \mathrm{P}_{4} \mathrm{~K}_{4}$ 。

As curvas de respostas de produção às closes crescentes de nitrogênio, nos anos de 1982/83, 1984/85, 1985/86 e no conjunto 1980-85, e de potássio nos anos de 1984/85, 1985/86 e no conjunto 1980-85, encontram-se nas Figuras $6,7,8,9$ e $10,11,12$, respectivamente.

Na Figura 6, analisando-se o ano 1982/83, verifica-se que ocorreu um acréscimo da produção, a qual atingiu o máximo com $103 \mathrm{~g} / \mathrm{planta}$ de $\mathrm{N}$.

No ano 1984/85, observa-se na Figura 7, que houve um acréscimo da produção, atingindo valor máximo com $107 \mathrm{~g} / \mathrm{planta}$ de $\mathrm{N}$.

A Figura 8, mostra que no ano 1985/86 ocorreu também um acrêscimo da produção, alcançando valor máximo com $110 \mathrm{~g} / \mathrm{planta}$ de $\mathrm{N}$. 
69.

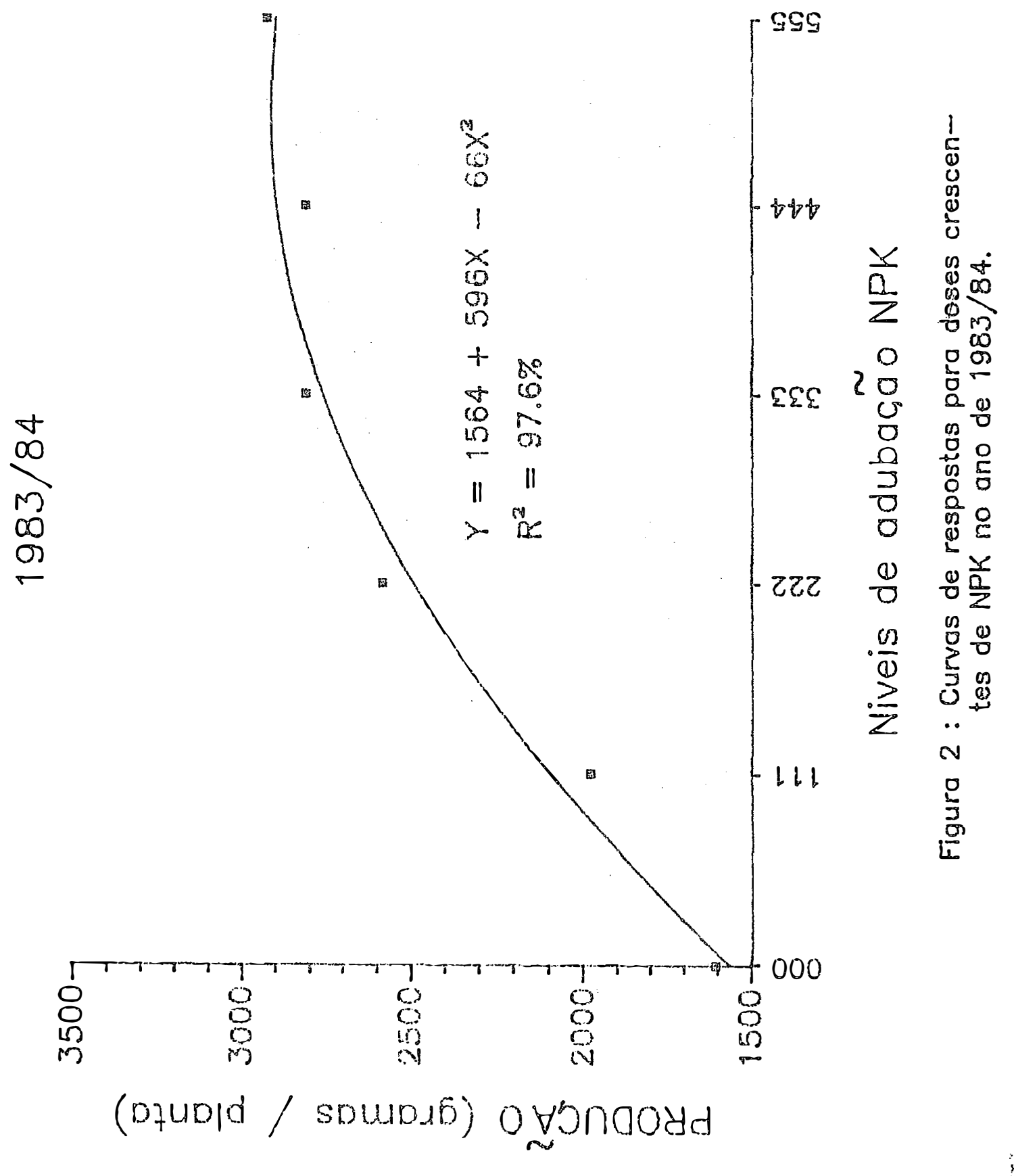




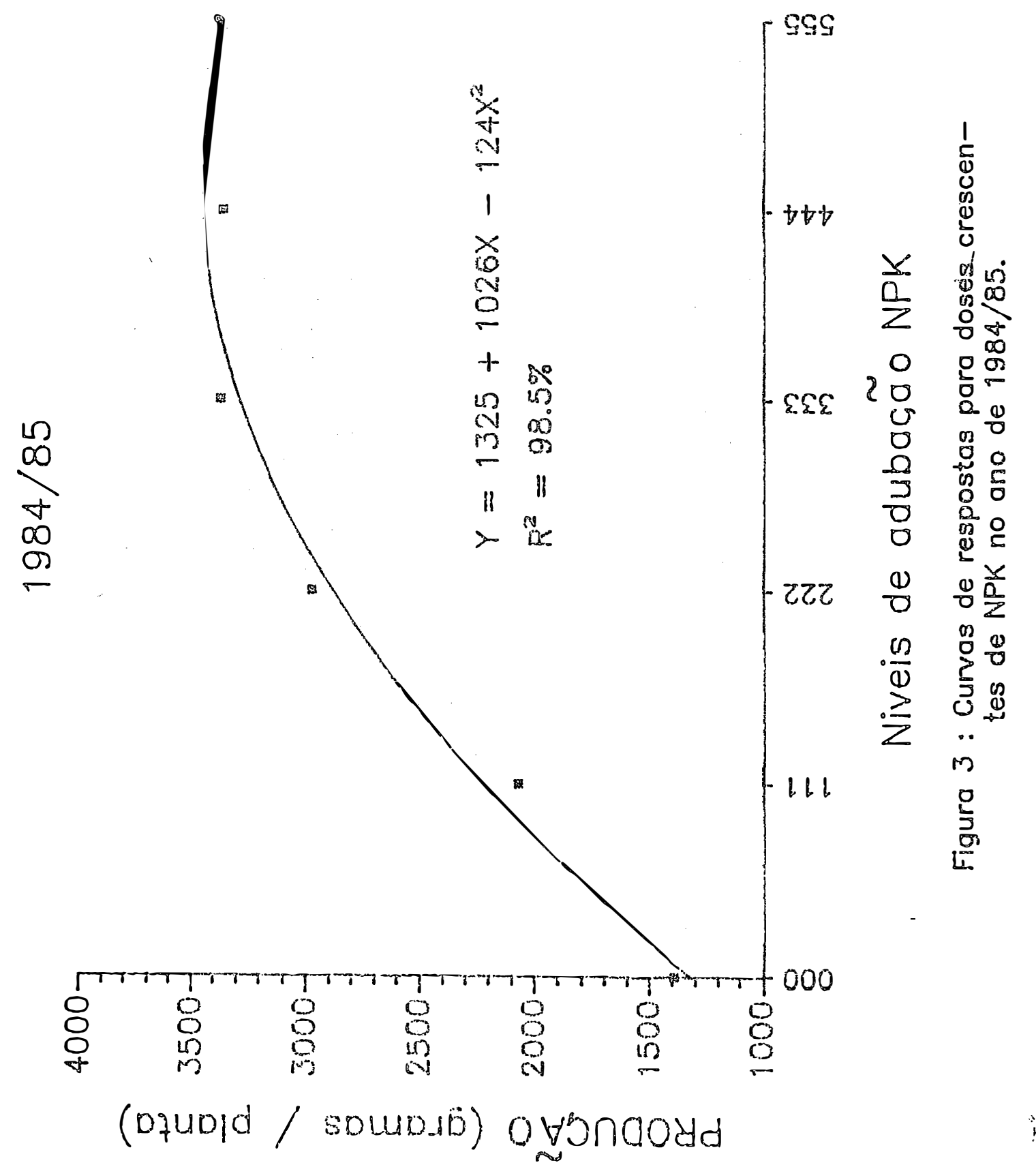


71.

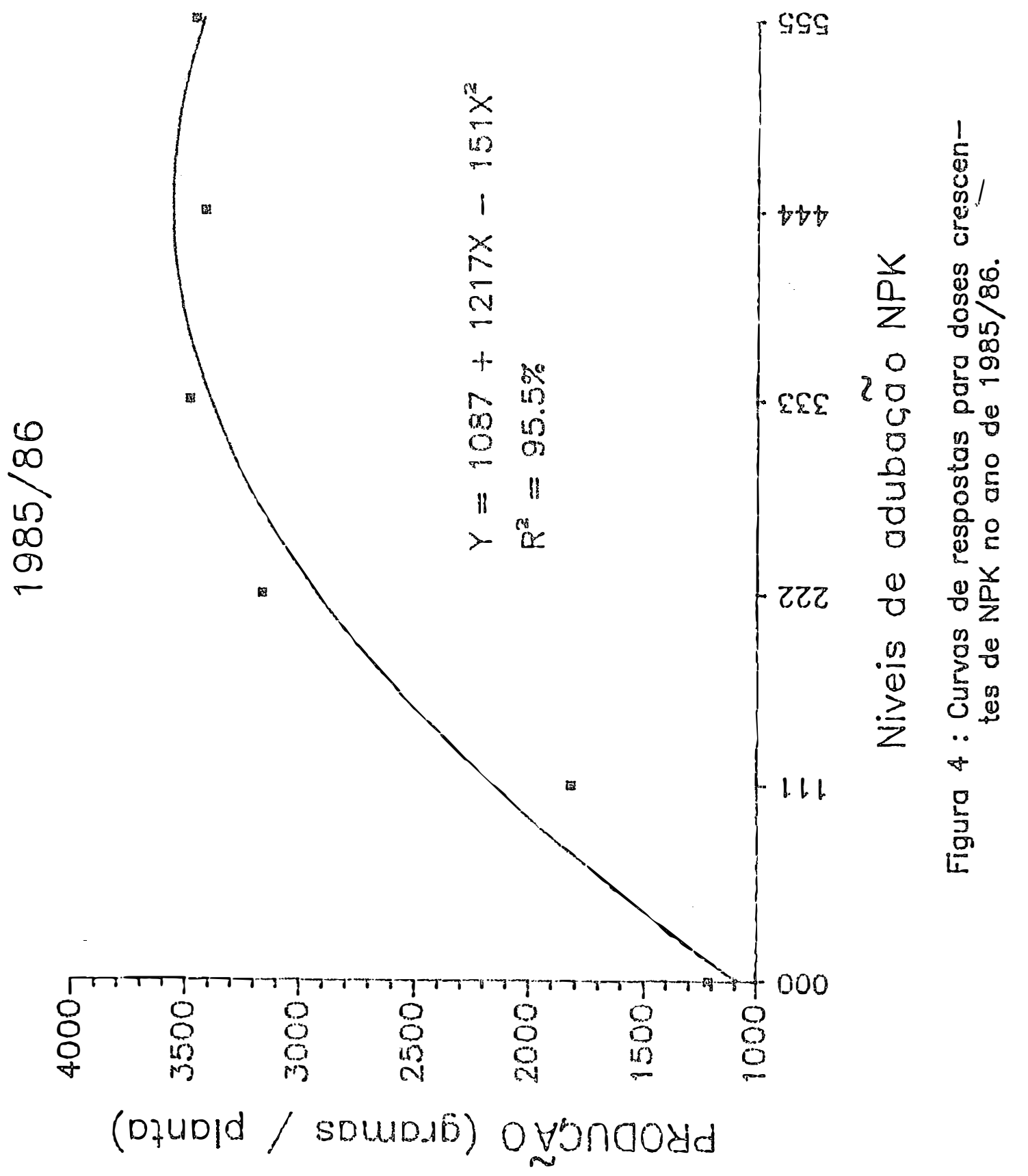




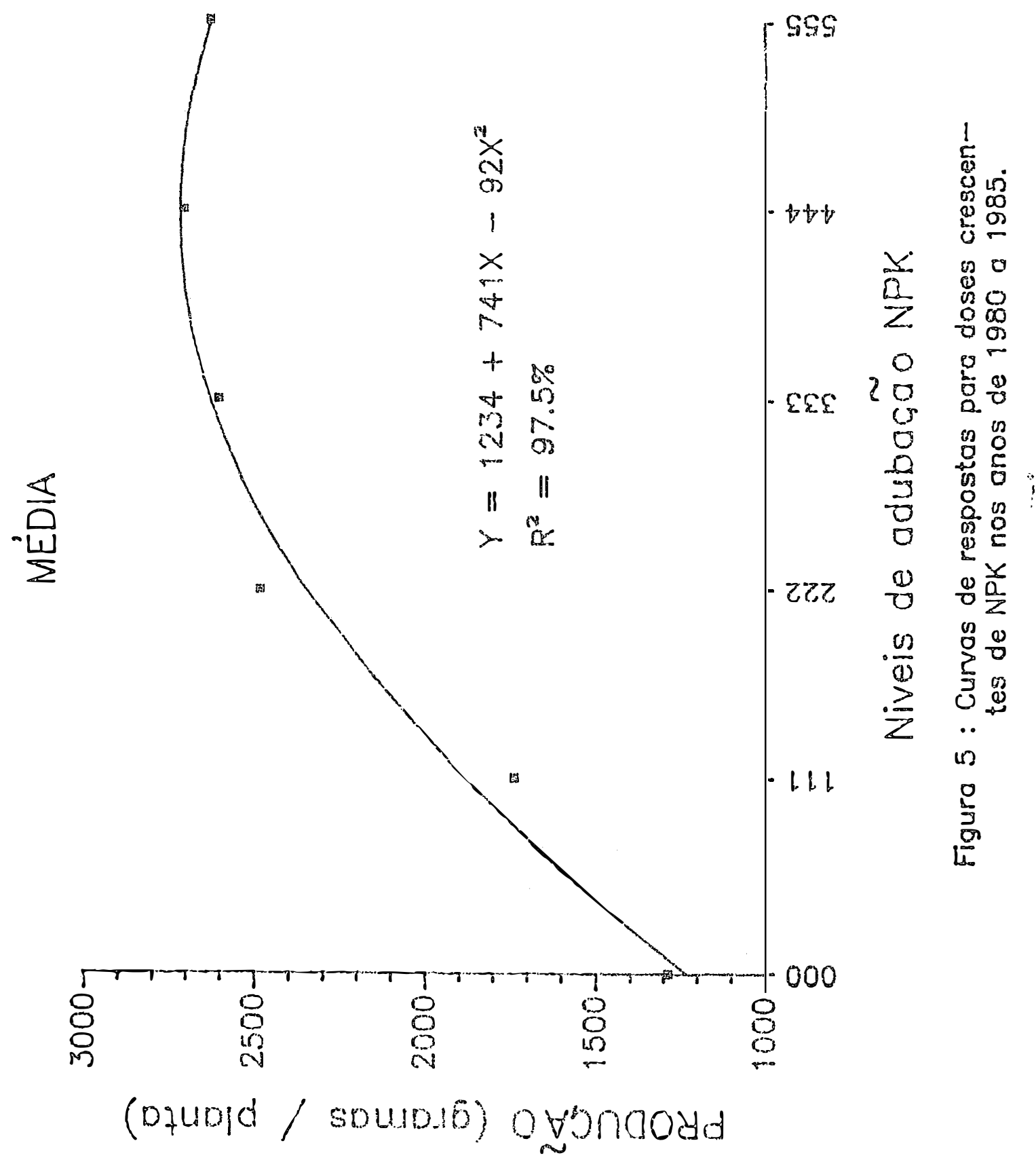


73.

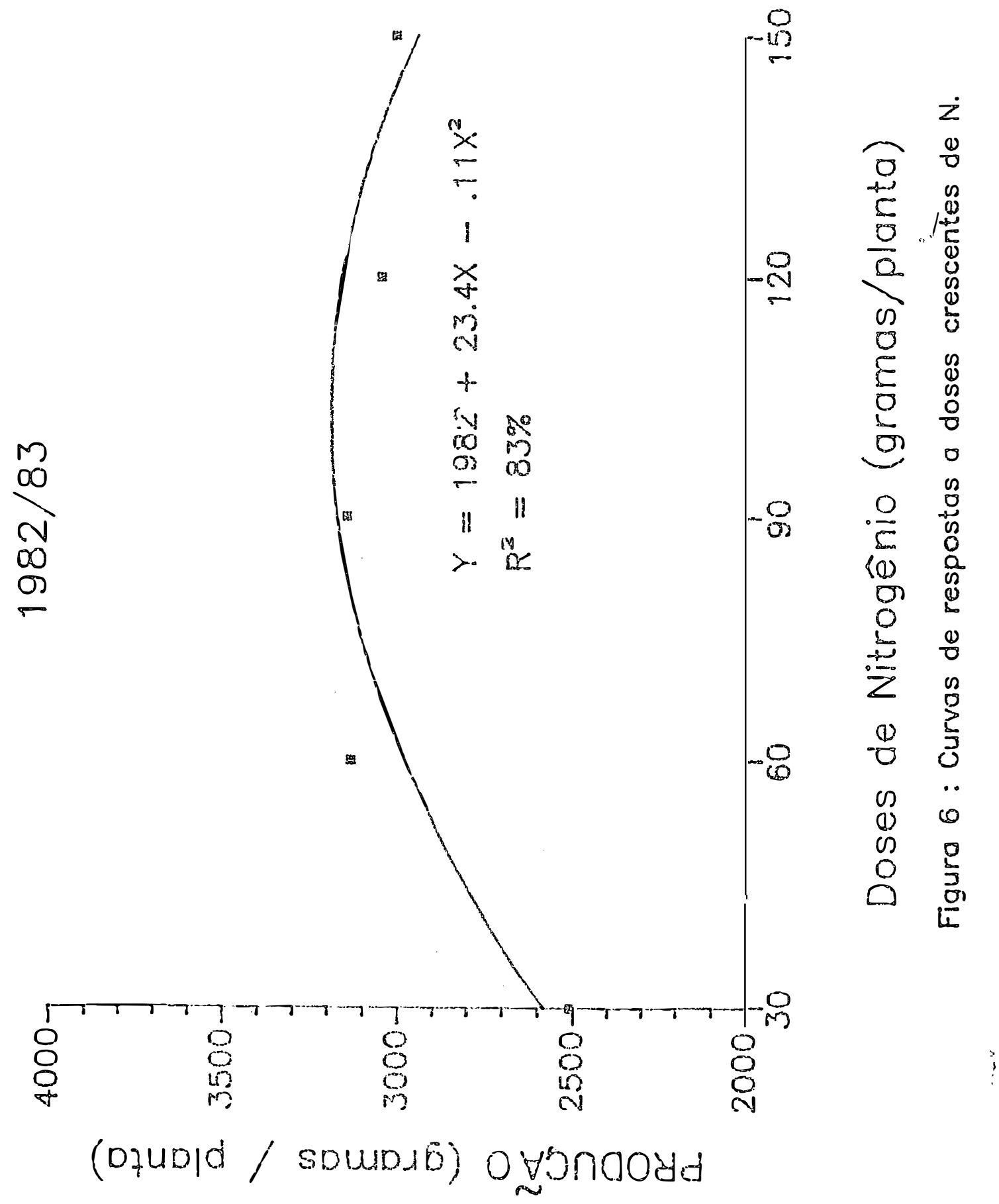


74.

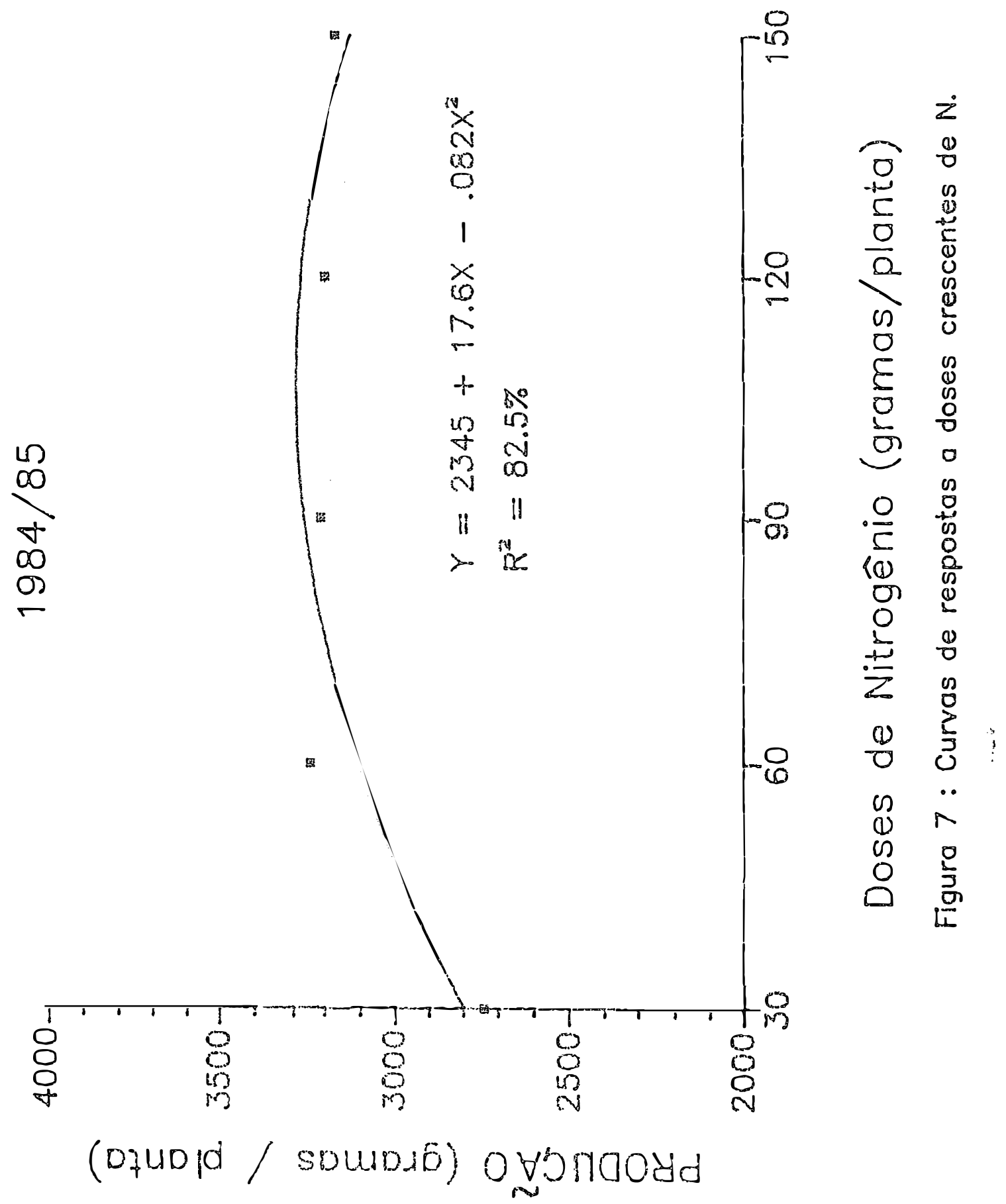


75.

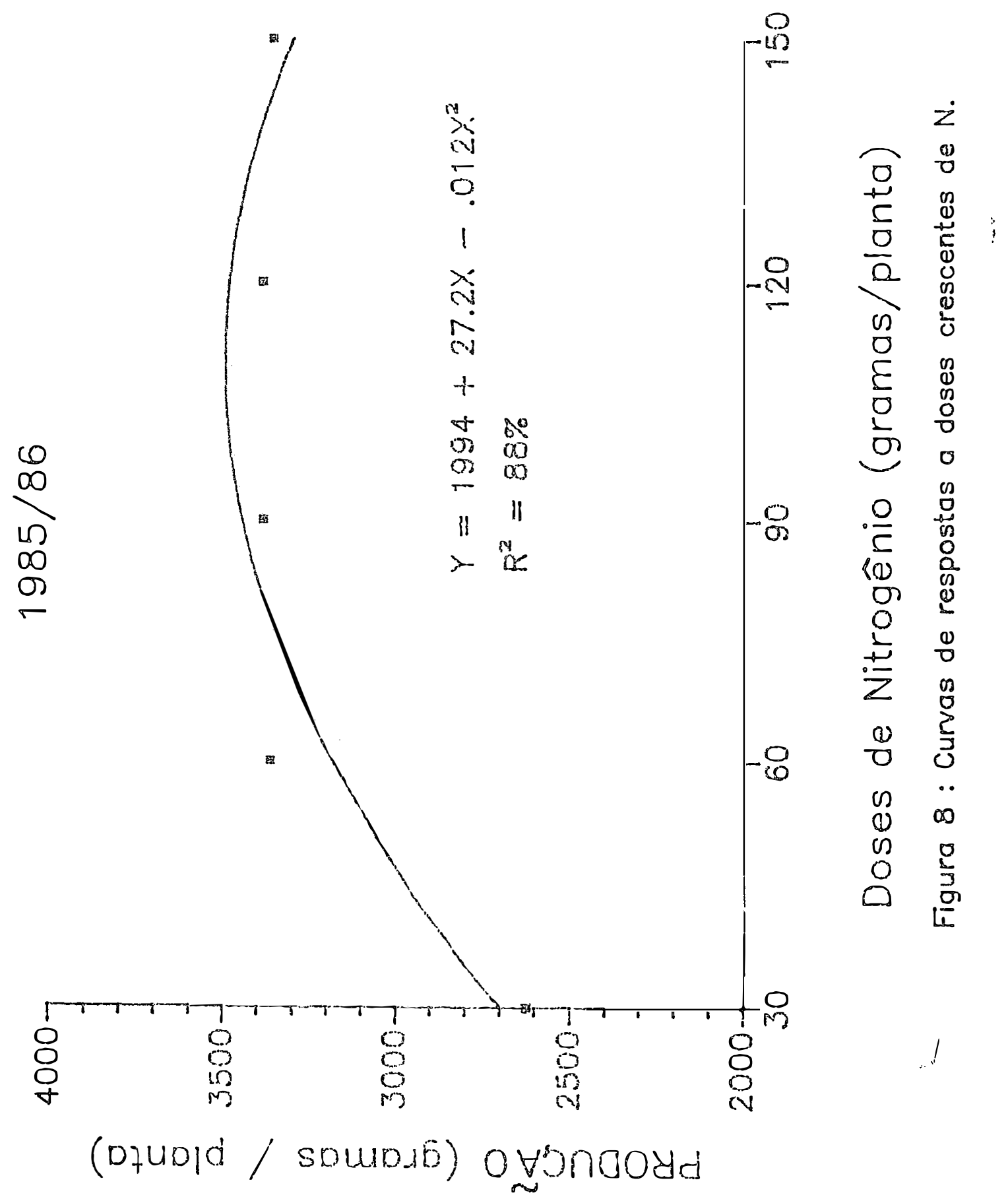


76.

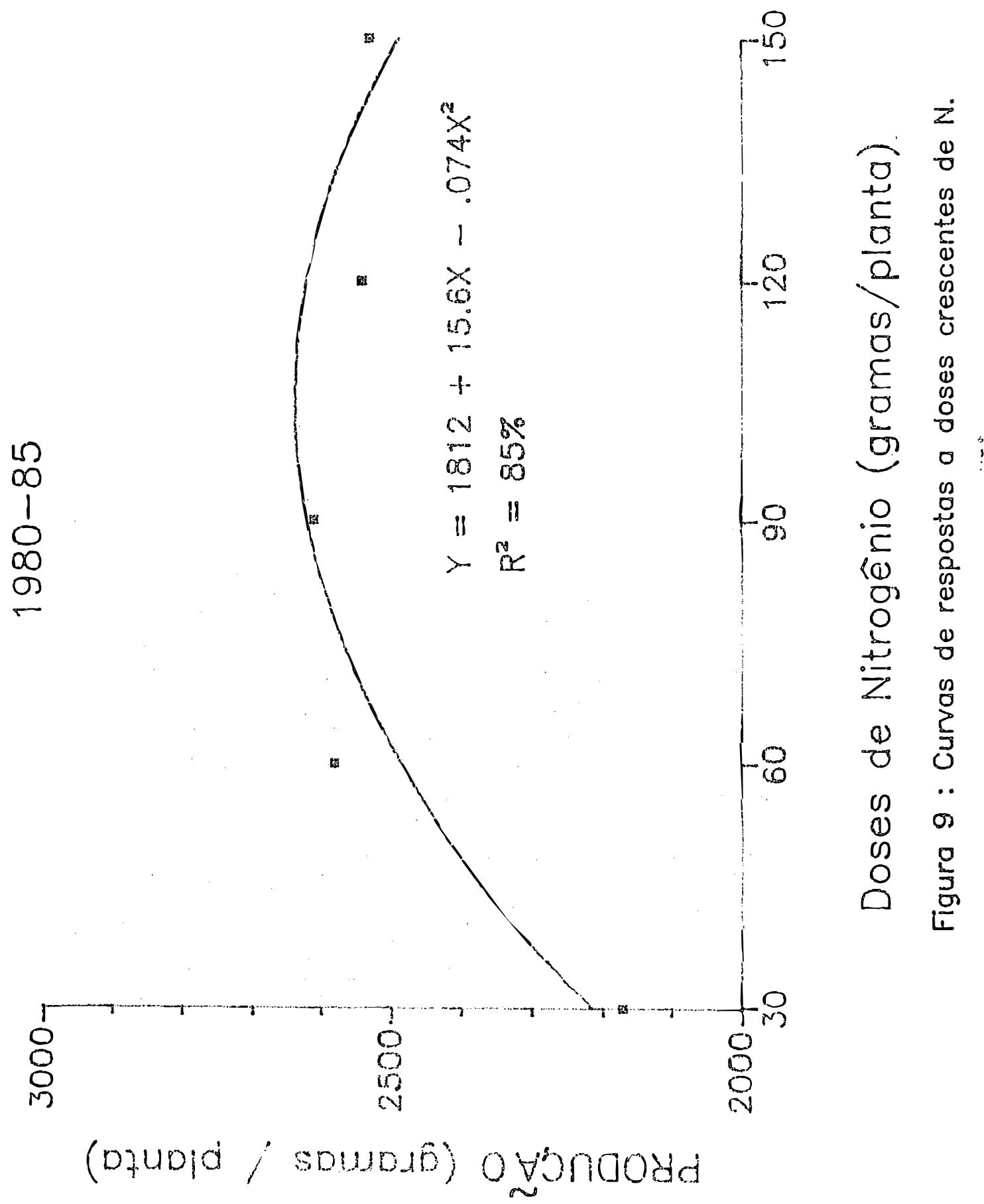




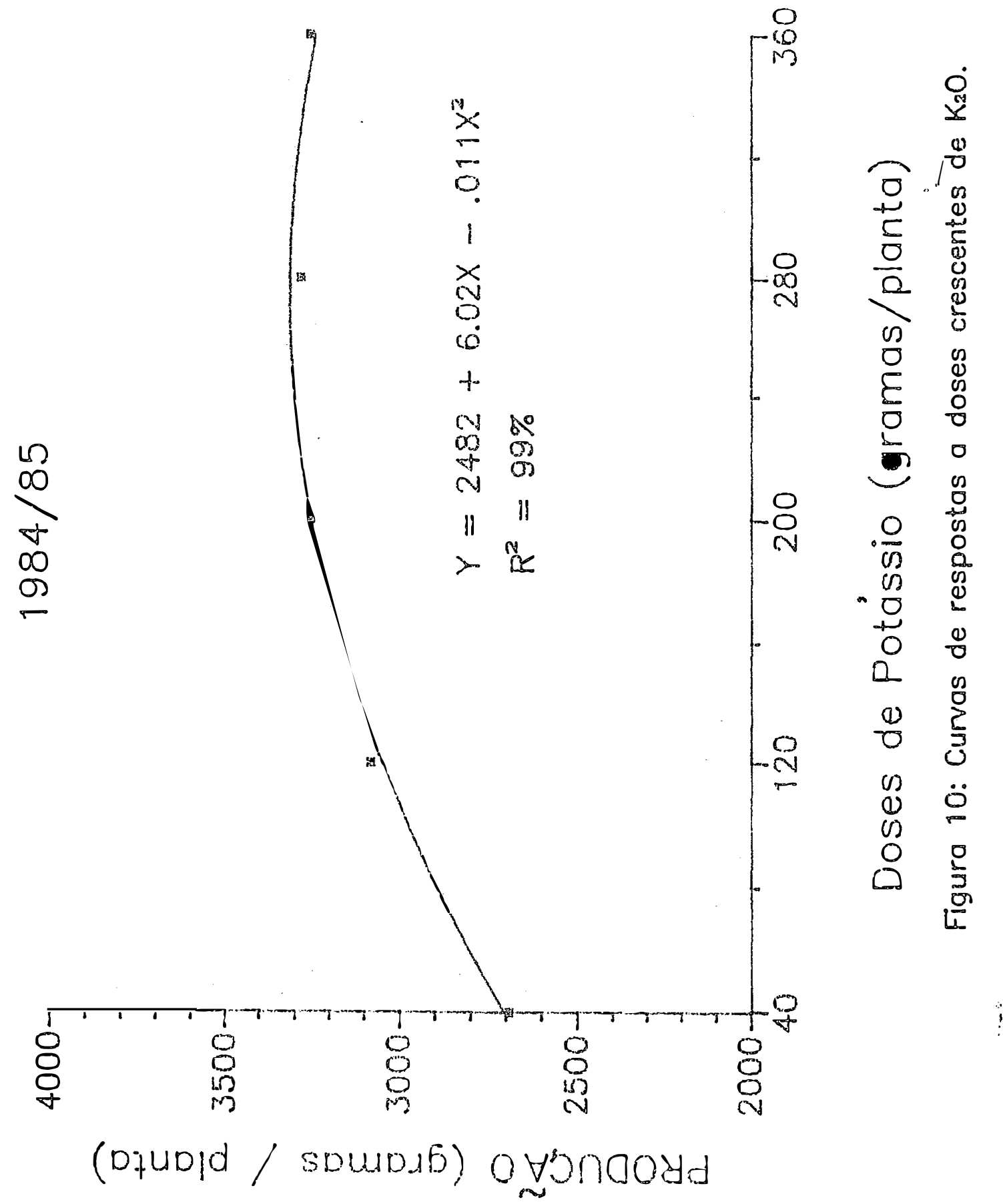




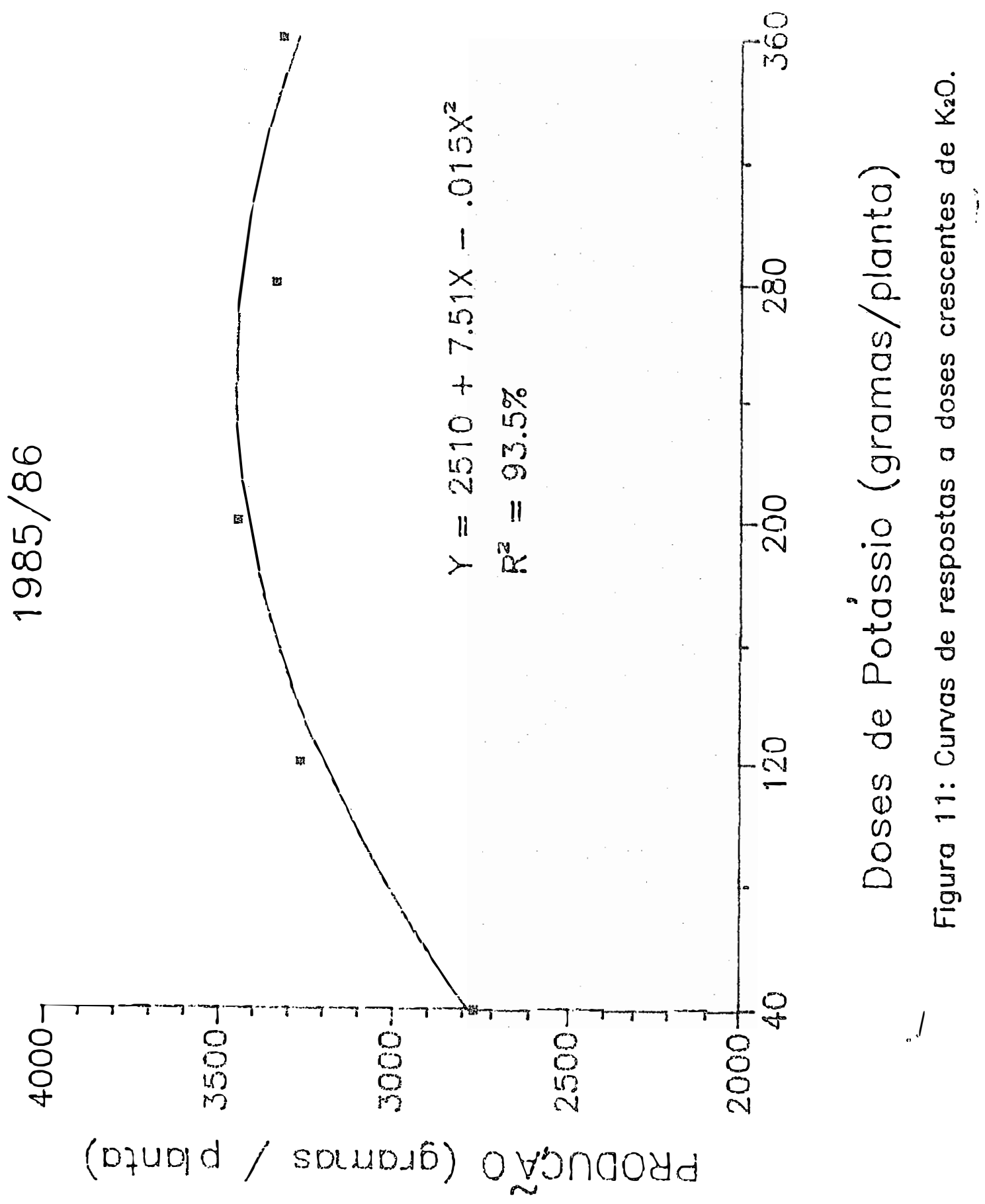




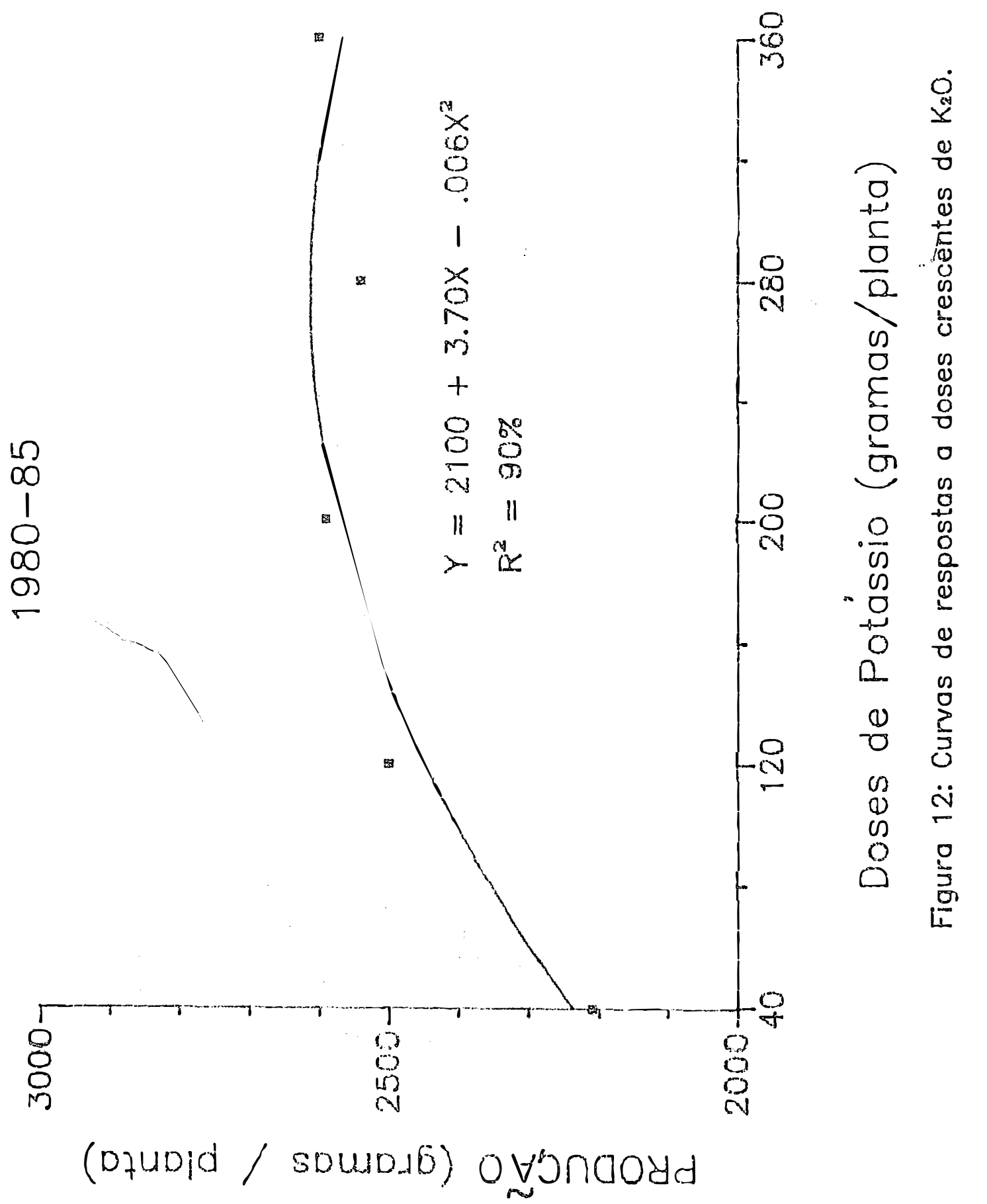


No conjunto 1980-85, pode-se observar ( Figu-

ra 9) que, como vinha acontecendo nos anos individuais, houve acréscimo da produção das videiras com o uso de doses crescen tes de N, atingindo valor máximo com $105 \mathrm{~g} / \mathrm{planta}$ deste elemento.

No ano 1984/85, houve um acréscimo da produção com o uso de doses crescentes de $\mathrm{K}_{2} \mathrm{O}$, alcançando valor máximo com 276 g/planta de $\mathrm{K}_{2} \mathrm{O}$ ( Figura 10) .

A Figura ll, mostra que no ano $1985 / 86$ houve um acréscimo da produção, atingindo valor máximo com 249 $\mathrm{g} / \mathrm{planta}$ de $\mathrm{K}_{2} \mathrm{O}$.

Considerando-se o conjuntodos seis anos, obser va-se na Figura 12, que houve um acréscimo da produção, sendo alcançado valor mäximo com $276 \mathrm{~g} / \mathrm{planta}$ de $\mathrm{K}_{2} \mathrm{O}$. !

4.1.4, Dose econômica

As relações de preços foram obtidas considerando o preço dos fertilizantes no mês de abril e o preço do produto agrícola (uva) no mês de dezembro de cada ano pesquisado neste experimento.

Na Tabela 13 encontram-se as doses econômicas de nitrogênio, calculadas para os anos agrícolas de resposta positiva, em Iunção de vārias relações de preço fertilizante /produto agrícola.

Nesta Tabela, pode-se observar que as quanti- 
TABELA 13. Doses econômicas de nitrogênio em gramas/planta de $\mathrm{N}$, determinadas em ensaio de adubação N, P e K para o cultivar Niagara Rosada, nos anos 1982/83, 1984/85, 1985/86 e no conjunto 1980-85, consideran do várias relações de preços fertilizante./produto agrĩcola

\begin{tabular}{lcccc}
\hline \multirow{2}{*}{$\begin{array}{l}\text { Relação de preços } \\
\text { KgN/Kg. uva. }\end{array}$} & \multicolumn{4}{c}{ Dose econômica de N } \\
\cline { 2 - 5 } & $1982 / 83$ & $1984 / 85$ & $1985 / 86$ & $1980-85$ \\
\cline { 2 - 5 } 2,0 & 87 & 95 & 102 & 92 \\
1,5 & 97 & 98 & 104 & 95 \\
1,0 & 99 & 101 & 106 & 99 \\
0,66 & 100 & 103 & 107 & 101 \\
0,50 & 101 & 104 & 108 & 102 \\
0,33 & 102 & 105 & 109 & 103 \\
\hline
\end{tabular}


dades ótimas econômicas recomendadas diminuem com o aumento da relação preço kg N/preço kg uva. No entanto, não há di ferenças muito acentuadas em termos de recomendação considerando a amplitude das relações de preços empregadas neste trabalho.

$\mathrm{Na}$ Tabela 14, acham-se descritas as doses eco nômicas de potässio, calculadas para os anos agrícolas de resposta positiva, em função de várias relações de preço fer tilizante /produto agrícola.

Na referida Tabela, pode-se verificar que as quantidades ótimas econōmicas recomendadas diminuem com a di minuição da relação preço fertilizante/preço produto. Entretanto, existem diferenças bem acentuadas em termos de reco mendação considerando a amplitude das relações de preços empregadas neste trabalho.

\subsection{Resultados de peso médio de cacho}

4.2.1. Comparação entre as fontes de potássio

Os resultados dos dados de peso médio de cacho de uva 'Niagara Rosada' em gramas, e os resultados parciais das anälises da variāncia, de 1980 a 1985, e no conjun to 1980-85, encontram-se na Tabela 15.

Nesta Tabela, verifica-se que não houve diferença significativa do tratamento $\mathrm{N}_{3} \mathrm{P}_{3} \mathrm{~K}_{3}$ do delineamento, usando-se como fonte de potássio o cloreto de potássio, em 
83.

TABELA 14. Doses econômicas de potássio em gramas/planta de $\mathrm{K}_{2} \mathrm{O}$, determinadas em ensaio de adubação $\mathrm{N}, \mathrm{P}$ e $\mathrm{K}$ para a videira 'Niagara Rosada', nos anos 1984/85, 1985/86 e no conjunto 1980-85, considerando vărias relações de preços fertilizante/produto agrícola.

\begin{tabular}{lcccc}
\hline Relação de preços & \multicolumn{3}{c}{ Dose econômica de $\mathrm{K}_{2} \mathrm{O}$} \\
\cline { 2 - 5 } $\mathrm{KgK}_{2} \mathrm{O} / \mathrm{Kg}$ uva & $1984 / 85$ & ! & $1985 / 86$ & 1. \\
\hline 1,0 & 231 & 216 & 202 \\
0,66 & 246 & 227 & 227 \\
0,50 & 253 & 232 & 239 \\
0,33 & 261 & 238 & 252 \\
0,25 & 265 & 241 & 258 \\
0,20 & 267 & 242 & 261 \\
\hline
\end{tabular}


84.

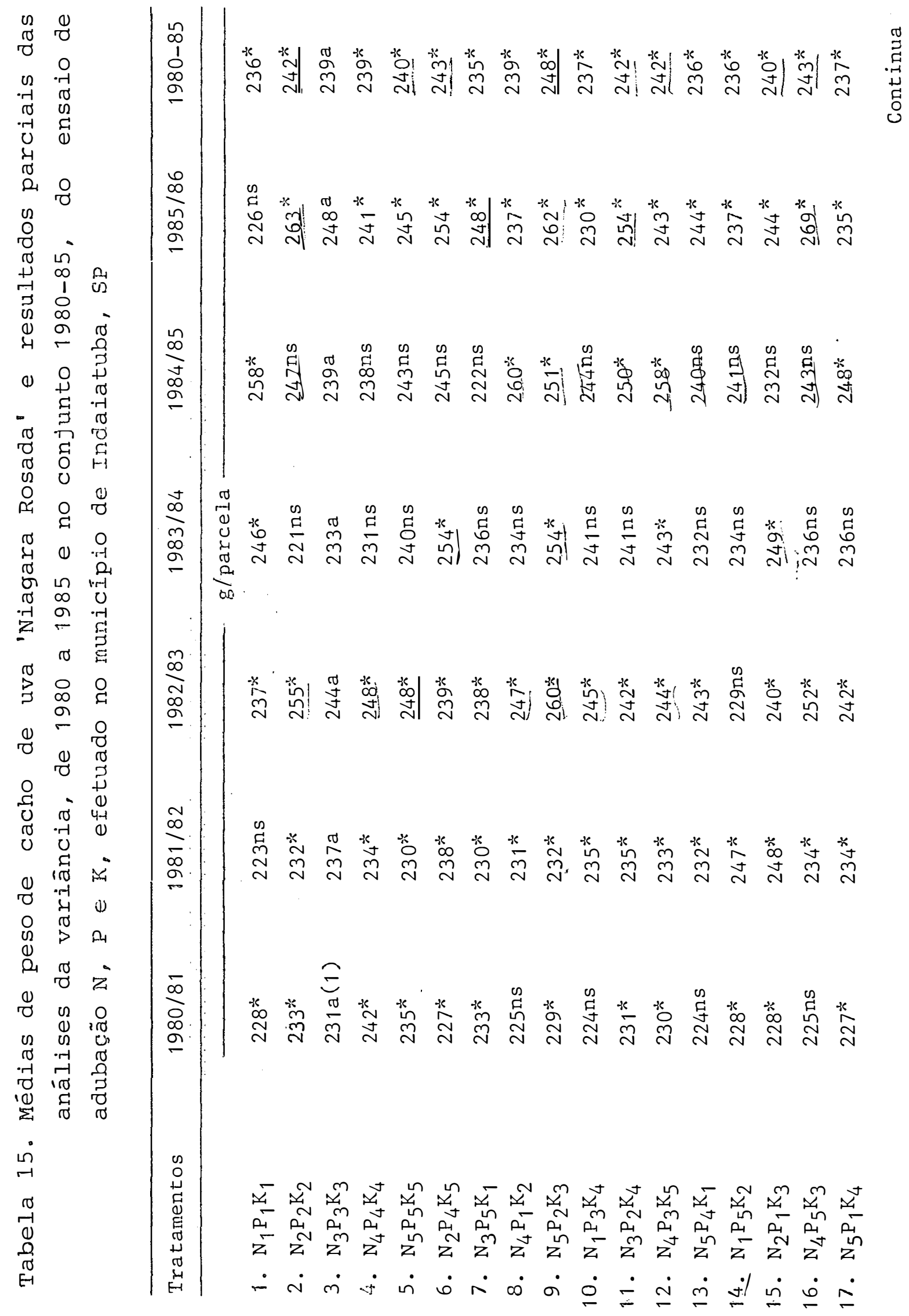




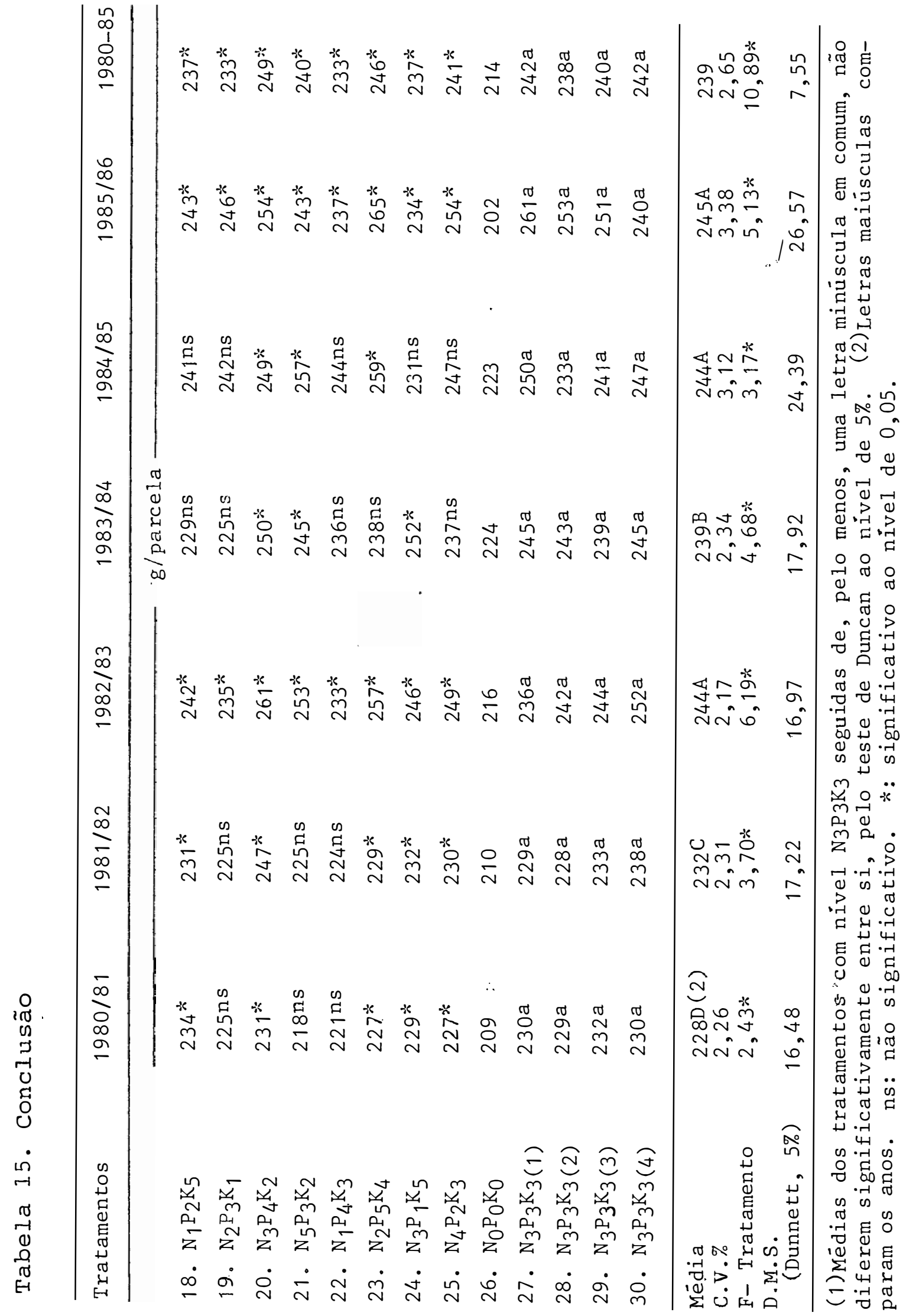


86 .

comparação com os tratamentos $\mathrm{N}_{3} \mathrm{P}_{3} \mathrm{~K}_{3}$ : mistura de duas fontes de potássio (cloreto de potássio e sulfato duplo de potássio e magnésio), aplicicadas, respectivamente, nas porcentagens $75: 25: 50: 50 ; 25: 75$ e 0:100, do nível 3 utilizado, isto é, $200 \mathrm{~g}$ de $\mathrm{K}_{2} \mathrm{O}$ por planta, nas análises individuais por ano ou no conjunto dos 6 anos.

Estes resultados indicam que o cloreto de potássio e o sulfato duplo de potássio e magnésio comportaramse de forma semenhante como fontes de potássio, quanto ao pe so médio de cacho, concordando com os resultados obtidos por LARSEN et alii (1959) e por CLINE \& BRADT (1980)。

4.2.2. Comparação com a testemunha sem adubo

A Tabela 15 mostra que, nos primeiros anos do ensaio a maioria dos tratamentos com adubo apresentou peso médio de cachos estatĩsticamente superior à testemunha; no entanto, nos anos 1983/84 e 1984/85, apenas alguns tratamentos com adubo diferiram significativamente da testemunha. No ano 1985/86, todos os tratamentos com adubo, à exceção do $\mathrm{N}_{1} \mathrm{P}_{1} \mathrm{~K}_{1}$ foram superiores ao controle, diferindo significativa mente.

Finalmente, no conjunto dos 6 anos, todos os tratamentos com adubo apresentaram peso médio de cacho estatisticamente superiores à testemunha.

Estes resultados indicam ' que, 
à mediala que os fertilizantes foram sendo aplicados às videi ras nas diferentes doses, deve ter havido translocação de nu trientes dos diversos örçãos da planta para os frutos, aumentando, assim,o peso dos cachos.

o efeito da interação tratamento $x$ anos mostrou-se estatisticamente significativo nos anos 1982/83, $1984 / 85$ e 1985/86.

$4.2,3$, Anälises de regressão

As estimativas dos coeficientes das equações de regressão, dos coeficientes de determinação múltipla e cs valores dos testes $t$ e F para regressão, obtidos nas análises dos dados de peso médio de cacho do 'Niagara Rosada' de 1980 a 1985, encontram-se na Tabela 16.

Nesta Tabela, observa-se inicialmente que pra ticamente não houve interações significativas entre os nutrientes N, P e $\mathrm{K}$, em todos os anos considerados individualmente.

Nota-se também, na mesma Tabela, que praticamente ñão houve respostas lineares e quadráticas significatí vas à aplicação dos adubos que contém $\mathrm{N}, \mathrm{P}$ e K.

Os resultados obtidos no presente trabalho indicam que as adubações nitrogenada, fosfatada e potássica práticameite não aumentaram o peso dos cachós de modo linear ou quadratico. 


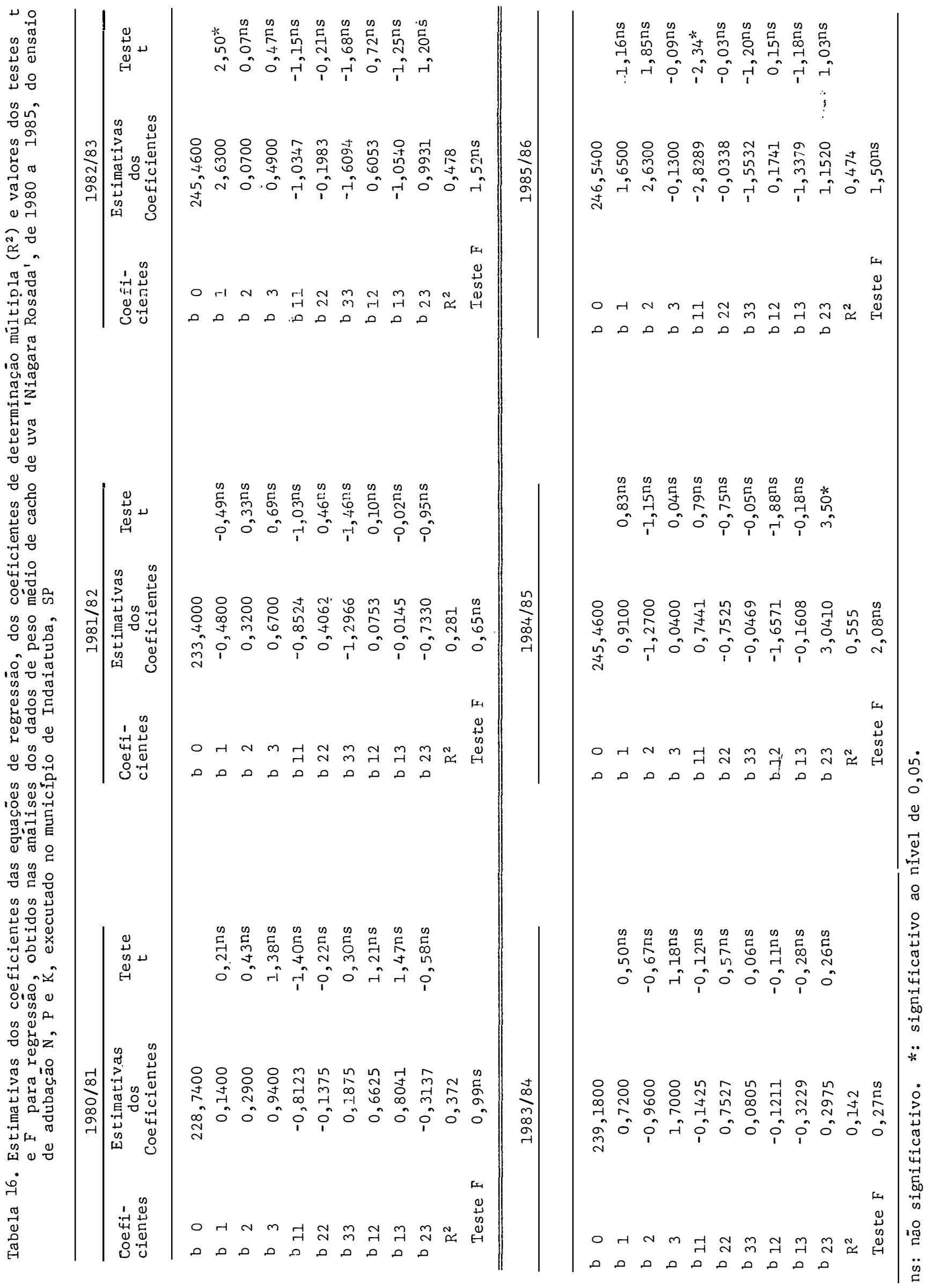


Estes resultados são concordantes com os veri ficados por GIORGESSI et alii (1984), que em ensaio de aduba ção N, P e K, aplicados em diferentes doses concluiram que não houve diferença significativa no peso médio do cacho.

4.3. Resultados de concentração de macronutrientes na matêria seca cas folhas

Os valores dos teores de macronutrientes estão expressos no presente trabalho em porcentagem da matēria seca.

4.3.1. Nitrogênio

GALLO \& OLIVEIRA (1960), HERNANDO \& MENDIOLA (1965), HIROCE et alii (1970), CUMMINGS et alii (1973) e PEREIRA et alii (1976), realizaram vārios experimentos com diversos cultivares de videira copa e porta-enxerto, encontran do variação de 1,50 a 4,76\% na concentração de $N$ na matéria seca das folhas. Os valores encontrados no presente trabalho estão dentro da faixa de variação dos valores observados nas pesquisas realizadas por aqueles autores.

GALLO \& RIBAS (1962), DECHEN (1979), HIROCE \& TERRA (1983), TERRA (1983) e HIROCE et alii (1989), em estudos sobre o estado nutricional da videira 'Niagara Ro'sada'en 
contraram variação de 1,71 a 4,87\% na concentração de $N$ na matëria seca das folhas. Os valores encontrados no trabalho ora em estudo estão dentro da faixa de variação dos valores verificados nos experimentos realizados por aqueles autores. KOROBKO (1973), estudando diferentes doses de N, P e K aplicadas em plantas do cultivar Riesling obteve produção máxima em vinhedos cujas folhas mostravam concentra ção de 5,9\% de N, valor este próximo aos encontrados no presente trabalho considerando todos os tratamentos e anos.

\subsubsection{Comparação entre as fontes de potássio}

Os resultados das médias dos teores de nitrogênio em porcentagem na matéria seca das folhas, por tratamento, da uva 'Niagara Rosada' e os resultados parciais das anălises da variância de 1980 a 1985, encontram-se na Tabela 17.

Nesta Tabela, observa-se que praticamente não houve diferença significativa do tratamento $\mathrm{N}_{3} \mathrm{P}_{3} \mathrm{~K}_{3}$ do delineamento, usando-se como fonte de potássio o cloreto de potássio, em comparação com os tratamentos $\mathrm{N}_{3} \mathrm{P}_{3} \mathrm{~K}_{3}$ extras, em todos os anos considerados individualmente.

Estes resultados indicam que o cloreto de potássio e o sulfato duplo de potássio e magnésio comportarain-se de forma semelhante como fontes de potássio, com referência à concentração de $\mathrm{N}$ na matéría seca das 


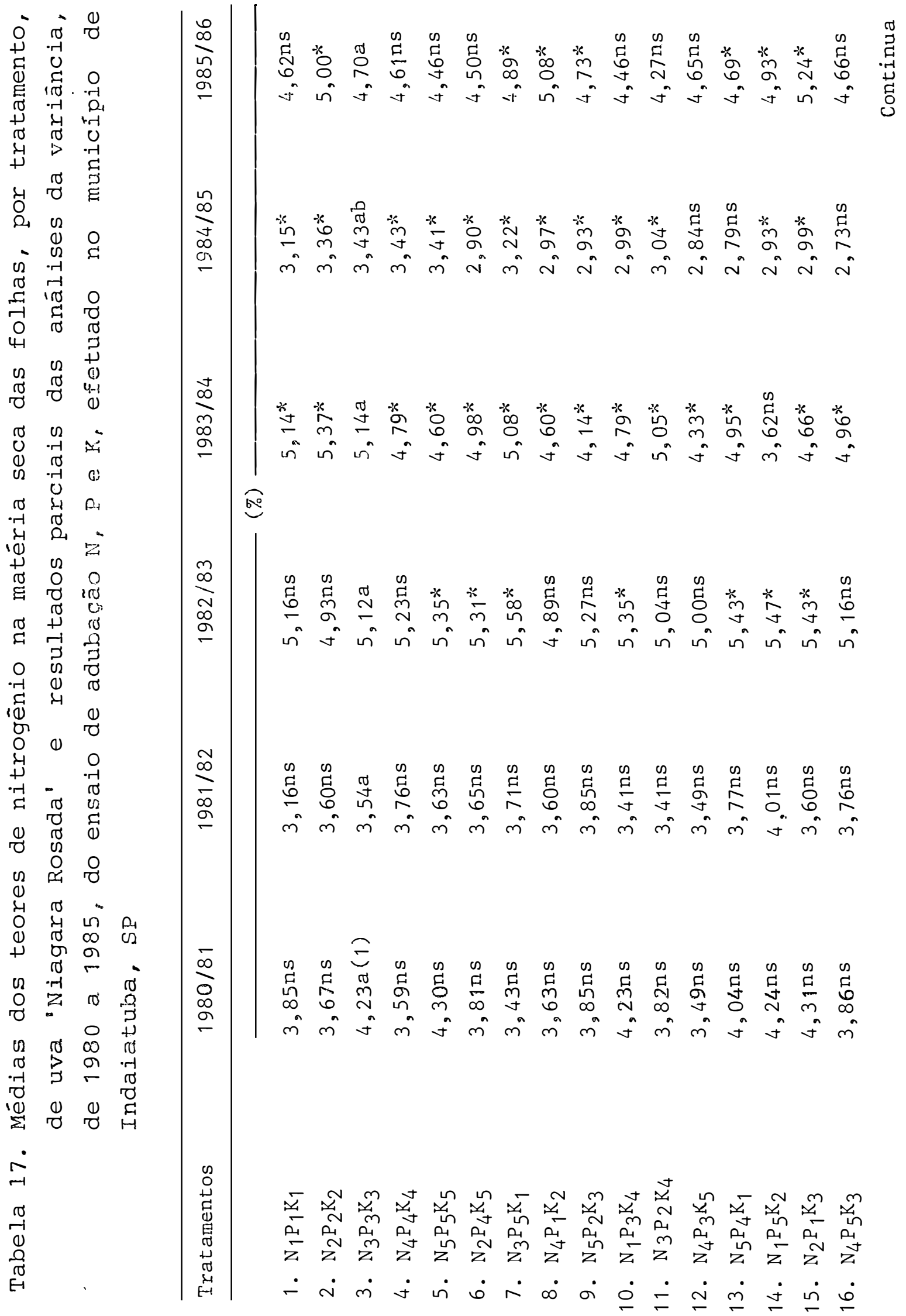




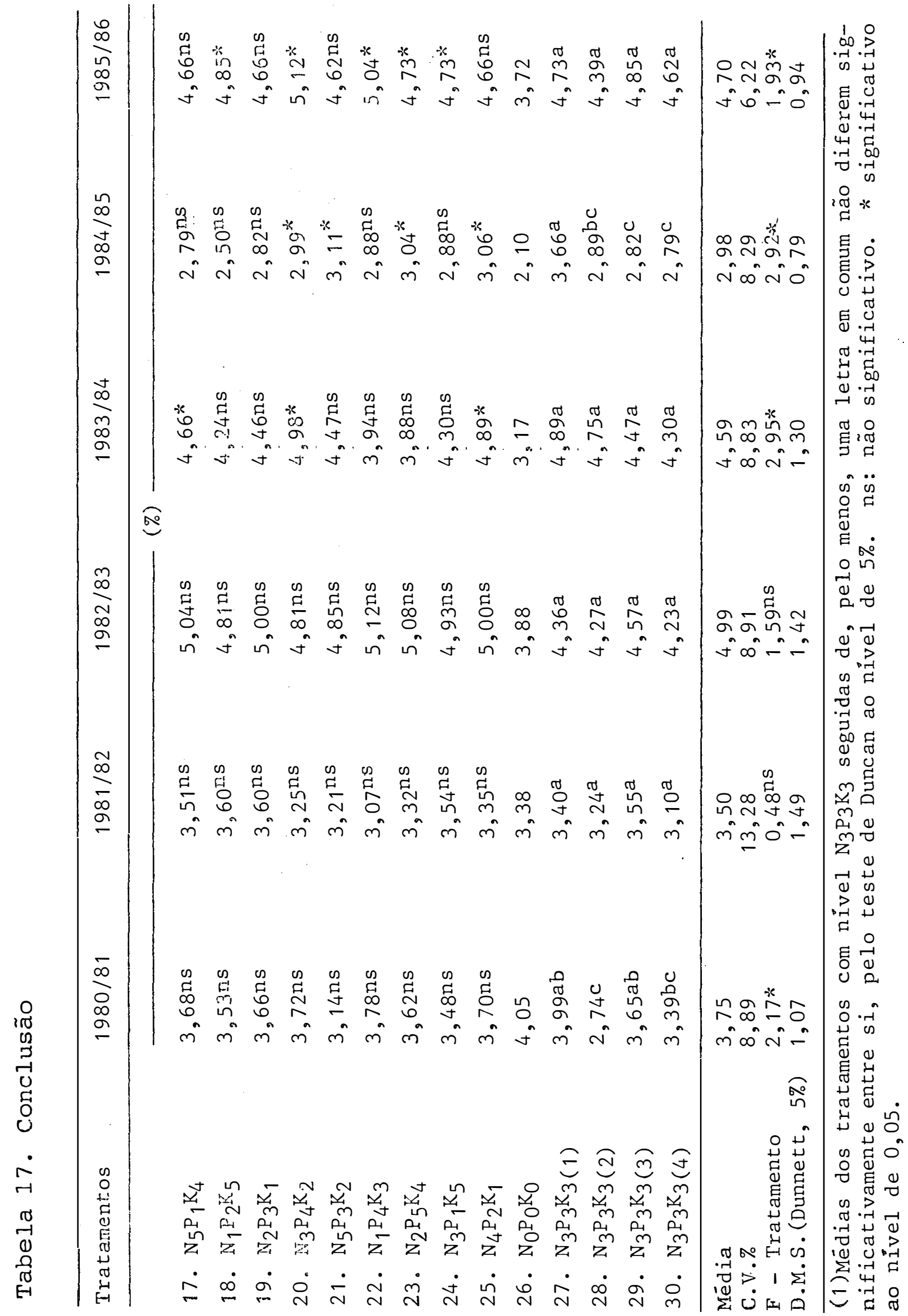


folhas.

\section{4,3,1,2. Comparação com a testemunha sem adubo}

A Tabela 17 mostra que, nos primeiros anos do ensaio os tratamentos com adubo não diferiram estatisticamen te da testemunha: no entanto, a partir de 1982/83 alguns tra tamentos com adubo diferiram significativamente da .testemunha.

$$
\text { Estes resultados indicam que }
$$

com o decorrer dos anos, gradativamente houve surgimento da diferença de resposta de alguns tratamentos adubados em rela ção ä testemunha, devido provavelmente ao esgotamento da fer tilidade do solo no tratamento controle.

\section{4,3,1,3, Anālises de regressão}

As estimativas dos coeficientes da' equações de regressão, dos coeficientes de determinação múitipla e os valores dos testes $t$ e F para regressão, obtiāos ras añai ses doss dados dos teores de nitrogênio na matêria seca das folhas, por tratamento, de uva 'Niagara Rosada' de 1980 a 1985, encontram-se na Tabela 18.

Nesta Tabela, verificamse inicialmente, que praticamente não houve interações signjficativas entre os nu 


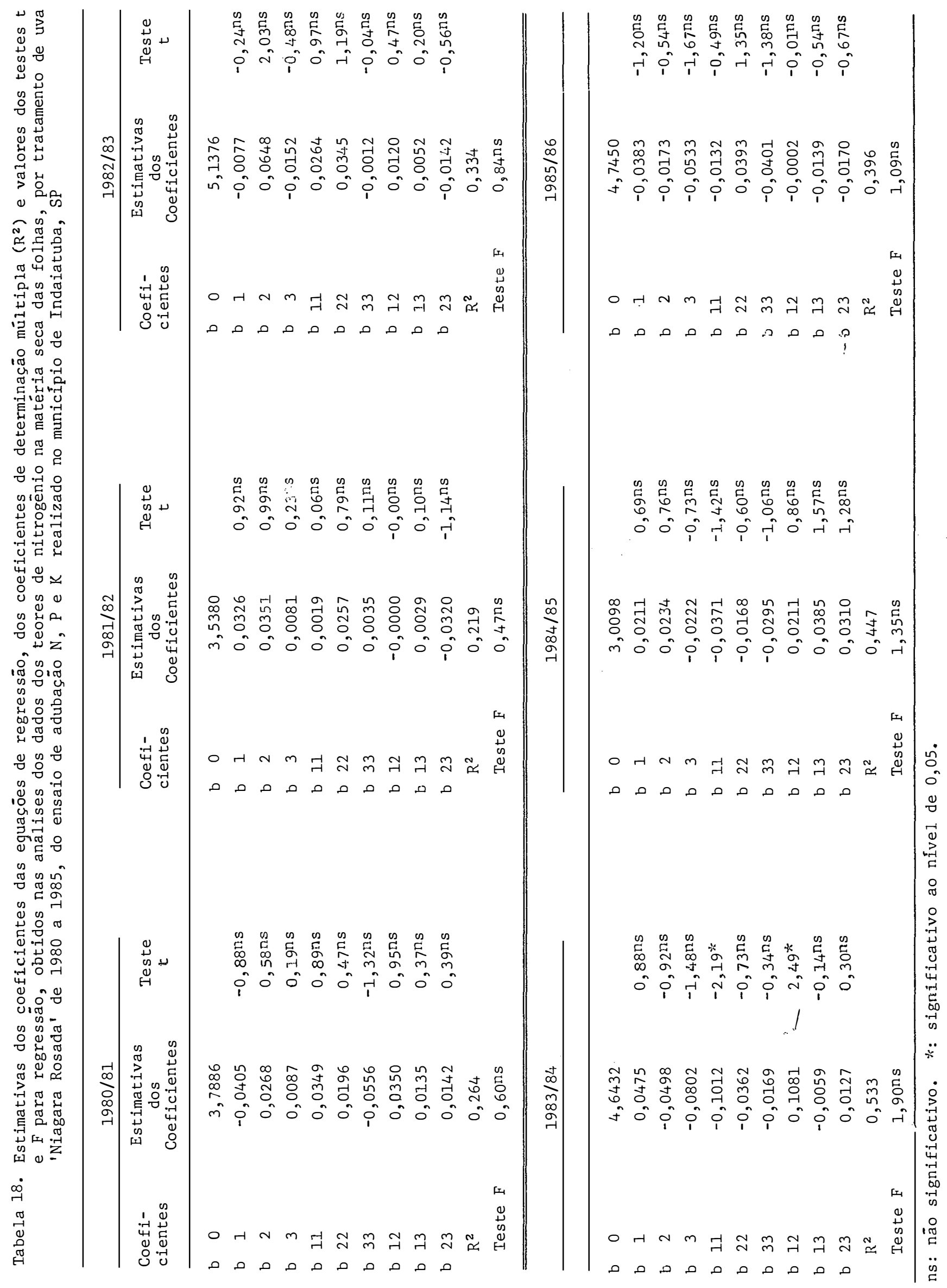


trientes N, P e $\mathrm{K}$, em todos os anos considerados individualmente.

Nota-se também, nesta Tabela, que praticamente não houve efeitos lineares e quadráticos significativos da aplicação dos adubos que contém N, P e K, sobre o teor de $\mathrm{N}$ das folhas.

Os resultados obtidos no presente trabalho in dicam que as adubações nitrogenada, fosfatada e potássica praticamente não interferiram positivamente no aumento da concentração de $\mathrm{N}$ na matéria seca das folhas.

Estes resultados concordam em parte com os ve rificados por LAVIN \& VALENZUELA (1986 b) que aplicando três doses de $\mathrm{N}$ em plantas do cultivar Pedro Jimenez observaram que o teor de $\mathrm{N}$ nas folhas não foi modificado com a aplica ção dessas diferentes doses.

4.3.2. Fósforo

Diversos autores (GALLO \& OLIVEIRA, 1960; HER NANDO \& MENDIOLA, 1965; HIROCE et alii, 1970; CUMMINGS et alii, 1973: PEREIRA et alii, 1976 e CHRISTENSEN et alii, 1978), estudando diversos cultivares de videira copa e porta enxerto, encontraram variação de 0,100 a $0,600 \%$ no teor de fósforo na matéria seca das folhas. Os valores encontrados no presente trabalho estão dentro da faixa de variação dos teores verificados por aqueles autores.

Enquanto isso, GALLO \& RIBAS (1962), DECHEN 
(1979), HIROCE \& TERRA (1983), TERRA (1983) e HIROCE et alii (1989), em estudos sobre o estado nutricional do cultivar Niagara Rosada, encontraram variação de 0,260 a 1,230\% na concentração de $\mathrm{P}$ na matēria seca das folhas. os valores verificados no presente trabalho encontram-se dentro da faixa de variação dos teores observados nos experimentos realizados por aqueles autores.

KOROBKO (1973), pesquisando diferentes; doses de $\mathrm{N}, \mathrm{P}$ e $\mathrm{K}$, aplicadas em videiras do $\mathrm{CV}$ Riesling, obteve pro dução mãxima em vinhedos cujas folhas mostravam concentração de 1,000\% de $\mathrm{P}$, valor este bem superior aos encontrados no presente estudo considerando todos os tratamentos e anos.

\section{$4,3,2,1$, comparação entre as fontes de potássio}

Os resultados das médias dos teores de fósforo em porcentagem na matêria seca das folhas, por tratamento, do 'Ni.agara Rosada' e os resultados parciais das análises da variância de 1980 a 1985, encontram-se na Tabela 19.

Nesta Tabela, verifica-se que praticamente não houve diferença significativa do tratamento $\mathrm{N}_{3} \mathrm{P}_{3} \mathrm{~K}_{3}$ do de lineamento, usando-se como fonte de potássio o cloreto de po tāssio, em comparação com os tratamentos $\mathrm{N}_{3} \mathrm{P}_{3} \mathrm{~K}_{3}$ extras, em todos os anos considerados individualmente.

De modo geral, estes resultados indicam que o 


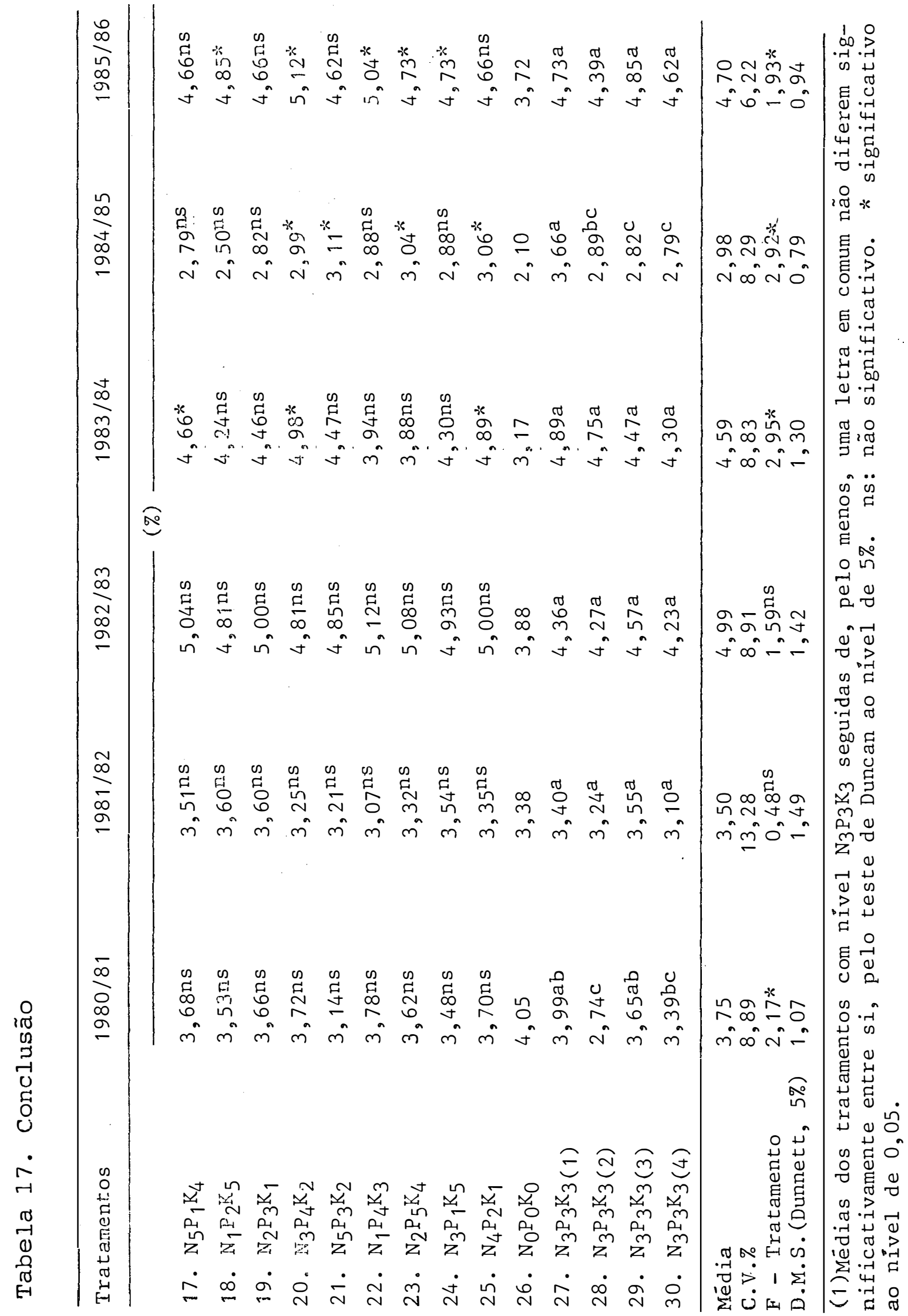




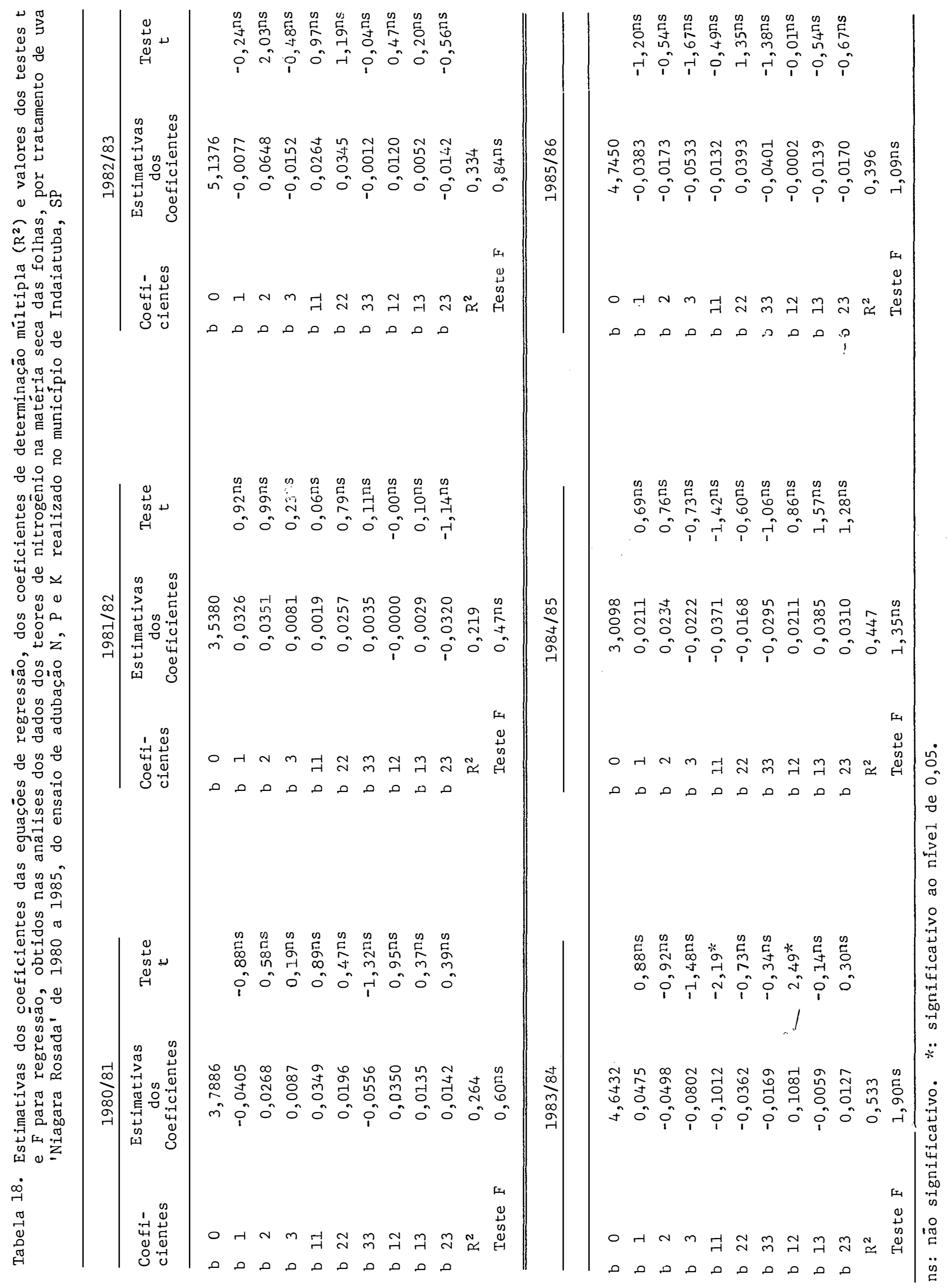




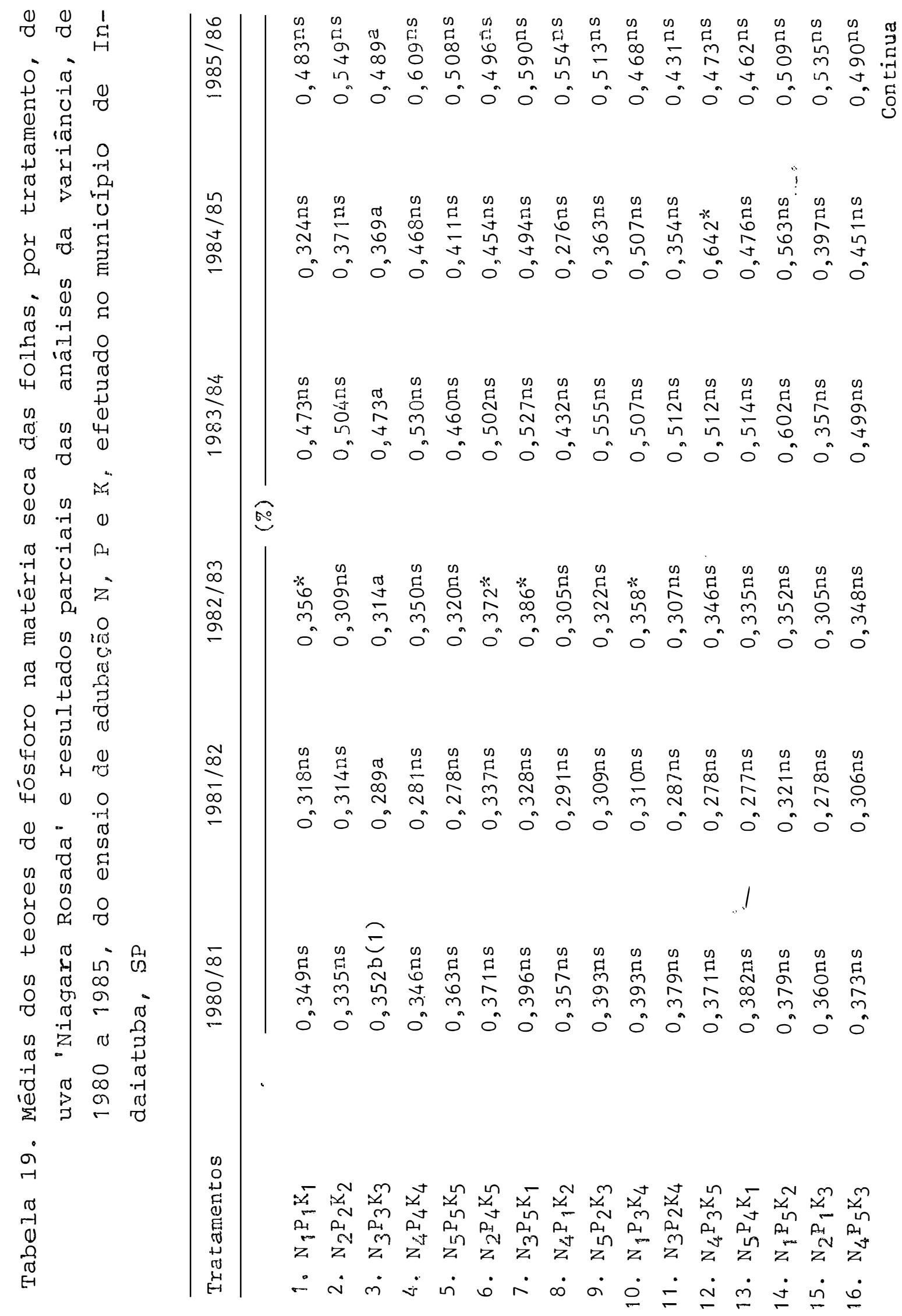




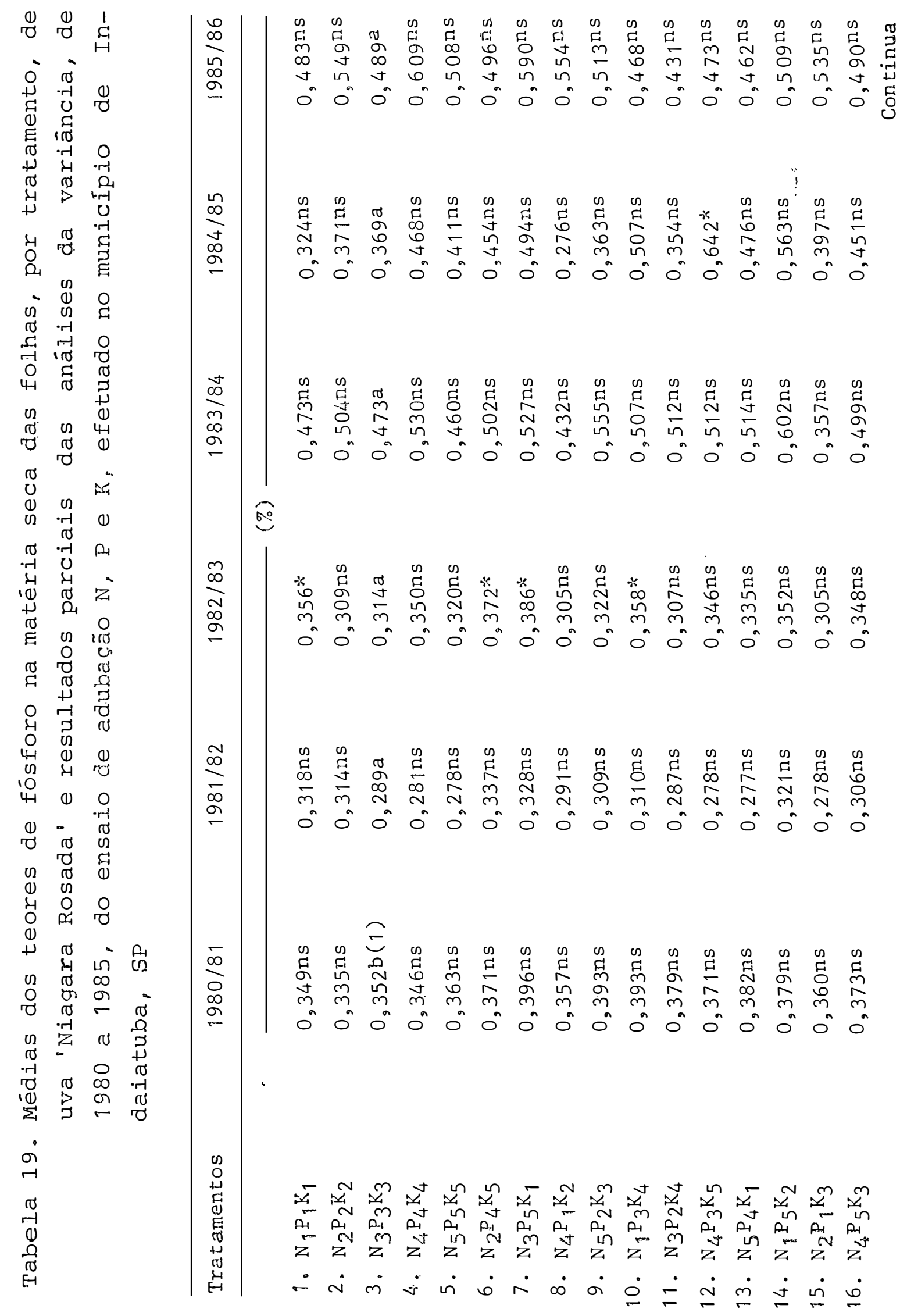




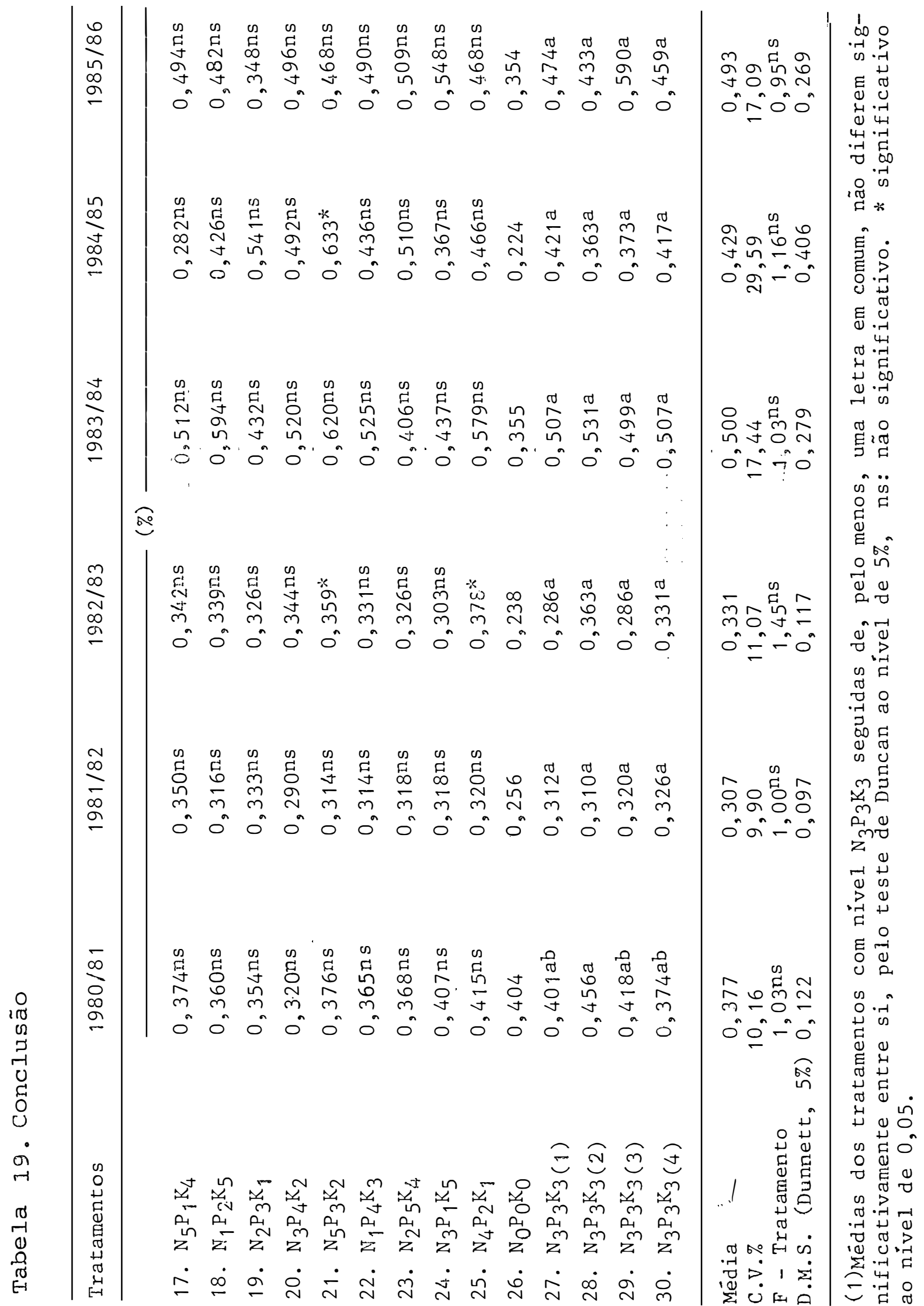


cloreto de potássio e o sulfato duplo de potássio e magnésio comportaram-se de forma semelhante como fontes de potássio, com referência à concentração de $P$ ną matéria seca das folhas.

4.3.2.2. Comparação com a testemunha sem adubo

A Tabela 19 mostra que, praticamente os trata mentos com adubo não diferiram estatisticamente da testemunha。

Estes resultados indicam que provavelmente o solo continha fôsforo em quantidade suficien te para um longo período. Os mesmos resultados indicam também que, provavelmente houve efeito residual do fósforo no solo no tratamento sem adubo.

$4,3,2,3$. Anālises de regressão

As estimativas dos coeficientes das equações de regressão, dos coeficientes de determinação múltipla e os valores dos testes te $F$ para regressão, obtidos nas anālises dos dados dos teores de füsforo na matéria seca das fo Ihas, por tratamento, de uva 'Niagara Rosada' de 1980 a 1985, encontram-se na Tabela 20.

Na referida Tabela, observa-se em primeiro lu 


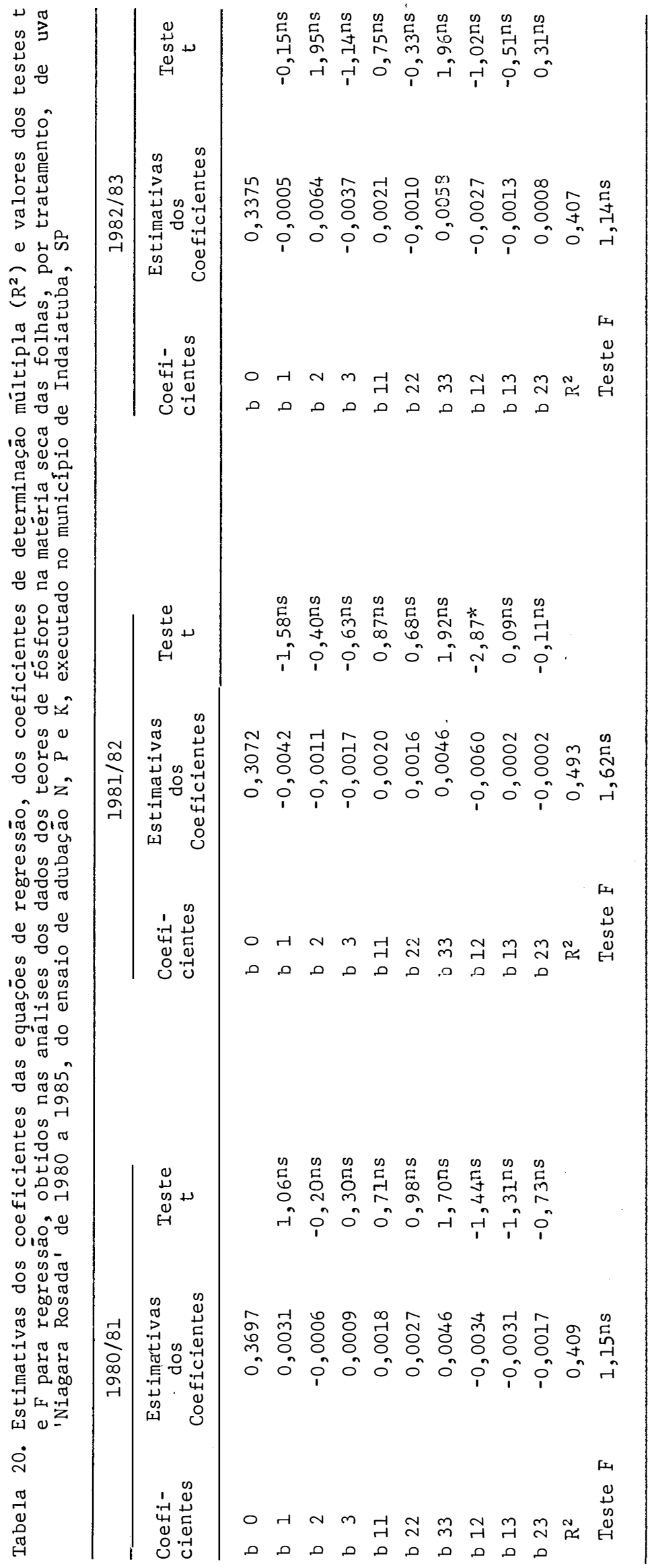

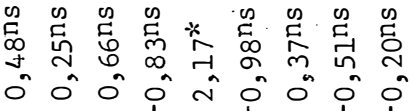

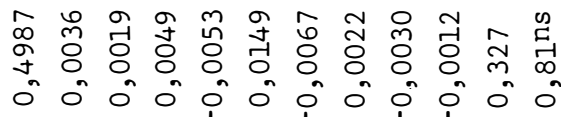

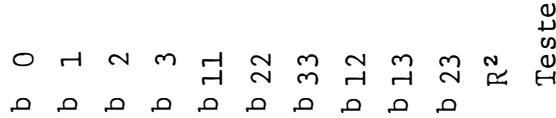

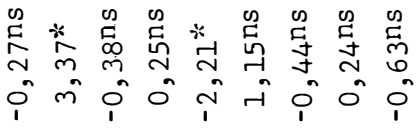

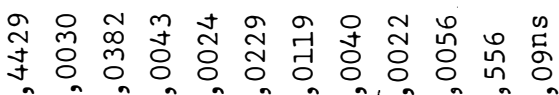
on $\begin{gathered}0 \\ 0\end{gathered}$

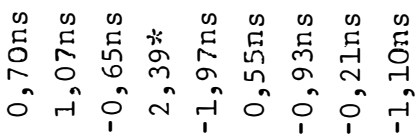

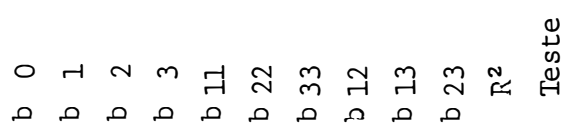

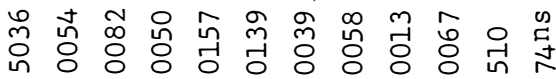

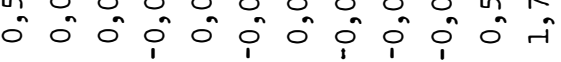

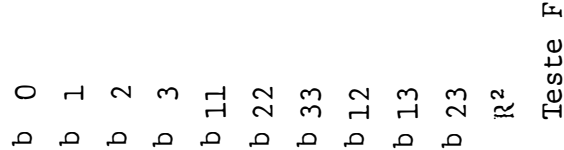

क्य 
gar, que praticamente não houve interações significativas eñ tre os nutrientes $\mathrm{N}, \mathrm{P}$ e $\mathrm{K}$ em todos os anos estudados indivi dualmente.

NIJJAR \& RAM (1969), em suas pesquisas com ađubação $\mathrm{N}$ e $\mathrm{P}_{2} \mathrm{O}_{5}$ em três níveis com värias combinações, con cluíram que havia interação entre os nutrientes $\mathrm{N}$ e $\because \mathrm{P}_{2} \mathrm{O}_{5}$, discordando na sua quase totalidade com os resultados apre sentados no presente trabalho.

Verifica-se também na Tabela 20 , que praticamente não houve efeitos Iineares e quadrāticos significativos à aplicação dos adubos com N, P e K, com exceção dos anos $1984 / 85$ e 1985/86, onde houve respostas significativas para a adubação fosf́atada.

No geral, os resultados observados no presente estudo indicam que as adubações nitrogenada e potássica praticamente não interferiram positivamente no aumento da concentração de fósforo na matéria seca das folhas, ao passo que a adubação Eosfatada interferiu positivamente na concentração de fósforo nos dois últimos anos do ensaio. Isto se deve, provavelmente ao efeito residual do fósforo, durante os 4 primeiros anos do ensaio, concordando assim cóm pesquisas realizadas por PIZA JUNIOR \& NEPTUNE (1966).

$$
\text { 4,3,3, Potássio }
$$


(1960), HERNANDO \& MENDTOLA (1965), HTROCE et alii

CUMMINGS et alii (1973), PERETRA et alii (1976) e CHRISTENSEN et alii (1978), com diversos cultivares de videira copa e porta-enxerto encontraram variação de 0,24 a 2,00\% no teor de potássio na matéria seca das folhas. Os valores encontrados no presente trabalho estão dentro da faixa de variação dos teores verjficados por aqueles autores.

GALLO : RIBAS (1962), DECHEN (1979), TERRA (1983) e HIROCE et alii (1989), realizando pesquisas com a videira 'Niagara Rosada', encontraram variação de 1,07 a $3,07 \%$ no teor de $\mathrm{K}$ na matéria seca das folhas. Os valores observados no presente trabalho estão, na grande 'maioria, dentro da faixa de variação das concentrações verificadas por aqueles autores.

No entanto, KOROBKO (1973), estudando diferen tes doses de N, P e K: aplicadas em plantas do CV Riesling, obteve produção mâxima em vinhedos cujas folhas mostravam concentração de $3,10 \%$ de $\mathrm{K}$, valor este bem superior aos encontrados no presente trabalho considerando todos os tratamentos e anos.

4.3.3.1. Comparação entre as fontes de potássio

Os resultados das médias dos teores de potássio em porcentagem na matēria seca das folhas, por tratamento, do 'Niagara Rosada' e os resultados parciais das aná- 
lises da variância de 1980 a 1985, acham-se descritos na Tabela 21 .

Nesta Tabela, observa-se que não houve diferença significativa do tratamento $\mathrm{N}_{3} \mathrm{P}_{3} \mathrm{~K}_{3}$ do delineamento, usando-se como fonte de potássio o cloreto de potássio, em comparação com os tratamentos $\mathrm{N}_{3} \mathrm{P}_{3} \mathrm{~K}_{3}$ extras, em todos os anos considerados individualmente.

Estes resultados indicam que o cloreto de potāssio e o sulfato duplo de potássio e magnésio comportaramse de forma semelhante como fontes de potássio, quanto à concentração de $\mathrm{K}$ na matéría seca das folhas.

\subsubsection{Comparação com a testemunha sem adubo}

A Tabela 21 mostra que, nos primeiros anos do ensaio os tratamentos com adubo não diferiram estatísticamen te da testemunha; no entanto, nos dois últimos anos do experimento apenas alguns tratamentos com adubo diferiram significativamente do controle.

Estes resultados indicam que com o decorrer dos anos, gradativamente houve surgimento da diferença de resposta de alguns tratamentos adubados em rela ção à testemunha, devido provavelmente ao esgotamento da fer tilidade do solo no tratamento controle. 
104.

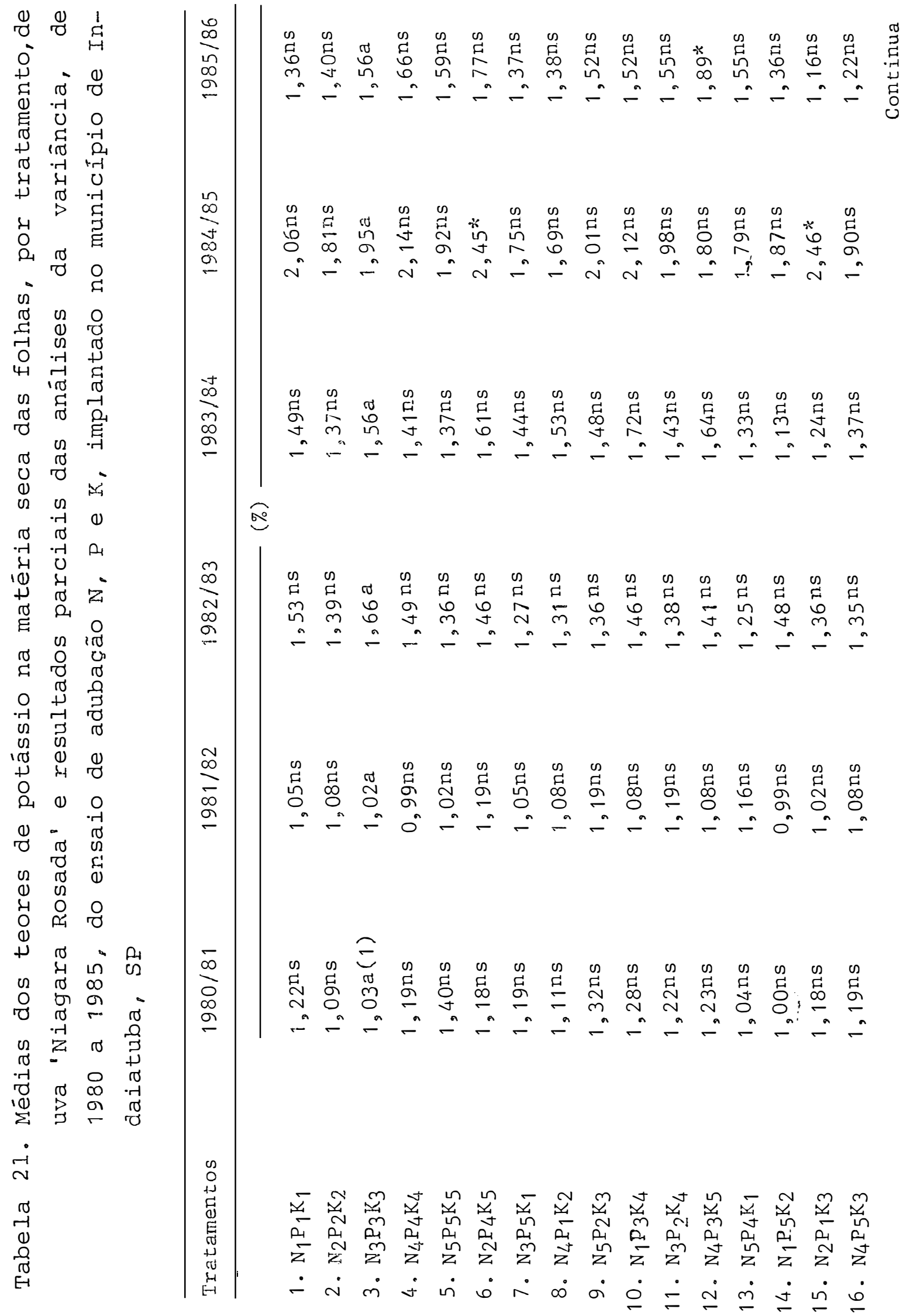


105.

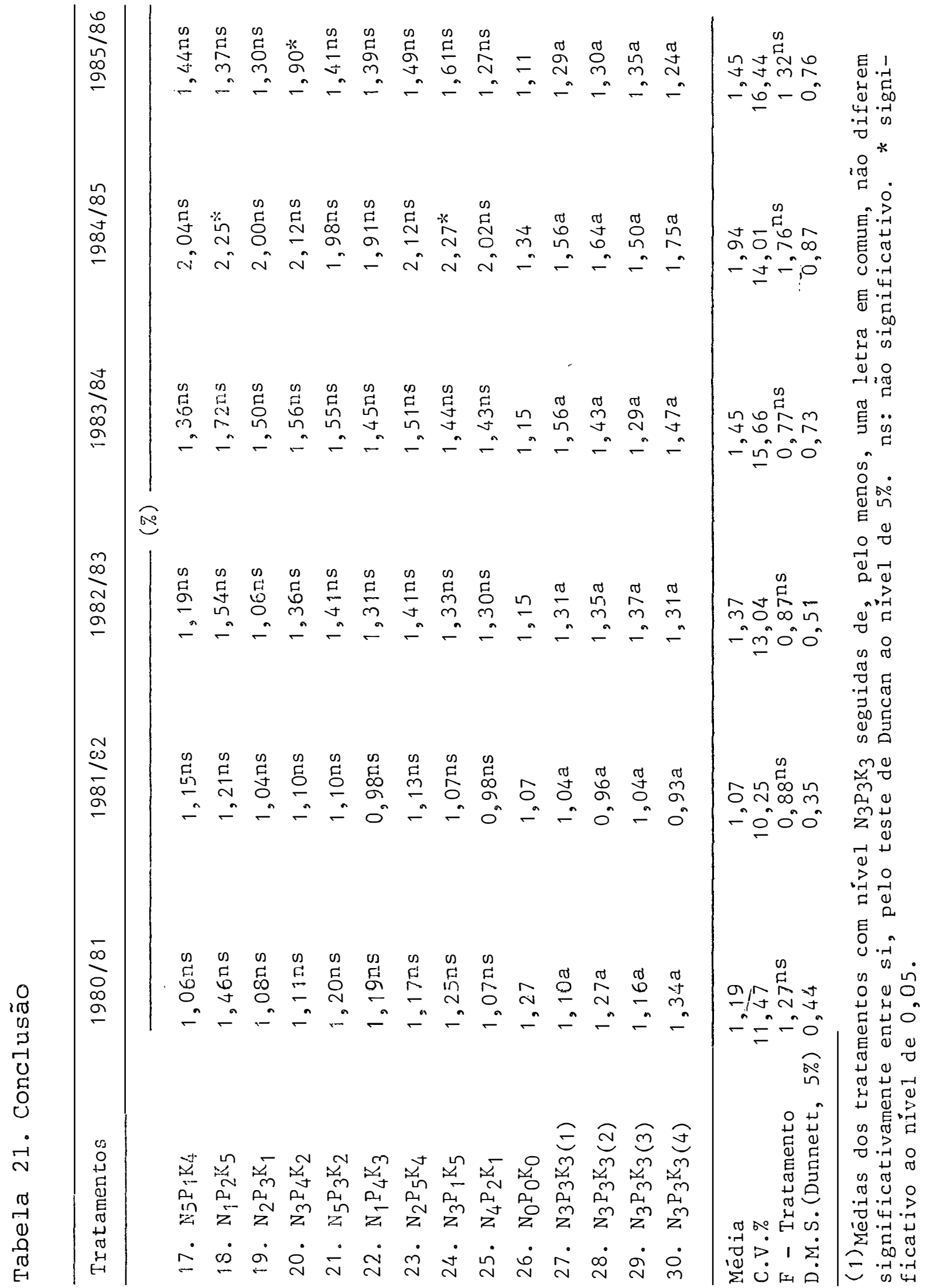


As estimativas dos coeficientes das equações de regressão, dos coeficientes de determinação múltipla e os valores dos testes $t$ e fr para regressão, obtidos nas análises dos dados dos teores de potássio na matéria seca das folhas, por tratamento, de uva 'Niagara Rosada' de 1980 a 1985, encontram-se na Tabela 22.

Nesta Tabela, observa-se inicialmente, que praticamente não houve interações significativas entre os nutrientes N, $P$ e $K$ em todos os anos estudados individualmente. Verifica-se também na mesma Tabela, que praticamente nã houve efeitos lineares e quadráticos significa tivos à aplicacão dos adubos com N, P e K, com exceção dos dois últimos anos do ensaio onde houve respostas significatí vas principalmente à acubação potássica.

Os resultados verificados na presenfe pesquisa indicam que praticamente as adubações nitrogenadas e fosfatada não interferiram positivamente no aumento da concentração de potássio na matéria seca das folhas, ao passo que a adubação potássica interferiu positivamente no teor de $K$ nos dois ultimos anos do ensaio. Isto se deve, provavelmente ao efeito residual do potássio, durante os 4 primeiros anos do ensaio. 


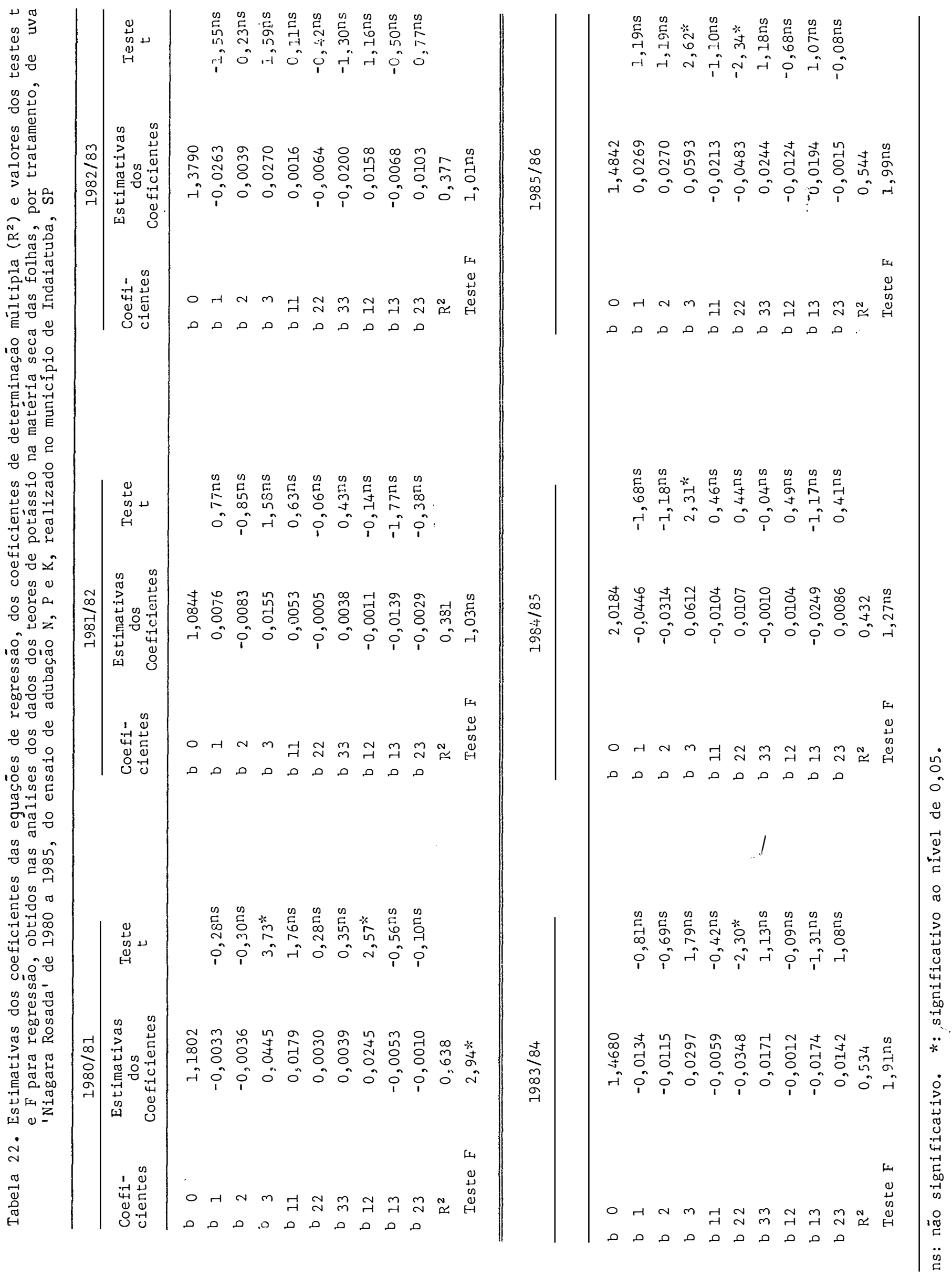


4.3.4. Cálcio

GALLO \& OLIVEIRA (1960), HERNANDO \& MENDIOLA (1965), HIROCE et alii (1970), CUMMINGS et alii (1973) e PEREIRA et alii (3.976), pesquisando diversos cultivares de videira copa e portamenxerto, encontraram variação de 0,75 a 4,80\% na concentração de cālcio na matéria seca das folhas. Os valores encontrados no presente estudo estão dentro da faixa de variação dos teores verificados por aqueles autores。

Enguanto isso, diversos autores (GALLO \& RIBAS, 1962; DECHENI, 1979; HIROCE \& TERRA, 1983; TERRA, 1983 e HIROCE et alii, 1989), estudando a videira 'Niagara Rosada', encontraram variação de 0,67 a $2,68 \%$ no teor de cálcio na matéria seca das folhas. Os valores observados no presente trabalho estão dentro da faixa de variação das concentrações verificadas por aqueles autores.

4.3.4.1. Comparação entre as fontes de potássio

Oss resultados das médias dos teores de cálcio em porcentagem na matéria seca das folhas, por tratamento, do Cv Niagara Rosada e os resulttados parciais das anälises da variância de 1980 a 1985, encontram-se na Tabela 23. Na referida Tabela, verifica-se que praticamente não houve diferença significativa do tratamento $\mathrm{N}_{3} \mathrm{P}_{3} \mathrm{~K}_{3}$ 


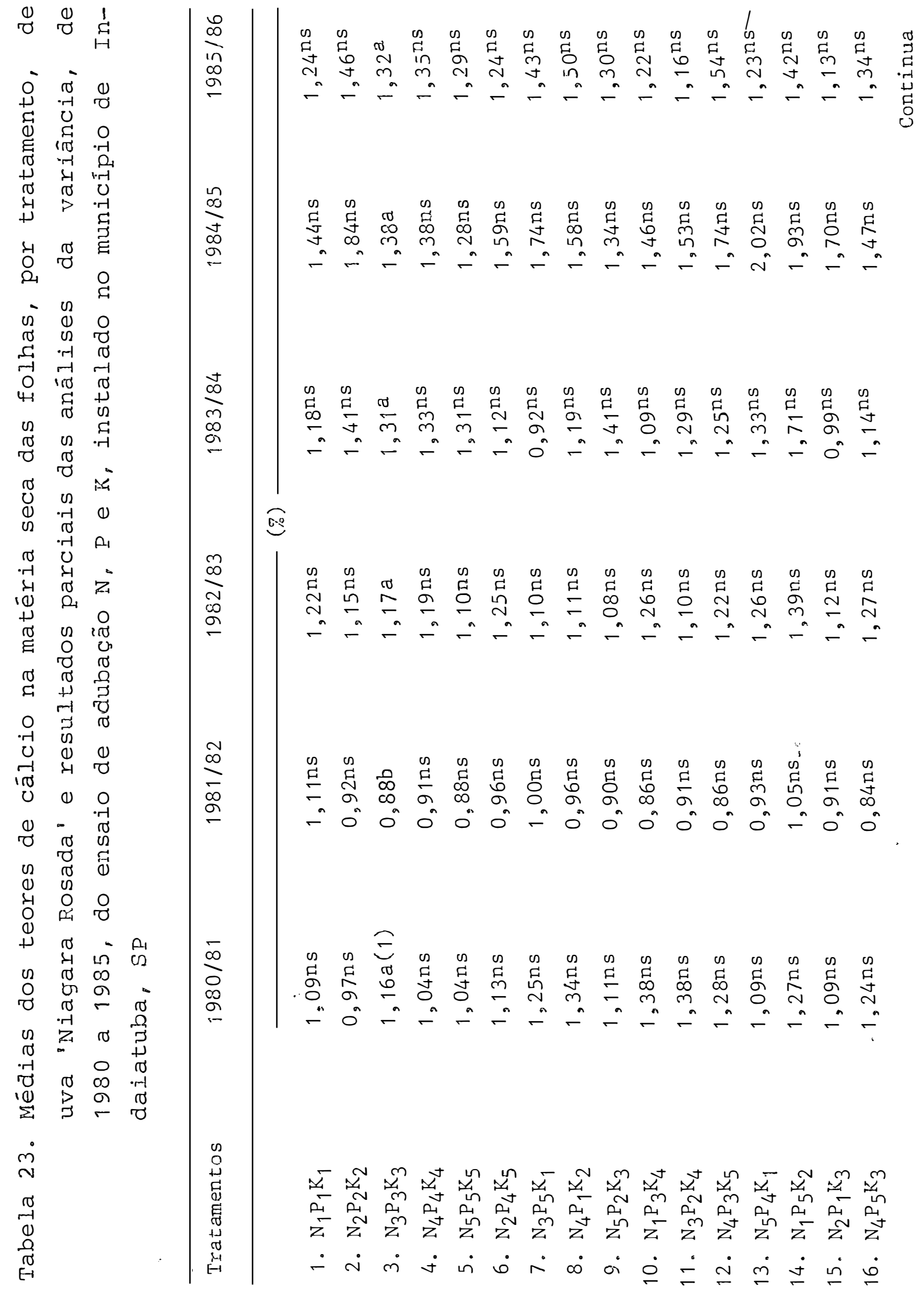


110 .

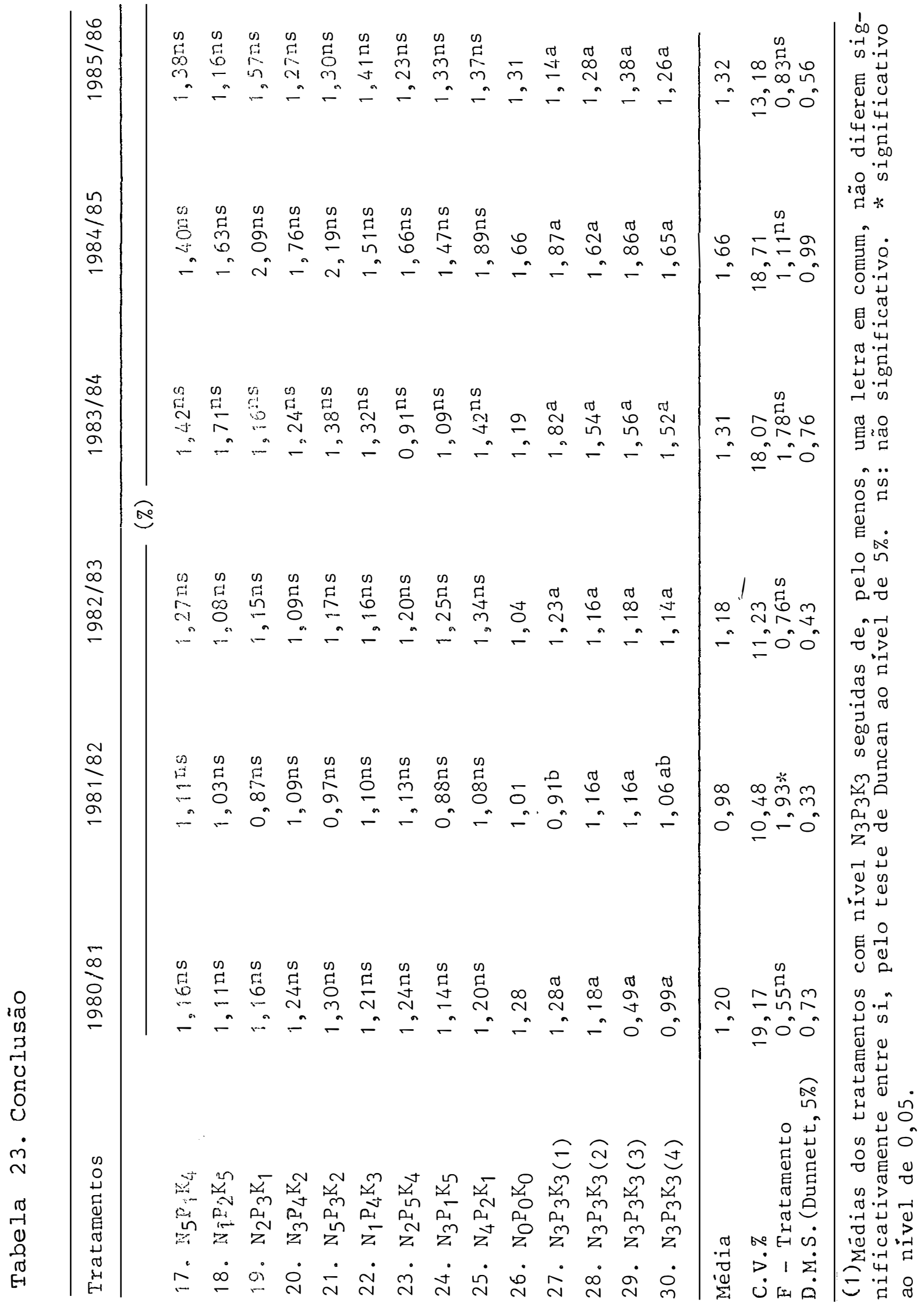


do delineamento, usando-se como fonte de potássio o cloreto de potássio, em comparação com os tratamentos $\mathrm{N}_{3} \mathrm{P}_{3} \mathrm{~K}_{3}$ extras, em todos os anos considerados individualmente.

$$
\text { Estes resultados indicam que o clo- }
$$

reto de potássio e o sulfato duplo de potássio e magnésio comportaram-se de forma semelhante como fontes de potássio, com referência a concentração de Ca na matéria seca das foIhas.

\subsubsection{Comparação com a testemunha sem adubo}

A Tabela 23 mostra que, os tratamentos com adubo não diferiram estatísticamente da testemunha.

Estes resultados indicam que, provavelmente 0 cálcio no sojo estavia em nível suficiente para não haver efeito deste elemento, que faz parte da composição do fertilizante superfosfato triplo, usado neste experimento.

\section{3,4,3: Anälises de regressão}

Is estinativas dos coeficientes das equações de regressão, dos coeficientes de determinação múltipla e os valores dos testes te $F$ para regressão, obtidos nas análises dos dados dos teores de cálcio na matéria seca das folhas, por tratamento, de uva 'Niagara Rosada' de 1980 a 
1985, encontram- se na Tabela 24.

Nesta Tabela, verifica-se que praticamente não houve interações significativas entre os nutrientes N, P e $\mathrm{K}$, em todos os anos estudados individualmente.

Observa-se tambẻm na referida Tabela, que pra ticamente não houve efeitos lineares e quadráticos significa tivos à aplícação dos adubos com N, P e K.

$$
\text { Os resultados verificados }
$$

no presente estudo indicam que praticamente as adubações nitrogenada, fos Eatada e potässica não interferiram positivamente no aumento da concentração de cálcio na matéria seca das folhas.

\section{$4,3,5$, Magnësio}

De acordo com GALLO \& OLIVEIRA (1960), HERNAN DO \& MENDIOIA (1965), HIROCE et alii (1970), CUPMINGS et alii (1973) e PEREIRA et alii (1976), em suas pesquisas com diversos cultivares de videira copa e porta-enxerto, encon traram varią̧ão de 0,165 a 1,060\% na concentração de magnésio na matéria seca das folhas. Os valores encontrados no presente trabalho estão dentro da faixa de variação dos teores verificados por aqueles autores.

GALIJO \& RJBAS (.1962), DECHEN (1979), HIROCE \& TERRA (1933) e HIROCE et alii (1989), pesquisando a videira 'Niagara Rosada' encontraram variação de 0,190 a 0,540\% 


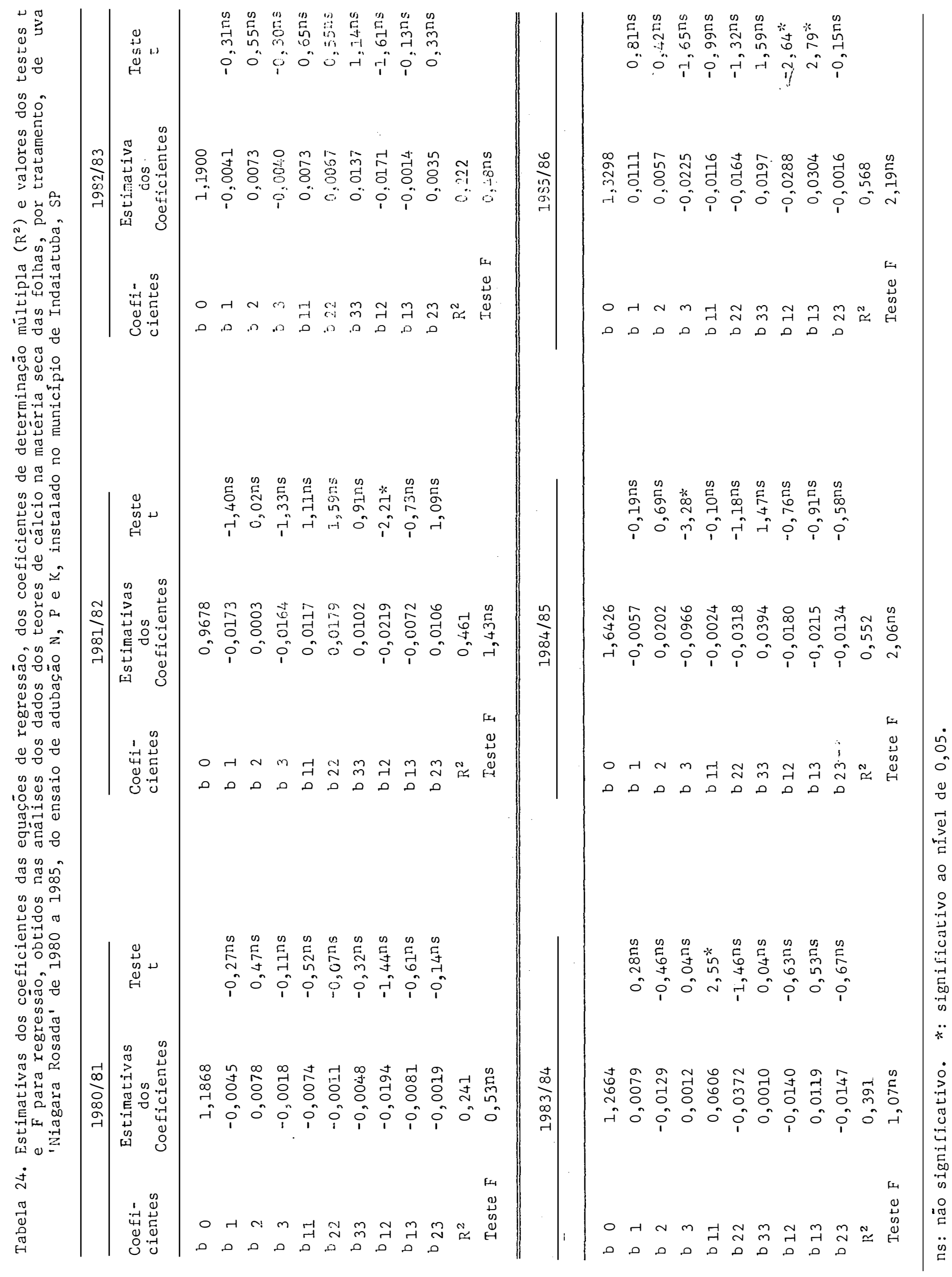


no teor de magnërio na matéria seca das folhas. Os valores observados no prosente trabalho estão dentro da faixa de variação das concentrrações verificadas por aqueles autores.

4.3.5.1. Comparação entre as fontes de potássio

Os resultados das médias dos teores de magnésio em porcentagem na matéria seca das folhas, por tratamento, da videira 'Miagara Rosada' e os resultados parciais das análises cla variância de 1980 a 1985, acham-se na Tabela 25 .

$$
\text { Nesta Tabela, verifica-se que praticamente }
$$

não houve diferença significativa do tratamento $\mathrm{N}_{3} \mathrm{P}_{3} \mathrm{~K}_{3}$ do de lineamento, em comparação com os tratamentos $\mathrm{N}_{3} \mathrm{P}_{3} \mathrm{~K}_{3}$ extras, em todos os anos considerados individualmente.

$$
\text { Estes resultados indicam que o clo- }
$$

reto de potässio e o sulfato duplo de potássio e magnésio comportaram-se de forma semelhante como fontes de potássio, quanto à concentiação de Mg na matéria seca das folhas.

4.3.5.2. Comparação com a testemunha sem adubo

A Tabela 25 mostra que, praticamente os tratamentos com adubo não diferiram estatisticamente da testemunha。 
115.

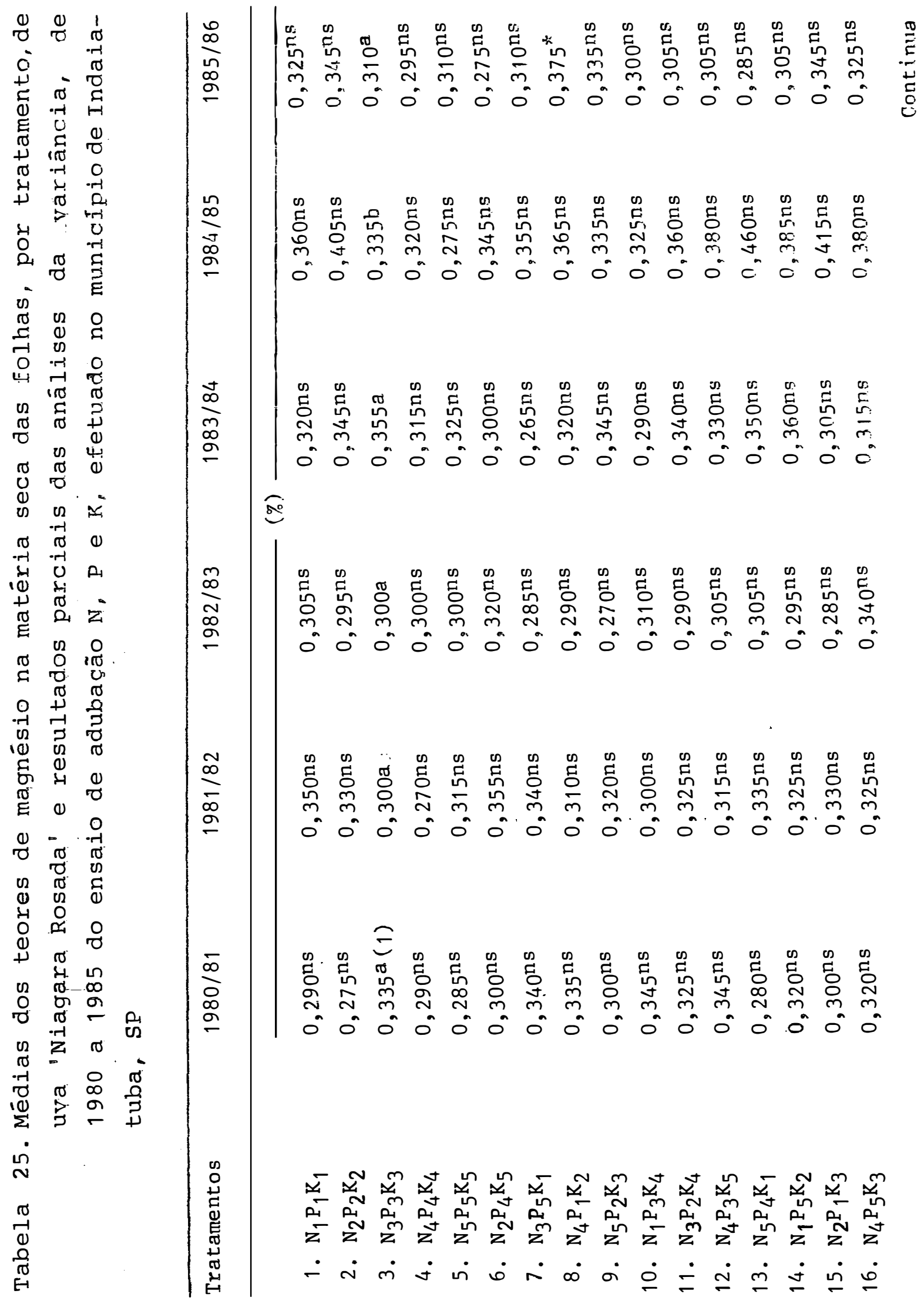


116.

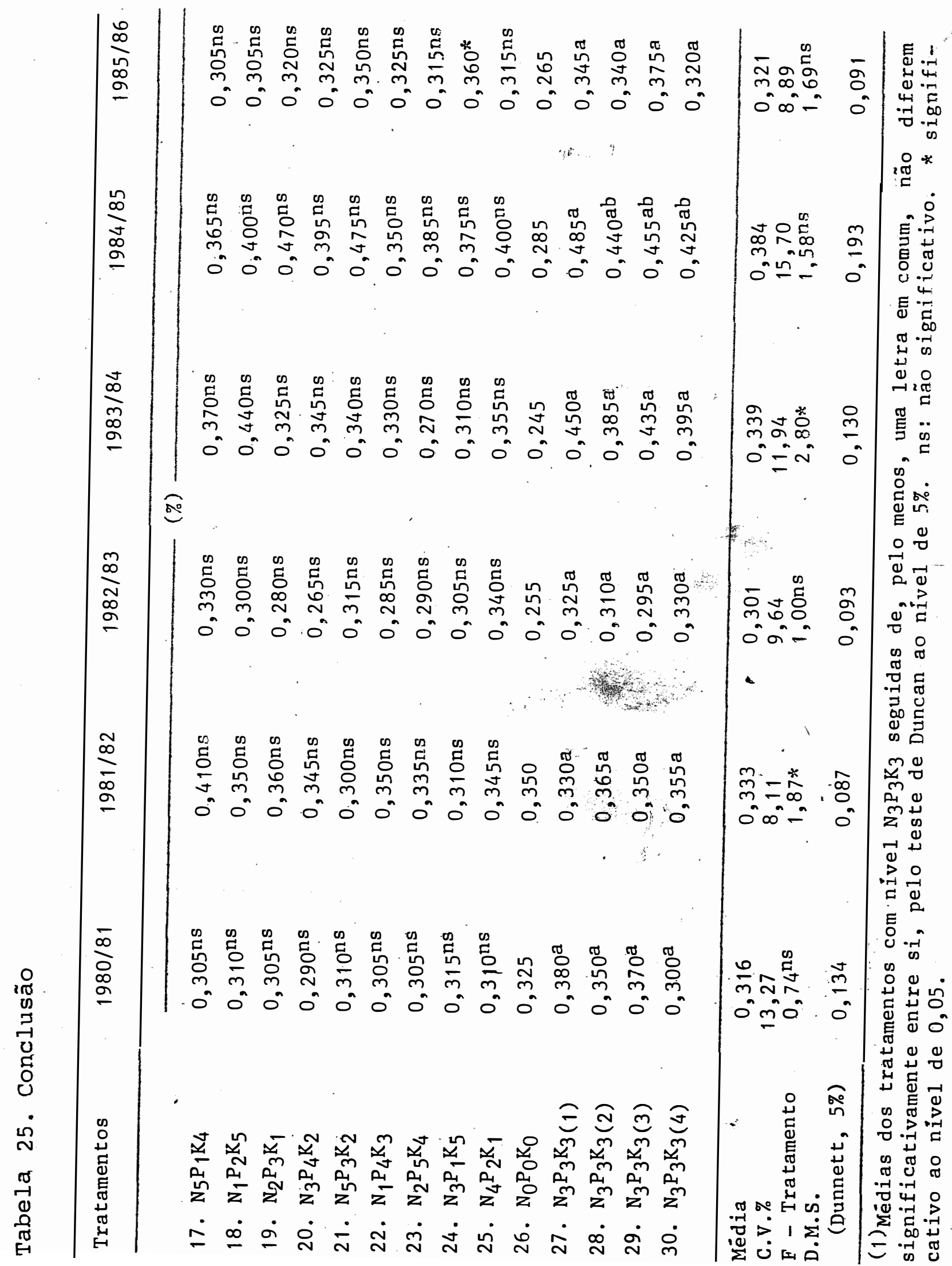


Como nenhum dos fertilizantes continha magnésio na sua composição, os resultados obtidos estão concordantes em relação à testemunha.

\subsubsection{Anâlises de regressão}

As estimativas dos coeficientes das equações de regressão, dos coeficientes de determinação múltipla e os valores dos testes $t$ e F para regressão, obtidos nas análises dos dados dos teores de magnésio na matéria seca das foIhas, por tratamento, de uva 'Niagara Rosada' de 1980 a 1985, encontram-se na Tabela 26.

Nesta Tabela, verifica-se que não houve interações significativas entre os nutrientes $\mathrm{N}, \mathrm{P}$ e $\mathrm{K}$, em todos os anos estudados individualmente.

Observa-se também na Tabela 26, que praticamente não houve efeitos lineares e quadrāticos significativos à aplicação dos adubos $\operatorname{com} N, P$ e .

Os resultados - verificados no presen te trabalho indicam que praticamente as adubações nitrogenada, fosfatada e potássica não interferiram positivamente no aumento da concentração de magnésio na matéria seca das foIhas. 


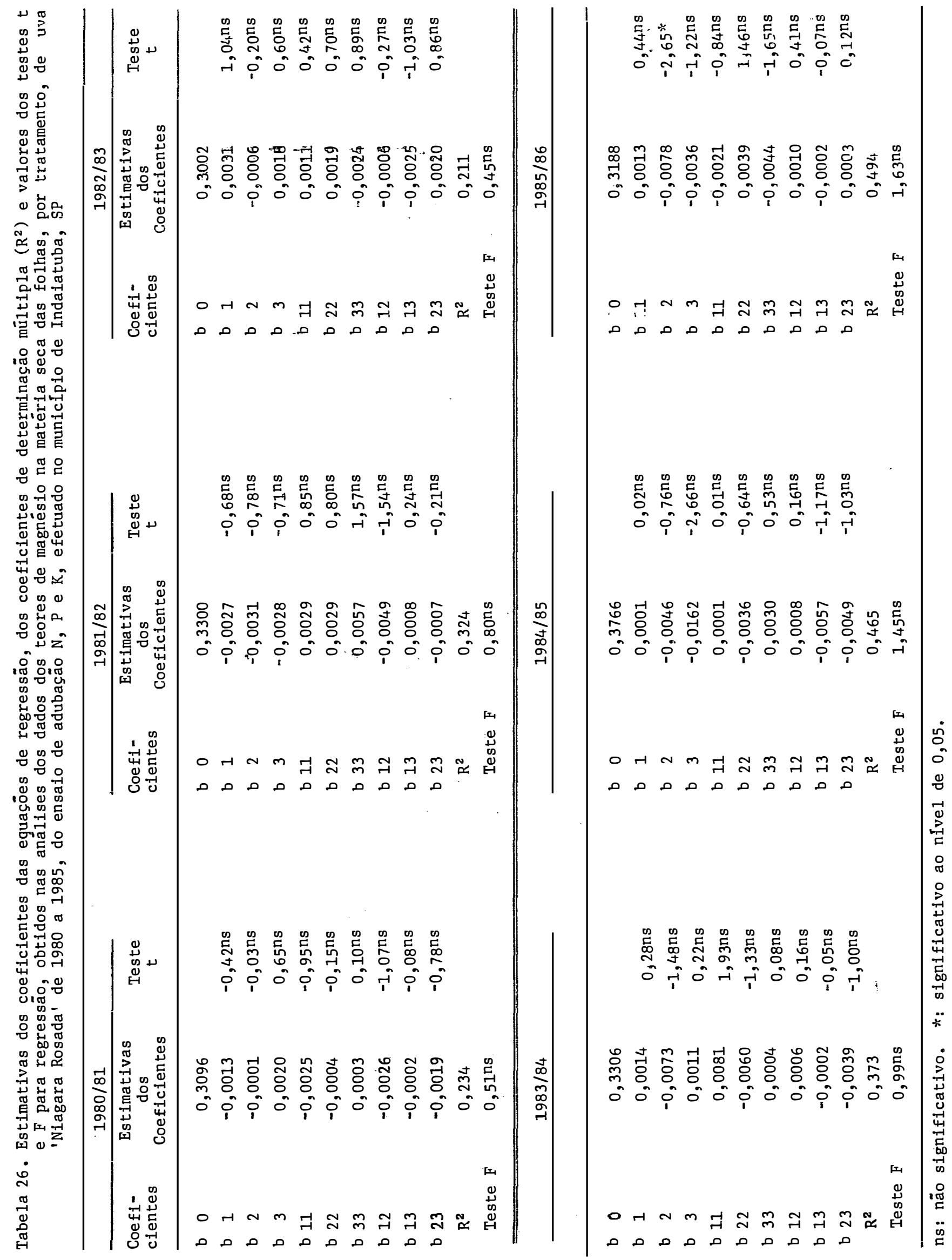


4.3,6. Enxofre

DECHEN (1979), HIROCE \& TERRA (1983), TERRA (1983) e HIROCE et alii (1989), realizando experimentos com - Cv Niagara Rosada, acharam variação de 0,160 a 0,470\% no teor de enxofre na matéria seca das folhas. Os valores encon trados no presente trabalho estão dentro da faixa de varia ção das concentrações verificadas por aqueles autores.

4.3.6.1. Comparação entre as fontes de potássio

Os resultados das médias dos teores de enxofre em porcentagem na matéria seca das folhas, por tratamento, da videira 'Niagara Rosada' e os resultados parciais das anâlises da variância de 1980 a 1985, acham-se descritos na Tabela 27.

Nesta Tabela, verifica-se que praticamente não houve diferença significativa do tratamento $\mathrm{N}_{3} \mathrm{P}_{3} \mathrm{~K}_{3}$ do de lineamento, em comparação com os tratamentos $\mathrm{N}_{3} \mathrm{P}_{3} \mathrm{~K}_{3}$ extras , em todos os anos considerados individualmente, com exceção dos anos 1983/84 e 1984/85, onde o tratamento com sulfato duplo de potássio e magnésio apresentou teor de enxofre supe rior estatísticamente àquele tratamento $\mathrm{N}_{3} \mathrm{P}_{3} \mathrm{~K}_{3}$ do delineamen to.

Estes resultados indicam que o cloreto de potássio e o sulfato duplo de potássio e magnésio 
120.

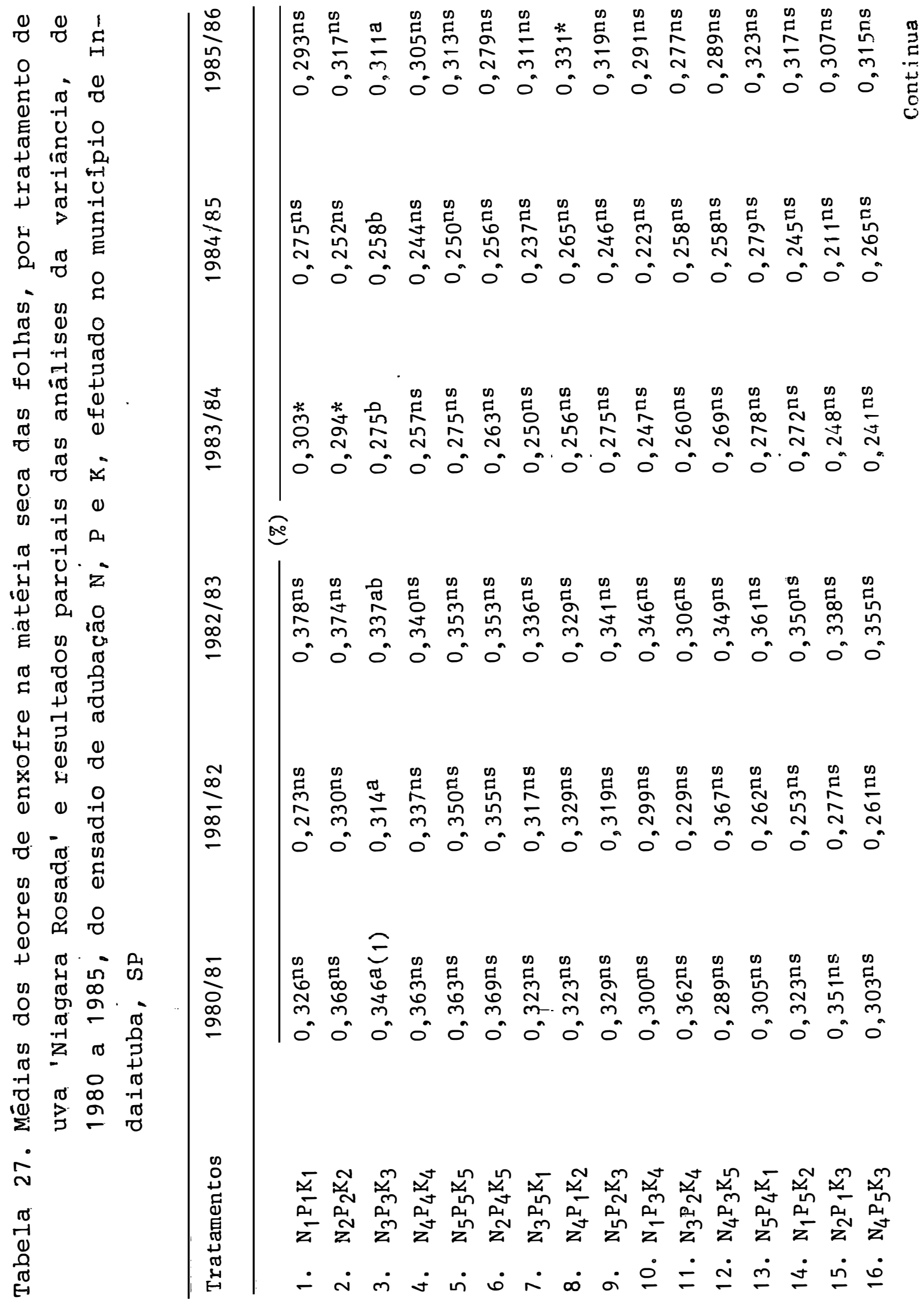


121.

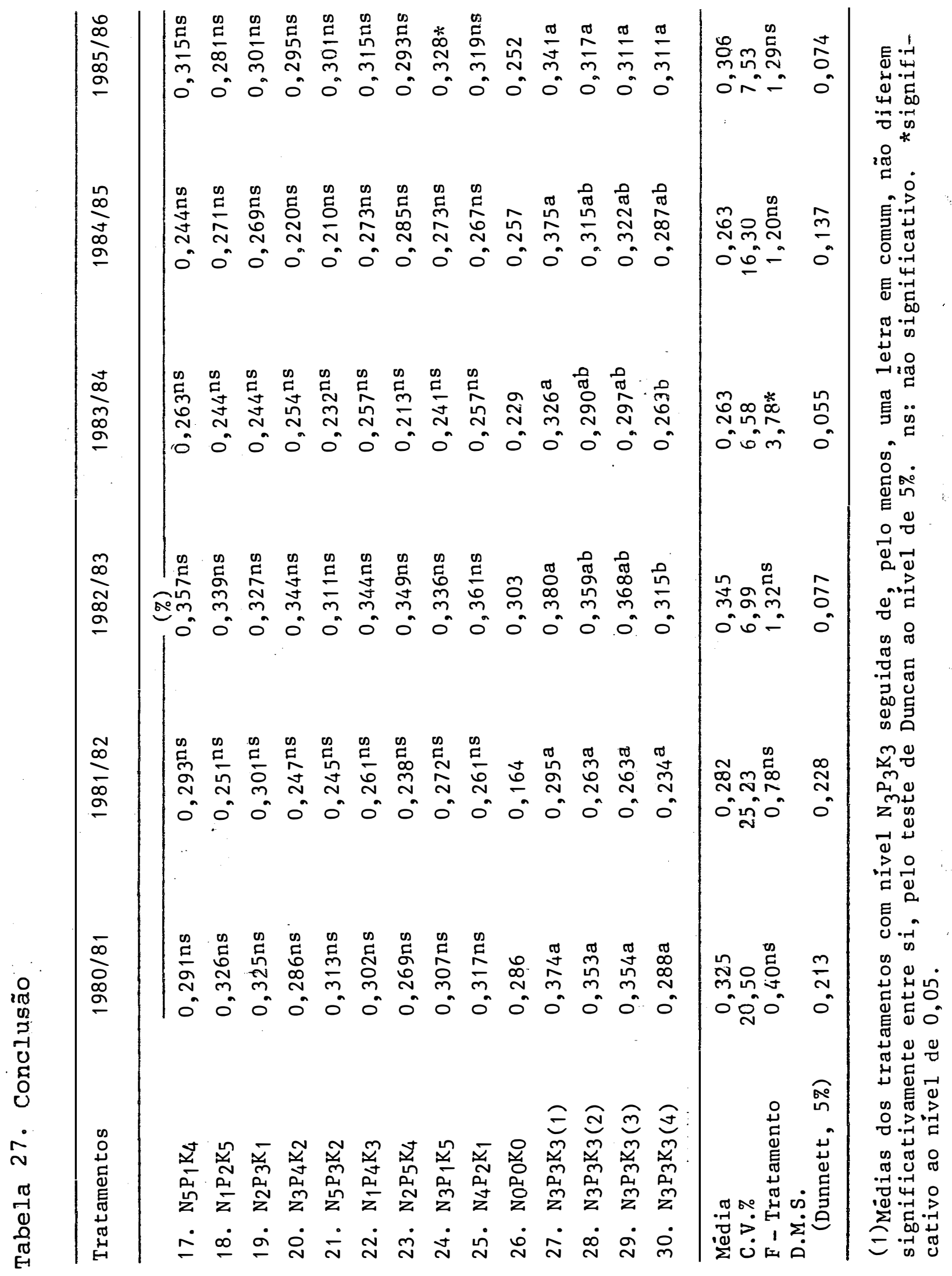


comportaram-se de forma semelhante como fontes de potássio, quanto à concentração de $s$ na matéria seca das folhas. As duas exceções foram verificadas quando se utilizou o sulfato duplo de potássio e magnésio em substituição ao cloreto de potássio, devido o fertilizante, sulfato duplo de potássio e magnésio utilizado conter 22-23\% de enxofre na sua composição.

$4,3,6.2$. Comparação com a testemunha sem adubo

A Tabela 27 mostra que, praticamente os trata mentos com adubo não diferiram estatísticamente da ' teste munha .

Como nenhum dos fertilizantes continha enxofre na sua composição, os resultados .. verificados estão concordantes em relação à testemunha.

$4,3,6,3$. Anālises de regressão

As estimativas dos coeficientes das equações de regressão, dos coeficientes de determinação múltipla e os valores dos testes $t$ e F para regressão, obtidos nas anāIises dos dados dos teores de enxofre na matéria seca das fo lhas, por tratamento, de uva 'Niagara Rosada' de 1980 a 1985, encontram-se na Tabela 28. 
123.

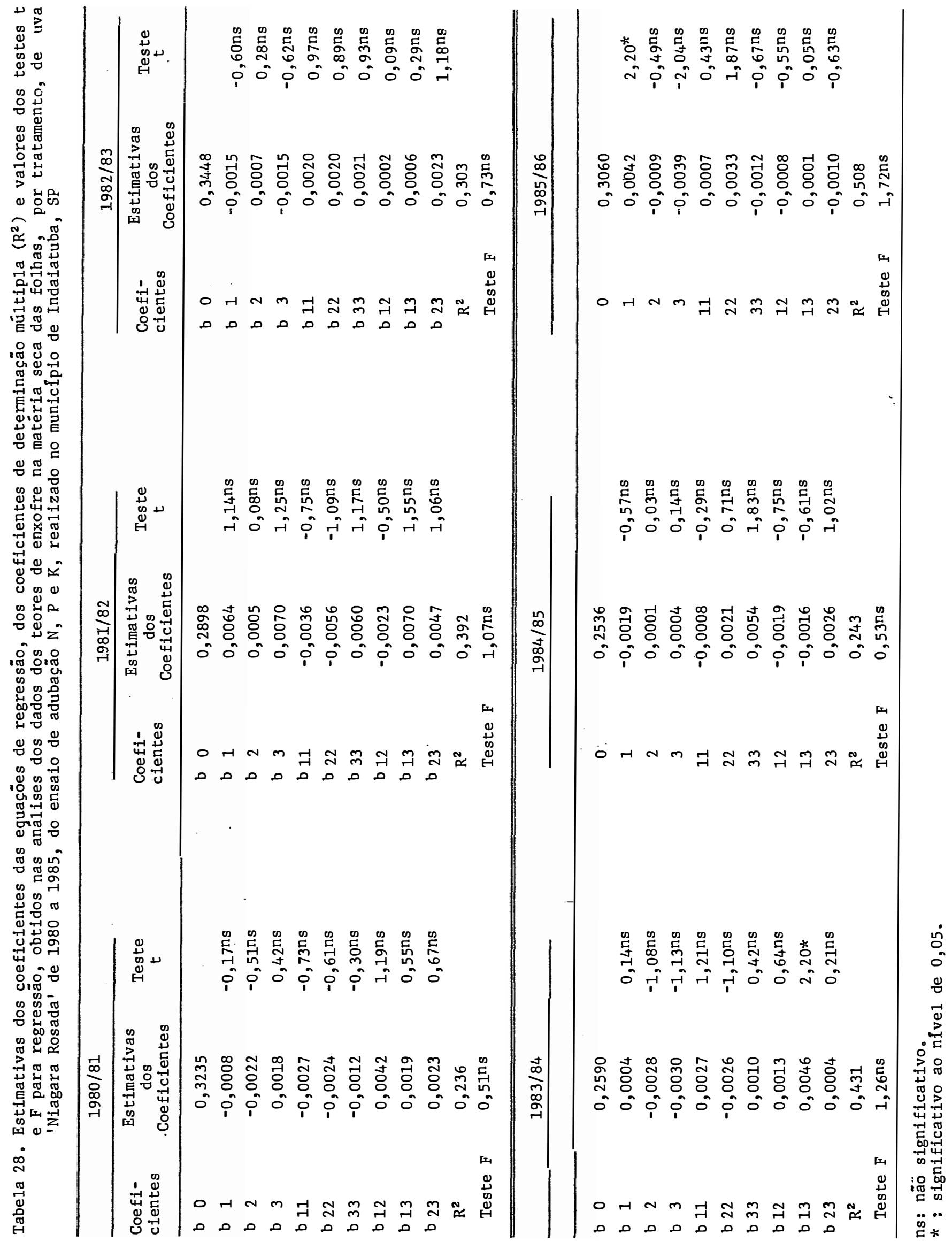


124.

Nesta Tabela, verifica-se que

praticamente

não houve interações significativas entre os nutrientes $\mathbb{N}$, $P$ e $K_{q}$ em todos os anos estudados individualmente.

Observa-se também na Tabela 28, que praticamente não houve efeitos lineares e quadráticos significativos à aplicação dos adubos $\operatorname{com} N, P$ e $K$.

Os : resultados verificados na pre-

sente pesquisa indicam que as adubações nitrogenada, fosfatada e potássica não interferiram positivamente no aumento da concentração de enxofre na matéria seca das folhas. 


\section{CONCLUSÖES}

Nas condições experimentais em que foi realiza do o presente trabalho, pode-se tirar as seguintes conclusões :

\subsection{Produção}

a) A fonte de potássio não influiu na produção da uva.

b) A produção de uva respondeu positivamente às aplicações de diferentes combinações de doses de $\mathrm{N}_{2} \mathrm{P}_{2} \mathrm{O}_{5}$ e $\mathrm{K}_{2} \mathrm{O}$ em relação à testemunha sem adubo.

c) Na análise conjunta dos seis anos, pode-se afirmar que houve resposta positiva às adubações nitrogenada e potássica, verificadas através das equações de regressão.

d) Considerando o conjunto dos anos 1980

a 1985 não houve resposta positiva para a adubação fosfatada, sendo a dose $40 \mathrm{~g} / \mathrm{planta}$ de $\mathrm{P}_{2} \mathrm{O}_{5}$ já ter sido suficiente.

e) As produções máximas observadas nos anos 
em que houve efeitos positivos da adubação foram os seguintes:

Ano

Ponto de máxima produção

Agricola

Nitrogēnio

Potássio

$\mathrm{g} / \mathrm{planta}$

$1982 / 83$

103

$1984 / 85$

107

276

$1985 / 86$

110

249

$1980 / 85$

105

276

f) A dose econômica recomendada para o nitrogênio situou-se na faixa de 87 a $102 \mathrm{~g} /$ planta no ano 1982/ 83; de 95 a $105 \mathrm{~g} / \mathrm{planta}$ no ano 1984/85; de 102 a $109 \mathrm{~g} / \mathrm{plan-}$ ta no ano 1985/86 e de 92 a $103 \mathrm{~g} / \mathrm{planta}$ no conjunto 198085 .

g) A dose econōmica recomendada para o potássio situou-se na faixa de 231 a $267 \mathrm{~g} / \mathrm{planta}$ em 1984/85; de 216 a 242 g/planta em 1985/86 e de 202 a 261 g/planta no conjunto 1980-85. 


\subsection{Peso médio de cacho}

a) A fonte de potássio não influiu no peso do cacho da uvà.

b) O peso do cacho da uva respondeu positivamente às aplicações de diferentes combinações de doses de $\mathrm{N}$, $\mathrm{P}_{2} \mathrm{O}_{5}$ e $\mathrm{K}_{2} \mathrm{O}$ em relação à testemunha sem adubo.

c) Não houve resposta positiva para as adubações nitrogenada, fosfatada e potássica, verificadas através das equações de regressão.

\subsection{Concentração de macronutrientes na matéria seca das folhas}

a) A fonte de potássio não influiu na concentração dos macronutrientes N, P, K, Ca, Mg e S na matéria se ca das folhas do cultivar Niagara Rosada.

b) No decorrer dos anos, a concentração de $\mathrm{N}$ e $\mathrm{K}$ na matéria seca das folhas respondeu gradativamente às aplicações de diferentes doses de $\mathrm{N}, \mathrm{P}_{2} \mathrm{O}_{5}$ e $\mathrm{K}_{2} \mathrm{O}$.

c) Considerando todos os anos individualmen te, não houve resposta positiva para as adubações nitrogena- 
128.

da, fosfatada e potássica, em relação às concentrações de N, Ca, Mg e S na matéria seca das folhas. 


\section{REFERÊNCIAS BIBLIOGRÁFICAS}

AHMED, F.F.; EL-SAYED, M.A.; MAATOUK, M.A. Response of red roomy grapevines to nitrogen applications. II.Yield and berries quality. Annals of Agricultural Science, Ain Shams. University, Minia, 33(1):451-469, 1988. Apud Horticultural Abstracts, London, 59(4):314-315, 1989.

ALANASOV, Ja. The effect of fertilizers on the yield and quality of the vine cultivar Siroka-Melniska. Nauka, $\underline{7}$ (7) :115-121, 1970. Apud Horticultural Abstracts, London, $\underline{41}(3): 752,1971$.

ALIEV, I.A. The effect of mineral fertilizers on the yield of unirrigated grapevines. Sudovodstvo, Vinozvadarstvo i Vinodelie Moldavii, Kishinev, (10):21-23, 1975. Apud Horticultural Abstracts, London, $\underline{46}(9): 717,1976$.

ANUÁRIO ESTATÍSTICO DO BRASIL - 1987/88, Rio de Janeiro, 48: 346,1988 .

ARTAMONOVA, N.P. The rates and ratios of nutrient elements during fertilization of unirrigated grapevines. Temat. Sb. Nauch. Tr. Tadzh. SSR, 8 $: 166-183,1976$. Apud Horticultural Abstracts, London; 48 (7):569, 1978 .

ASSOCIAÇÃO NACIONAL PARA DIFUSÃO DE ADUBOS. Manual de adubação. 2.ed. São Paulo, 1975. $346 \mathrm{p}$. 
ASSOCIAÇÃO NACIONAL PARA DIFUSÃO DE ADUBOS E CORRETIVOS AGRICOLAS, São Paulo. Plano nacional de fertilizantes. São Paulo, 1987. 235p.

AVRAMOV, L.; GERJOVIC, S.; HRCEK, L. The effect of potassium and nitrogen on the yield and growth of the grapevine cultivar Merlot. Zbornik Biotehniske Fakultete Univerze v Ljubljani, Kmetijstvo, Ljubljana, 25:113-117, 1975. Apud Horticultural Abstracts, London, $\underline{47}(3): 224,1977$.

BALCAR, J.; MEYER, L.H.; PRAVIA, L. Eficiência de la absorcion del fosforo por la vitis vinifera aplicado en funcion de distintas profundidades $y$ distancias a la planta, en condiciones de campo. Uruguay, Instituto de Enseñanza de Vitivinicultura, 1970. 14p.

BATAGLIA, O.C.; FURLANI, A.M.C.; TEIXEIRA, J.P.F.; FURLANI, P.R.; GALLO, J.R. Análise química de plantas. Campinas, Instituto Agronômico, 1983. 31p. (Boletim técnico, 78)

BELOV, E.A.; BONDARENKO, S.G.; PURIS, M.F.; REZNIK, CH. M. Long-term trials with mineral fertilizers in vine-yards. Sadovodstvo, Vinogradarstvo $i$ Vinodelie Moldavii,kishïnev, (10):12-14, 1983. Apud Horticultural Abstracts, London, $\underline{55}(7): 525,1985$.

BICER, Y. \& OZEL, M. Nitrogen and phosphorus requirement of grapevine in Cukurova. Tarsus, Tarsus Research Institute for Village Affairs, 1986. 52p.

BRAR, S.S. \& BINDRA, A.S. Effect of plant density on vine growth, yield, fruit quality and nutrient status in Perlette grapevines. Vitis, Siebeldingen, 25:96-106, 1986. 
CAMPINAS. Instituto Agronômico. Videira. In: _ _ Tabelas de adubação e calagem das principais culturas econōmicas do Estado de São Paulo. Campinas, 1977. p.194-196, (Boletim, 209)

CENTRO NACIONAL DE ENSINO E PESQUISAS AGRONÔMICAS. Comissão de Solos. Levantamento de reconhecimento de solos no Estado de são Paulo. Rio de Janeiro, Serviço de Pesquisas Agronômicas, 1960. 634p. (SNPA, Boletim, 12)

CHADHA, K.L. \& SINGH, L. Effect of varying levels of nitrogen on growth, yield and quality of Thompson seedless and Kandhari, varieties of grape. Indian Journal of Horticulture, Ludhiana, $28(4): 257-263$, 1971. Apud Horticultural Abstracts, London, $44(1): 24,1974$.

CHAUHAN K.S.; KHERA, A.P.; SINGH, S.P.; JAIN, R.K. Response of grape cultivar Beauty seedless to graded doses of nitrogen. Haryana Agricultural University Journal of Research, Hissar, 13(2):299-303, 1983. Apud Horticultural Abstracts, London, $\underline{54}(6): 322,1984$.

CHRISTENSEN, L.P.; KASIMATIS, A.N.; JENSEN, F.L. Grapevine nutrition and fertilization in the San Joaquim Valley. Berkeley, University of California, 1978. 40p.

CHRISTENSEN, P. Potash puts new life into vineyards. Better Crops, washington, $48(2): 20-21,1964$. Apud Horticultural Abstracts, London, $\underline{34}(4): 679,1964$.

CLINE, R.A. \& BRADT, O.A. The effect of source and rate of potassium on the performance of 'Concord' grape vines grown on clay loam soils. Journal of the American Society for Horticultural Science, Ontario, 105(5):650-653, 1980. Apud Horticultural Abstracts, London, $\underline{51}(4): 208,1981$. 
CONAGIN, A. \& JORGE, J.P.N. Delineamentos $(1 / 5)\left(5^{3}\right)$. Bragantia, Campinas, $\underline{36}(3): 23-58,1977$.

CONRADIE, W.J. \& SAAYMAN, D. Effects of long-term nitrogen, phosphorus and potassium fertilization on Chenin Blanc vines. I. Nutrient demand and vine performance. American Journal of Enology and Viticulture, Lockeford, $\underline{40}(2): 85-$ 90,1989 .

CUMMINGS, G.A.; FISH, A.S.; NESBITT, W.B.; UNDERWOOD, V.H. The influence of mineral nutrition and time of year upon the elemental concentration of muscadine grapes (Vitis Rotundifolia). Communications in Soil science and Plant Analysis, Raleigh, $\underline{4}(3): 211-218,1973$. Apud Horticultural Abstracts, London, $\underline{44}(6): 201,1974$.

DECHEN, A.R. Acúmulo de nutrientes pela videira (Vitis Zabrusca L x Vitis vinifera L) cv 'Niagara Rosada', durante um ciclo vegetativo. Piracicaba, 1979. 133p. (Mestrado - Escola Superior de Agricultura "Luiz de Queiroz"/USP)

DECHEN, A.R. Nutrição e adubação da videira. Piracicaba, ESALQ/USP, 1980. 43p. (Mimeografado)

DYUZHEV, P.K.; ZAITSEVA, Yu.; KOLESNIKOVA, T.I. Some results of studies on vineyard fertilization. Udobr. i Agropochvovedeniya (21):181-186, 1973. Apud Horticultural Abstracts, London, $\underline{45}(5): 267,1975$.

EL-SHOURBAGY, M.A. \& ISMAIL, Z. Growth and yield of the Red Romy european grape variety as affected by added nitrogen. Agricultural Research Review, Cairo, 39:219-226, 1961. Apud Horticultural Abstracts, London, 34 (1):69, 1964. 
FREGONI, M. \& ZIONI, E. La concimazione della vite. Inf. agrar., Verona, 25:1507-1508, 1969. Apud Horticultural Abstracts, London, $\underline{40}(3): 718,1970$.

GALLO, J.R. \& OLIVEIRA, A.S. Variações sazonais na composição mineral de folhas de videira e efeitos do porta-enxerto e da presença de frutos. Bragantia, Campinas, 19: $883-889,1960$.

GALLO, J.R. \& RIBAS, W.C. Análise foliar de diferentes combinações enxerto-cavalo para dez variedades de videira. Bragantia, Campinas, 21:397-410, 1962.

GEORGIEVA, S. Determination of the fertilizer requirement of grapevines by qualitative tests. Lozarstvo i Vinarstvo, Plovdiv, 25(3):22-24, 1976. Apud Horticultural Abstracts, $\underline{47}(8): 775,1977$.

GIORGESSI, F.; ZAZZI, A.; SCALABRELLI, G.; CAPPELLERI, G. Risultati di provi di concimazione sulla viti conseguiti in toscana. Rivista di Viticoltura e di Enologia, Conegliano, $37(10): 565-580,1984$.

GOBBATO, C. Manual do viti-vinicultor brasileiro. 4.ed. Porto Alegre, Oficinas Gráficas da Escola de Engenharia, 1940. 356p.

HABEEB, H.; MOSTAFA, I.; SHAFEEK, A. Effect of $\mathrm{N}$ fertilization rate, timing and frequency on Italia grapevine behaviour. Agricultural Research Review, Cairo, 54(3):1722, 1976. Apud Horticultural Abstracts, London, 48(2): 122,1978 . 
HABEEB, H.; MOSTAFFA, I.; SHAFEEK, A. Effects of $P$ and $K$ on Italia grapevine behaviour. Agricultural Research Review, Cairo, 54(3):23-27, 1976. Apud Horticultural Abstracts, London, $\underline{4} 8(2): 122-123,1978$.

HAESEL首R, C.W.; SMITH, C.B.; KARDOS, L.T.; FLEMING, H.K. Response of mature vines of Vitis labrusca L. Cv. 'Concord' to applications of phosphorus and potassium over and eight-year span in Pennsylvania. American Journal of Enology and Viticulture, Lockeford, 31(3):237-244, 1980.

HERNANDO, V. \& MENDIOLA, J. Estudio de la nutricion mineral en viñedos de Ciudad Real. Anales de Edafologia y Agrobiologja, Madrid, 24:193-203, 1965.

HIROCE, R. Nutrição mineral da videira. O Estado de São Paulo, São Paulo, 20.ago. 1980. Suplemento Agrícola, $1310: 5$.

HIROCE, R.; GALLO, J.R. \& RIBAS, W.C. Efeitos de dez diferentes cavalos de videira na composição foliar da copa do cùltivar 'Seibel 2'. Bragantia, Campinas, 29:XXI-XXIV, 1970. (Nota, 5)

HIROCE, R.; TERRA, M.M.; GREGORI, P.T. Levantamento nutriciona'l de videira de Itupeva, região de Jundiaí-SP. In: CONGRESSO BRASILEIRO DE FRUTICULTURA, 10., Fortaleza, 1989. Resumos. Fortaleza, Sociedade Brasileira de Fruticultura, 1989. p.63.

IANNINI, B. Risultati di un triennio de ricerche sulla concimazione epigea di due c.v. di vite. Rivista di Viticultura e di Enologia, Conegliano, 25(5):197-204, 1972. 
INGLEZ DE SOUSA, J.S. Mutações somáticas na videira

'Niagara'. Bragantia, Campinas, 18:387-415, 1959. (Nota, 27)

INGLEZ DE SOUSA, J.S. Uvas para o Brasil. São Paulo, Melhoramentos, 1969. 456p.

IONCHEV, P. \& MINEVA, S. Effect of mineral nutrition on the growth and fruiting of vineyards planted on slopes. Lozarstvo i Vinarstvo, Novo Selo, $22(5): 10-15,1973$. Apud Horticultural Abstracts, London, $\underline{44}(11): 754,1974$.

IONEV, S. The relationship between fertilizer rate and the in-row planting distance. Gradinarska i Lozarska Nauka, $13(4): 117-124,1976$. Apud Horticultural Abstracts, London, $\underline{47}(7): 617,1977$.

ISMAIL, Z .; HABEEB, H.; ELWAKEEL, A.T. Further evaluation of the relationship between $\mathrm{N}, \mathrm{P}$ and $\mathrm{K}$ composition of the cluster axis and the nutritional status of the grapevine. Agricultural Research Review, Cairo, 는(1):1-18, 1.964. Apud Horticultural Abstracts, London, 35 (3):565, 1965.

KHUDAVERDOV, E.N.; CHEMULOV, A.N.; KEKHAEVA, L. YA.; MARKELOV, V.A. Fertilization and yields. Sadovodstvo, Krasnodar, (4):33-34, 1977. Apud Horticultural Abstracts, London, $\underline{47}(10): 943,1977$.

KOROBKO, I.I. The effect of mineral fertilizers on the chemical composition of grapevine leaves. Sadovodstvo, Vinogradarstvo i Vinodelie Moldavii, Kishinev, (6):56-58, 1973. Apud Horticultural Abstracts, London, $43(3): 127$, 1973. 
KOROBKO, I.I. The effect of mineral fertilizers on vine growth, yield and fruit quality. Vinodelie $i$. Vinogradarstvo SSSR, $32(4): 46-47,1972$. Apud Horticultural Abstracts, London, $\underline{44}(9): 581,1974$.

LARSEN, R.P.; KENWORTHY, A.L.; BELL, H.K.; BENNE, E.J.; BASS, S.T. Effects of nitrogen, phosphorous, potassium and magnesium fertilizers on yield and petiole nutrient con-. tent of a Concord grape vineyard. Quarterly Bulletin, Michigan, $41(4): 812-819,1959$.

LAVIN, A.A. \& VALENZUELA, B.J. Fuentes y dosis de nitrogeno aplicadas sobre vides cv. Pedro Jimenes, bajo secano. I. Efectos sobre crecimiento y produccion. Agricultura tecnica, Santiago de Chile, $46(3): 253-259,1986 a$.

LAVIN, A.A. \& VALENZUELA, B.J. Fuentes y dosis de nitrogeno aplicadas sobre vides cv. Pedro Jimenes, bajo secano. II. Efectos sobre niveles de macronutrientes a pleno flor $y$ madurez del fruto. Agricultura tecnica, Santiago de Chile, $\underline{46}(3): 261-270,1986 \mathrm{~b}$.

LICUL, R. The effect of mineral fertilizers on the yield and quality of the cultivar Teran Crni in Istrian vineyards. Poljoprivredna Znanstvena Smotra, Zagreb, 30.(40):301-316, 1973. Apud Horticultural Abstracts, London, $44(6): 347$, 1974 .

MAATOUK, M.A.; AHMED, F.F.; EL-SAYED, M.A. Response of Red Roomy grapevines to nitrogen applications. I. Vegetative growth and leaf composition. Annals of Agricultural Science, Ain Shams University, Minia, 33(1):435-449, 1988. Apud Horticultural Abstracts, London, 59(4):314, 1989. 
MALAVOLTA, E. Manual de química agrícola. 3.ed. São Paulo, Editora Agronômica Ceres, 1981. 528p.

MALAVOLTA, E. Manual de química agrícola: adubos e adubação. São Paulo, Editora Agronômica Ceres, 1959. 487p.

MALAVOLTA, E. O potássio e a planta. 2.ed. Piracicaba, Instituto da Potassa e Fosfato, 1980. 62p. (Boletim técnico, 1)

MACAVOLTA, E. \& NEPTUNE, A.M.L. Caracteristicas e eficiência dos adubos nitrogenados. São Paulo, 1983. 45p. (Boletim técnico, 2)

MUZYCHENKO, P.I. Fertilization of vineyards on meadow soils. Vinodelie i Vinogradarstvo SSSR, $\underline{32}(2): 42,1972$. Apud Horticultural Abstracts, London, $\underline{43}(3): 127,1973$.

NEGRINI, F. Macroelementi in Viticoltura. Vignevini, Bologna, $15(4): 41-42,1988$.

NEILSEN, G.H.; STEVENSON, D.S .; GEHRINGER, A. The effect of NPK fertilization on element uptake, yield and fruit composition of Foch grapes in British Columbia. Canadian Journal of Plant Science, Ottawa, 67 (2):511-520, 1987.

NIJAR, G.S. \& RAM, S. Effect of different doses of nitrogen and phosphorus on the cropping and quality of grapes, variety Anab-e-Shahi. Journal of Research, dhiana, 6: 68-77, 1969. Apud Horticultural Abstracts, London, 40 (3) : 718,1970 .

NIJENSOHN, L.; AVELLANEDA, O.M.O.; PIZARRO, O.C.; OLMOS, F.S. Respuesta de la vid (Vitis vinifera cvs. Criollas y Cereza) a la fertilización en suelo "Barrancas arenoso fino" del Departamento de Maipú, Mendoza. Revista de la Facultad de. Ciencias Agrarias, Mendoza, $16(1-2): 3-18,1970$. 
NIJJAR, G.S. \& RAM, S. Effect of different doses of nitrogen and phosphorus on the cropping and quality of grapes, variety Anab-e-Shahi. Journal of Research, Ludhiana, $\underline{6}$ : 68-77, 1969. Apud Horticultural Abstracts, London, 40 (3) : 718,1970 .

NOGUEIRA, R.K. Adubação da videira. In: ENCONTRO DE TÉCNICOS EM AGRICULTURA, 2., 1965, Campinas. Anais. Campinas, DEMA, 1965. p.94-96.

PAIVA NETO, J.E. Consideraçōes sobre adubação para videira. em geral. Campinas, Instituto Agronōmico, 1941. 5p. (Mimeografado)

PEREIRA, F.M. Caracterização das principais variedades de. videira em cultivo no Estado de São Paulo. Jaboticabal, FCAV/UNESP, 1982. 12p. (Mimeografado)

PEREIRA, F.M. Videira (Vitis spp.) In: Campinas, Instituto Agronômico. Instruções agrícolas para o Estado de São Paulo. Campinas, 1972. p.269-270. (Boletim, 200)

PEREIRA, F.M.; HIROCE, R.; IGUE, T.; OLIVEIRA, J.C. Pegamento, desenvolvimento e extração de macronutrientes de cinco diferentes porta-enxertos de videira. Bragantia, Campinas, $\underline{35}(1)$ : XLVII-LIV, 1976. (Nota, 11)

PEROV, N.N.; CHEPELENKO, A.P.; PEROVA, L.I.; IL'YASHENKO, O. M. The role of potassium in grapevine nutrition and fertilization. Doklady Vsesoyuznoi Ordena Lenina Akademii. Sel'skokhozyaistvennykh Nauk imeni V.I, Lenina, (4):20-22, 1973. Apud Horticultural Abstracts, London, $\underline{44}(3): 127$, 1974 . 
PEROVIC, N. Influence of increasing doses and different combinations of NPK fertilizers on the contents of mineral substances in the vine leaf and on the grape yield. In: INTERNATIONAL COLLOQUIUM FOR THE OPTIMIZATION OF PLANT NUTRITION, 6., Montpellier, France, 1984. Proceedings. Montpellier, AIONP/GERDAT, 1984. v.4, p.1191-1198.

PHILLIPINE COUNCIL FOR AGRICULTURAL RESEARCH. The phillipines recommends for grapes, 1976. Los Baños, 1976. p. $24-28$.

PIMENTEL GOMES, F. Curso de estatistica experimental. 10.ed. 'São Paulo, Livraria Nobel, 1982. 430p.

PIRES, E.J.P. \& TERRA, M.M. Aspectos da viticultura paulista. In: SIMPÓSIO LATINO-AMERICANO DE ENOLOGIA E VITICULTURA, 2., JORNADA LATINO-AMERICANA DE VITICULTURA E ENOLOGIA, 2., E SIMPÓSIO ANUAL DE VITICULTURA, 2., Garibaldi/ Bento Gonçalves, 1987. Anais. Bento Gonçalves, Associação Brasileira dos Técnicos em Viticultura e Enologia, 1987a. p.206-213.

PIRES, E.J.P. \& TERRA, M.M. Uvas. São Paulo, Editora Três, 1987b. 12p. (Plante no sitio, 5)

PIZA JUNIOR, G.T. \& NEPTUNE, A.M.L. Observações preliminares sobre o modo de aplicação do fósforo e sua absorção pela videira, empregando-se superfosfato radioativo. Anais da. Escola Superior de Agricultura "Luiz de Oueiroz", Piracicaba, 23:350-355, 1966 .

POMOHACI, N.; DVORNIC, V.; POMOHACI, A. The effect of chemical fertilizers on the yields of table grape varieties during the first few year of fruiting. Lucrari Stiintifice, Institutul Agronomic "N.Balcescu", 14:365-371, 1973. Apud Horticultural Abstracts, London, $\underline{46}(2): 97,1976$. 
POPA, C. \& IONESCU, P. Effect of fertilizers on the Pinot Gris vine cultivar grown on terraces. Rev. Hort. Vitic., $19(2): 35-41,1970$. Apud Horticultural Abstracts, London, $\underline{41}(2): 447,1971$.

QUISPE, M.G.C. Efecto de três niveles de nitrogeno bajo tres formas de aplicación en rendimiento y calidad de vid. var Italia B. Lima, 1977. 66p. (Graduação - Universidad Nacional Agraria La Molina, Peru)

RAIJ, B. van \& QUAGGIO, J.A. Métodos de análise de solo para fins de fertilidade. Campinas, Instituto Agronômico, 1983. 31p. (Boletim, 81)

RAIJ, B. van \& ZULLO, M.A.T. Métodos de análise do solo para fins de fertilidade. Campinas, Instituto Agronômico, - 1977. 16p. (Circular, 63)

RETAMALES, J. \& RAZETO, M.B. Efecto de altos niveles de nitrogeno em parrons de vid. cv. Sultanina. Agricultura técnica, Santiago de Chile; 45 (1):53-56, 1985.

RODRIGUES, M.B. \& KIEHL, J.C. Volatilização de amônia após emprego de uréia em diferentes doses e modos de aplicação. Revista Brasileira de Ciência do Solo, Campinas, $10(1): 37$ 43,1986 .

SANGHAVI, K.U. \& NIJJAR, G.S. Effect of factorial combinations of nitrogen, phosphorus and potassium on the yield and quality of Himrod grape. Punjab Horticultural Journal Ludhiana, $\underline{18}(1 / 2): 48-52$, 1978. Apud Horticultural Abstracts, London, $\underline{50}(5): 273,1980$.

SANTOS NETO, J.R.A. A cultura da videira. Campinas, Instituto Agronômico, 1973. 108p. (Boletim, 203) 
SCHALLER, K. Assessment of nutrient status of grapevines by leaf analysis in four P - fertilization studies with special regard to the DRIS system. Mitteilungen Klosterneuburg Rebe und Wein; Obstbau ung Frllchteverwertung, 38 (4): 151-163, 1988. Apud Horticultural Abstracts, 58(11):920, 1988.

SERPUKHOVITINA, K.A. Fertilizers and yields. Sadovodstvo, $(10): 34,1975$. Apud Horticultural Abstracts, London, 46 (8) : 650, 1976 .

SERPUHOVITINA, K.A. The reaction of vine varieties to mineral fertilizers. Vinodelie i Vinogradarstvo, Kiev, $\underline{30}$ (5) : 41-44, 1970. Apud Horticultural Abstracts, London, $41(2): 447,1971$.

SETZER, J. Atlas climático e ecológico do Estado de são Paulo. São Paulo, Instituto Geológico e Geográfico, 1966. $61 \mathrm{p}$.

SHASHKOV, I.G.; VOLOSHINA, Yu. S.; KRASNOVA, N.A. Interactions of increased rates of mineral fertilizers and shoot load on the productivity and quality of the grapevine cultivar Aligoté. Vinogradarstvo i Vinodelie, Kiev, (30): 34-37, 1987. Apud Horticultural Abstracts, London, 58 (2): 96,1988 .

SITUATION de la viticulture dans le monde en 1986. Bulletin de I'O.I.V., Paris, 60 (681-682):971-1025, 1987.

TAKHMAZOV, V.G. \& ASKENDEROV, Kh. N. Effectiveness of applying mineral fertilizers in vineyards. Vinodelie $i$ Vinogradarstvo, (6):40-41, 1976. Apud Horticultural Abstracts, London, $\underline{47}(5): 462,1977$. 
TERRA, M.M. Carências de macronutrientes afetando o crescimento, concentração, acúmulo e interação de nutrientes na videira cv 'niagara rosada', desenvolvida em solução nutritiva.. Piracicaba, 1983. 221p. (Mestrado - Escola Superior de Agricultura "Luiz de Queiroz"/USP)

TERRA, M.M.; FAHL, J.I.; RIBEIRO, I.J.A.; MARTINS, F.P.; SCARANARI, H.J. Efeitos da calciocianamidos sobre a videira 'iv.iagara Rosada' (Vitis labrusca L. X Vitis vinifera L.). In: CONGRESSO ANUAL DA SOCIEDADE AMERICANA DE CIENCIAS HORTÍCOLAS - REGIÃO TROPICAL, 29., Campinas, 1981. Proceedings. Campinas, American Society for Horticultural Science, 1982. p.473-477.

THORNTHWAITE, C.W. \& MATHER, J.R. The water balance.

Centerton, Drexed Institute of Technology, 1955. 104p. (Publicacions in Climatology, v.8, n.1).

TULIN, A.S. \& MOROZOV, V.S. The effect of nitrogen fertilizers on the productivity of systematically fertilized grapevines growing on gravel soil. Vinogradarstvo, Odessa, $82-86,1976$.

URETA, C.F. Fertilizacion de la vid. El Campesino, Santiago do Chile, $\underline{6}: 25-34,1981$.

VELICHKO, A.I. The effect of bud-load and fertilizers on economic effectiveness in viticulture. Sadovodstvo, Vinogradarstvo i Vinodelie Moldavi, Kishinev, (4):48-50, 1974. Apud Horticultural Abstracts, London, $\underline{45}(5): 267$, $1975 a$. 
VELICHKO, A.I. The effect of bud-load and fertilizers on yield and grape quality. Sadovodstvo, Vinogradarstvo $i$. Vinodelie Moldavii,Kishinev, (3):23-26, 1974. Apud Horticultural Abstracts, London, $\underline{45}(5): 267$, 1975b.

VERMA, H.S. \& NIJJAR, G.S. Response surface studies on the effects on $N, P$, and $K$ fertilizers on vine growth yield and fruit quality. Journal of Horticultüral Science, London, $\underline{53}(3): 163-166,1978$.

VIALA, P. \& VERMOREL, V. Ampélographie. Paris, Masson \& Companie Edit., 1909. 323p.

WINKLER, A.J. General viticulture. 2.ed. Berkeley, University of California, 1965. 633p.

WOLF, J.K. \& POOL, R.M. Effects of rootstock and nitrogen fertilization on the growth and yield of Chardonnay grapevines in New York. American Journal of Enology and Viticulture, Lockeford, 39(1):29-37, 1988. 


\section{BIBLIOGRAFIA RECOMENDADA}

ARUTYUNYAN, S.S. Mineral fertilizer rates and their economic effectiveness. Vinodelie i Vinogradarstvo SSSR, (2):1516, 1987. Apud Horticultural Abstracts, London, 57 (9): 725,1987 .

BUKATAR, E.B. \& BABUSHKIN, Yu.V. Effectiveness of the methods of fertilizer application in vineyards. Sadovodstvo, Vinogradarstvo i Vinodelie Moldavii, Kishinev, (6):12-13, 1976. Apud Horticultural Abstracts, London, $\underline{47}(4): 304$, 1977 .

CHAUVET, M. \& REYNIER, A. Manual de viticultura, trad. de José Gaspar. Lisboa, Litexa Portugal, 1984. 304p.

COMMISSION ROMANDE DES FUMURES, SOUS-COMMISSION VITICOLE. La fumure de la vigne, directives pour la Suisse romande (revision 1983). Revue Suisse de Viticulture, Arboriculture, Horticulture, Lausanne, 15(3):155-163, 1983.

FREGONI, M. Il potassio in viticoltura. Vignevine, Bologna, $\underline{12}(12): 9-18,1985$.

HIROCE, R. \& TERRA, M.M. Teores de macronutrientes em pecíolo e limbo da videira 'Niagara Rosada'. In: CONGRESSO BRASILEIRO DE FRUTICULTURA, 7., Florianópolis, 1983. Anais. Florianópolis, SBF/EMPASC, 1984. p.1184-1187. 
HUGUET, C. Efectos que ejerce el potasio sobre el comportamiento de la vid. Revista de la Potasa, Berna, Seccion $29(5): 1-8,1978$.

JUNQUEIRA, W.R. Uva. In:____ Manual técnico das cul_ turas. Campinas, Coordenadoria de Assistência Técnica Integral, 1986. p.464-469.

LIXANDRU, G.; ALEXANDRESCU, I.; TARNAUCEANU, E. Fertilizer application to grapevines in the cotnari vineyard. Horticultura, Iasi, 30:89-92, 1986. Apud Horticultural Abstracts, London, $58(10): 721$, 1988.

MAHORKAR, V.K.; PATIL, V.K.; DEVGIRE, D.V. Effect of N, P, $\mathrm{K}, \mathrm{B}$ and $\mathrm{Zn}$ on Thompson Seedless vines trained on head system. II. Effect on yield. Research Journal, Parbhani, $10(2): 125-129$, 1986. Apud Horticultural Abstracts, London, $\underline{58}(4): 229,1988$.

MALAVOLTA, E.; HAAG, H.P.; MELLO, F.A.F.; BRASIL SOBRINHO, M. O.C. Nutrição mineral e adubação de plantas cultivadas. São Paulo, Livraria Pioneira Editora, 1974. 752p.

MILLER, G.W. La funzione fisiologica degli elementi minerali nelle piante e nella viti-impriego di prodotti fogliari nella boro nutrizione. Vignevini, Bologna, 13(5):21-28, 1986.

PEACOCK, W.L.; BROADBENT, F.E.; CHRISTENSEN, L.P. Late-fall nitrogen application in vineyards is inefficient. California Agriculture, Berkeley, $36(1 / 2): 22-23,1982$. 
RASSKAZOVA, V.E. Utilization of mineral fertilizers in relation to different spacing of grapevines. 'Sadovodstvo Vinogradarstva $i$ Vinodelie, $(40): 38-42$, 1979. Apud Horticultural Abstracts, London, $50(9): 578,1980$.

REZNIK, Ch.M. The effect of fertilizers on grapevine root growth. Sadovodstvo Vinogradarstvo i Vinodelie Moldavii, Kishinev, (10):14-16, 1983. Apud Horticultural Abstracts, London, 포 $(7): 525,1985$.

SOLDATOVA, R. Yu. \& EPSHTEIN, V.B. The effect of direct placement of fertilizers on the productivity of low yielding grapevines. Sadovodstva i Vinogradarstva, Uzbek, 105108, 1977. Apud Horticultural Abstracts, London, $48(7)$ : 569,1978 .

TERRA, M.M. Uvas finas para mesa e passa, rústicas para mesa e suco. In: CAMPINAS. Instituto Agronōmico. Recomendações de adubação e calagem para o Estado de são Paulo. Campinas, 1985. p.33-34. (Boletim técnico, 100)

TERRA, M.M. \& PIRES, E.J.P. Deficiências nutricionais e adubação da videira. In: SIMPÓSIO LATINO-AMERICANO DE ENOLOGIA E VITICULTURA, 2., JORNADA LATINO-AMERICANA DE ENOLOGIA E VITICULTURA, 2., e SIMPÓSIO ANUAL DE VITICULTURA, 2., Garibaldi/Bento Gonçalves, RS, 1987. Anisis. Bento Gonçalves, Associação Brasileira dos Técnicos em Viticultura e Enologia, 1987. p.296-302.

TERRA, M.M.; PIRES, E.J.P.; PASSOS, I.R. da S.; RIBEIRO, I.J. A. Videira Vitis spp. In: Campinas. Instituto Agronômico. Instruções Agrícolas para o Estado de São Paulo. 4.ed. Campinas, 1987. p.207-208. (Boletim, 200) 
WEAVER, R.J. Mineral nutrition. In: - Grape growing. New York, John Wiley \& Sons, 1976. p.160-171.

WEBSTER'S New Collegiate Dictionary, based on Webster's third new international dictionary. Springfield, G. \& C. Merriam Company, 1973. 1536p. 
148.

\section{A P E NDICES}




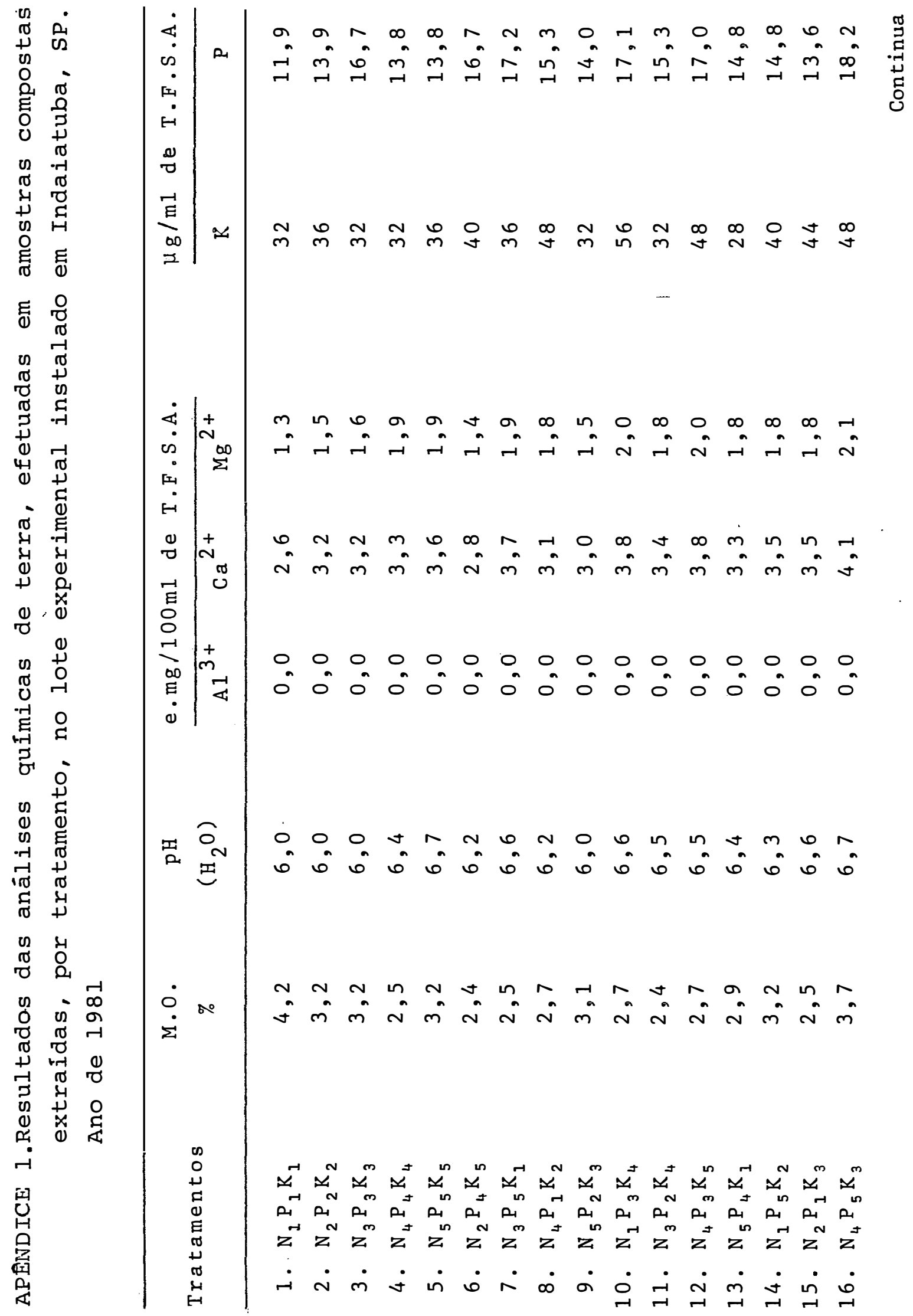


150.

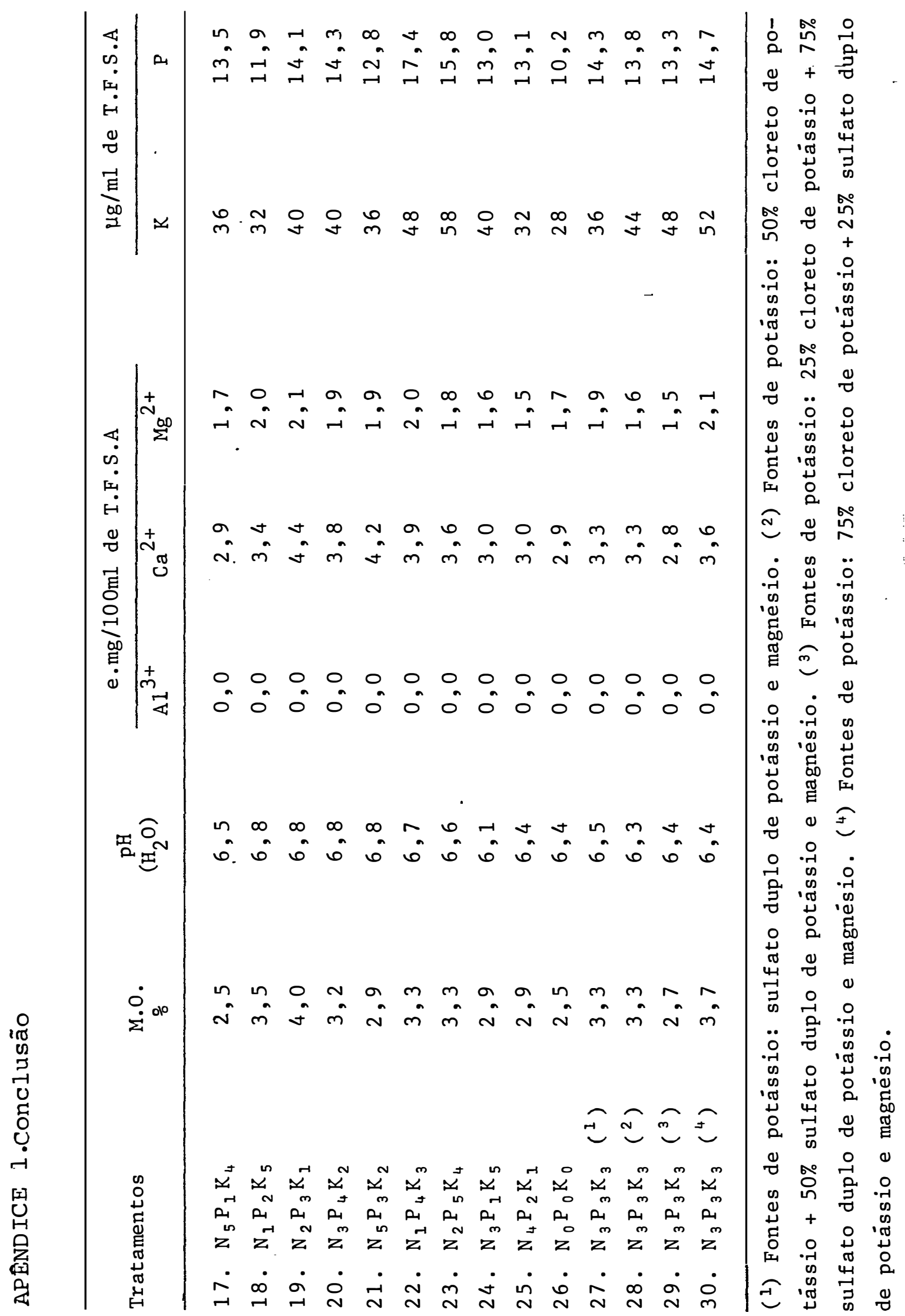


151.

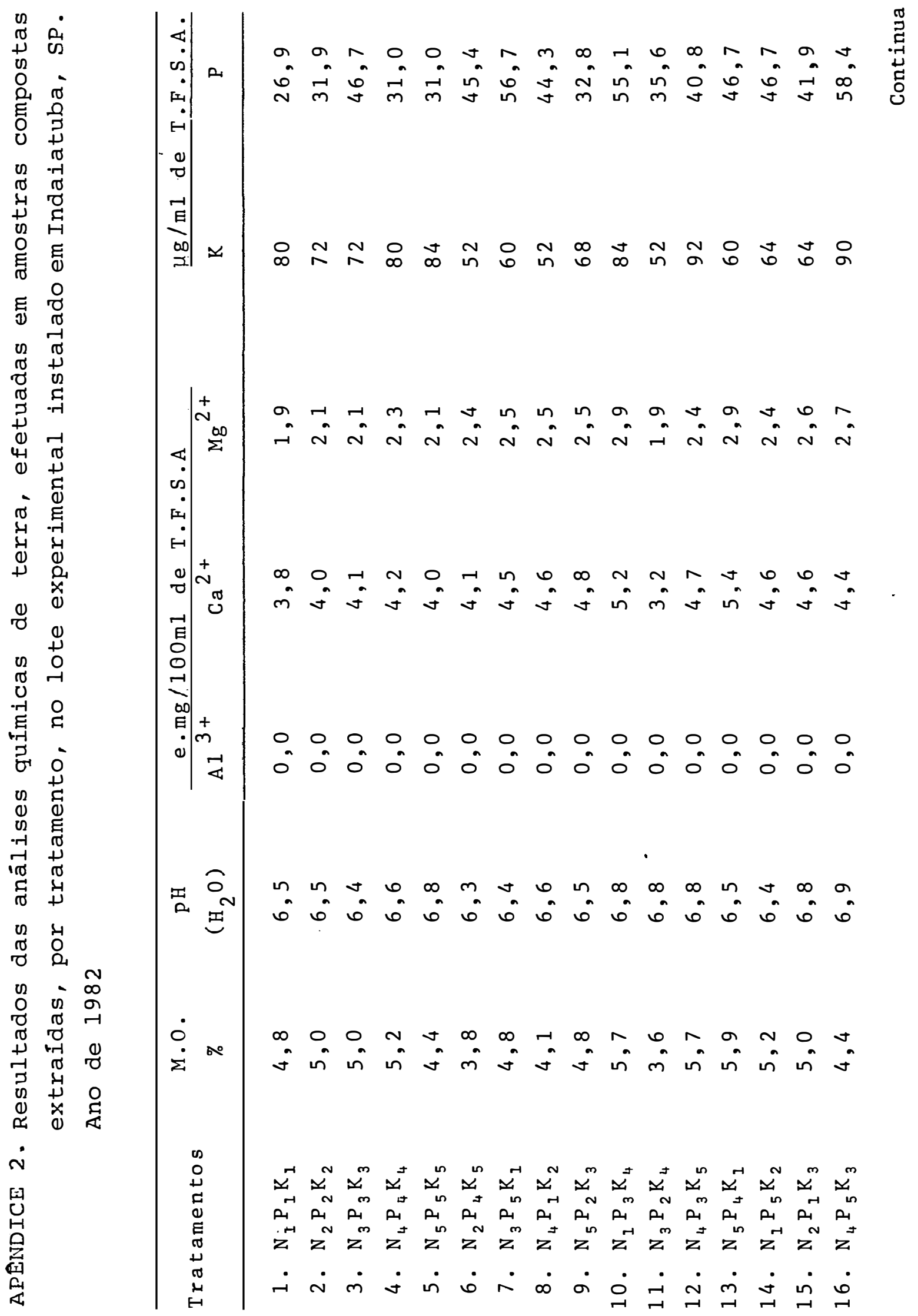




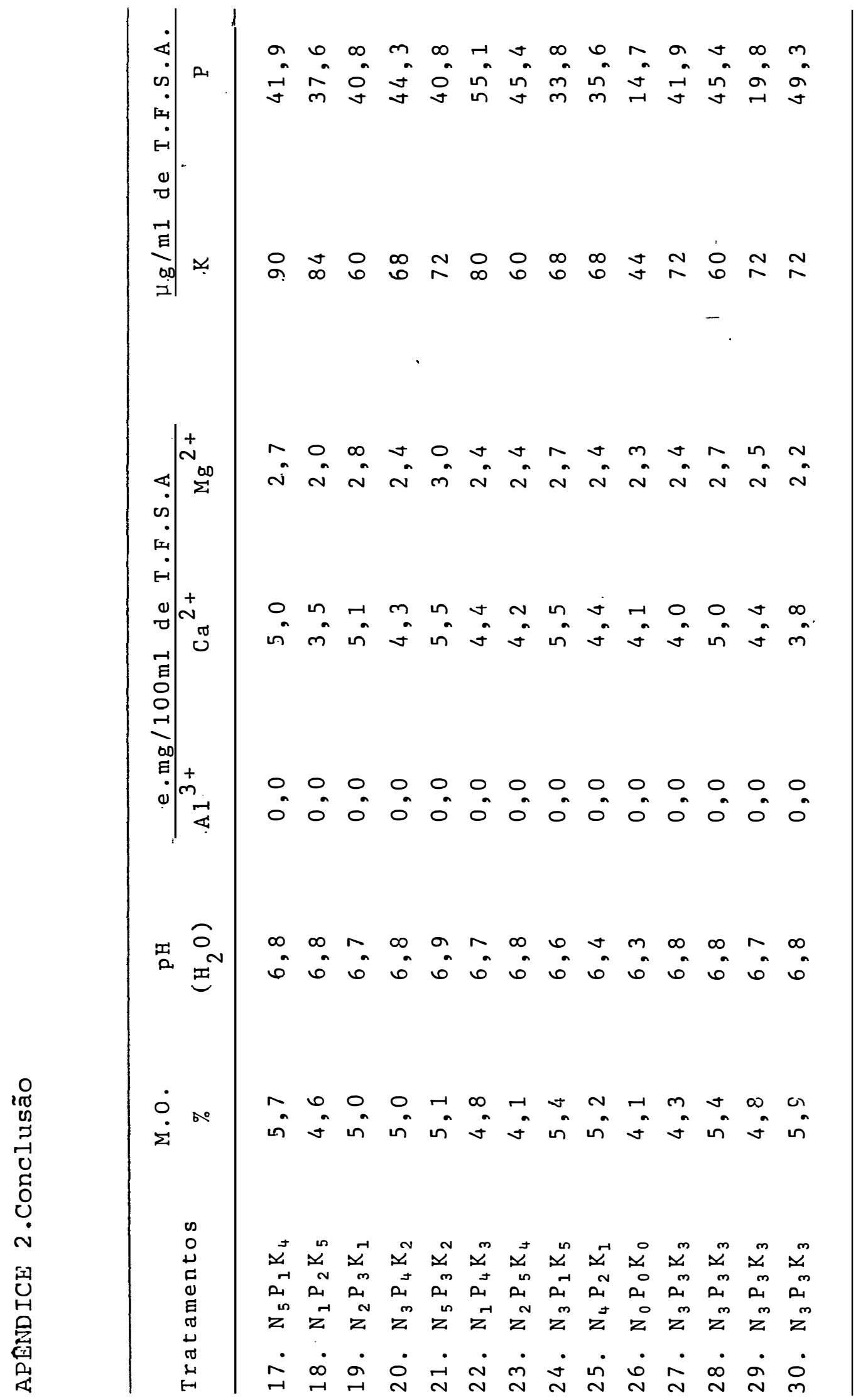




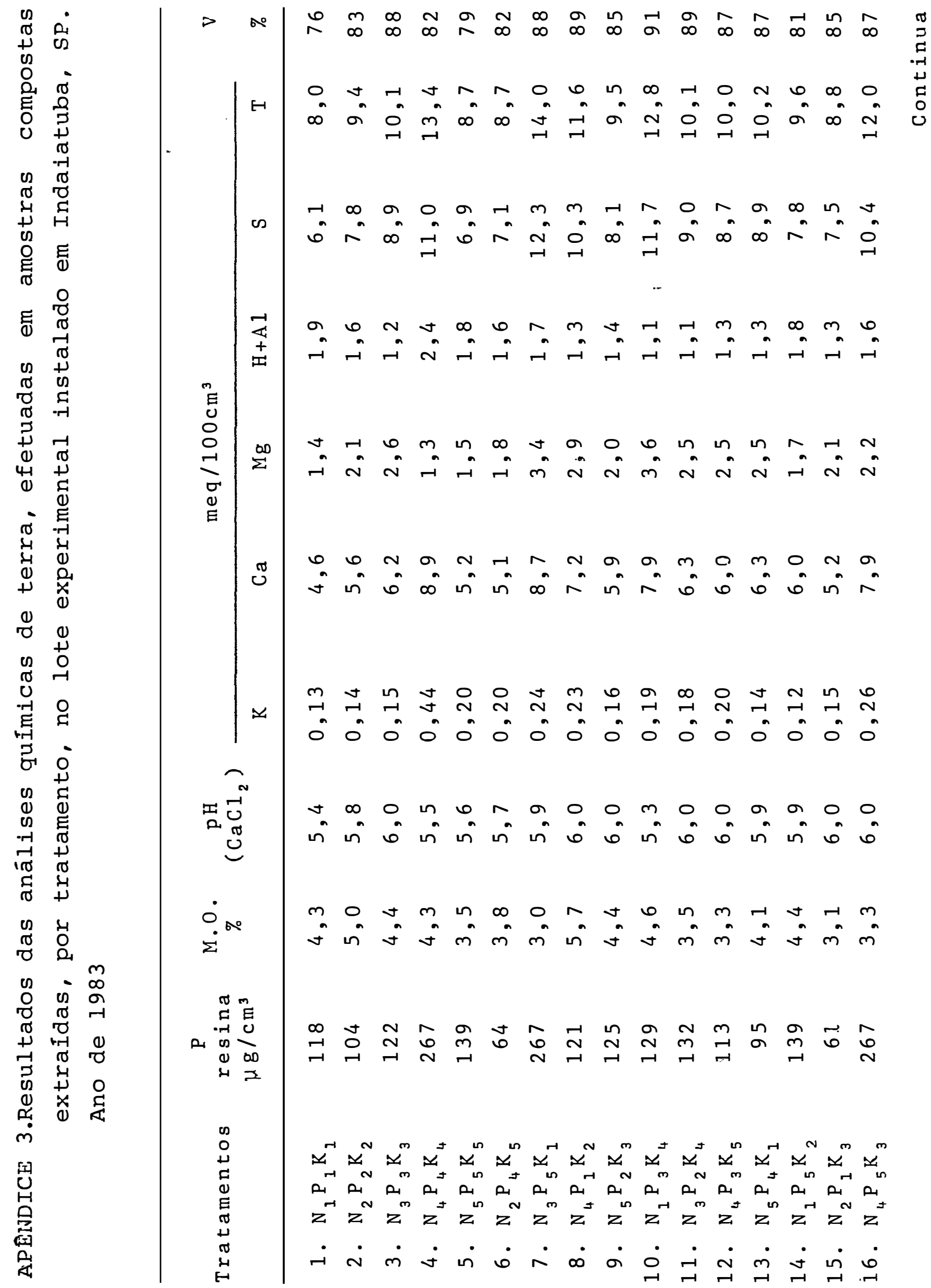




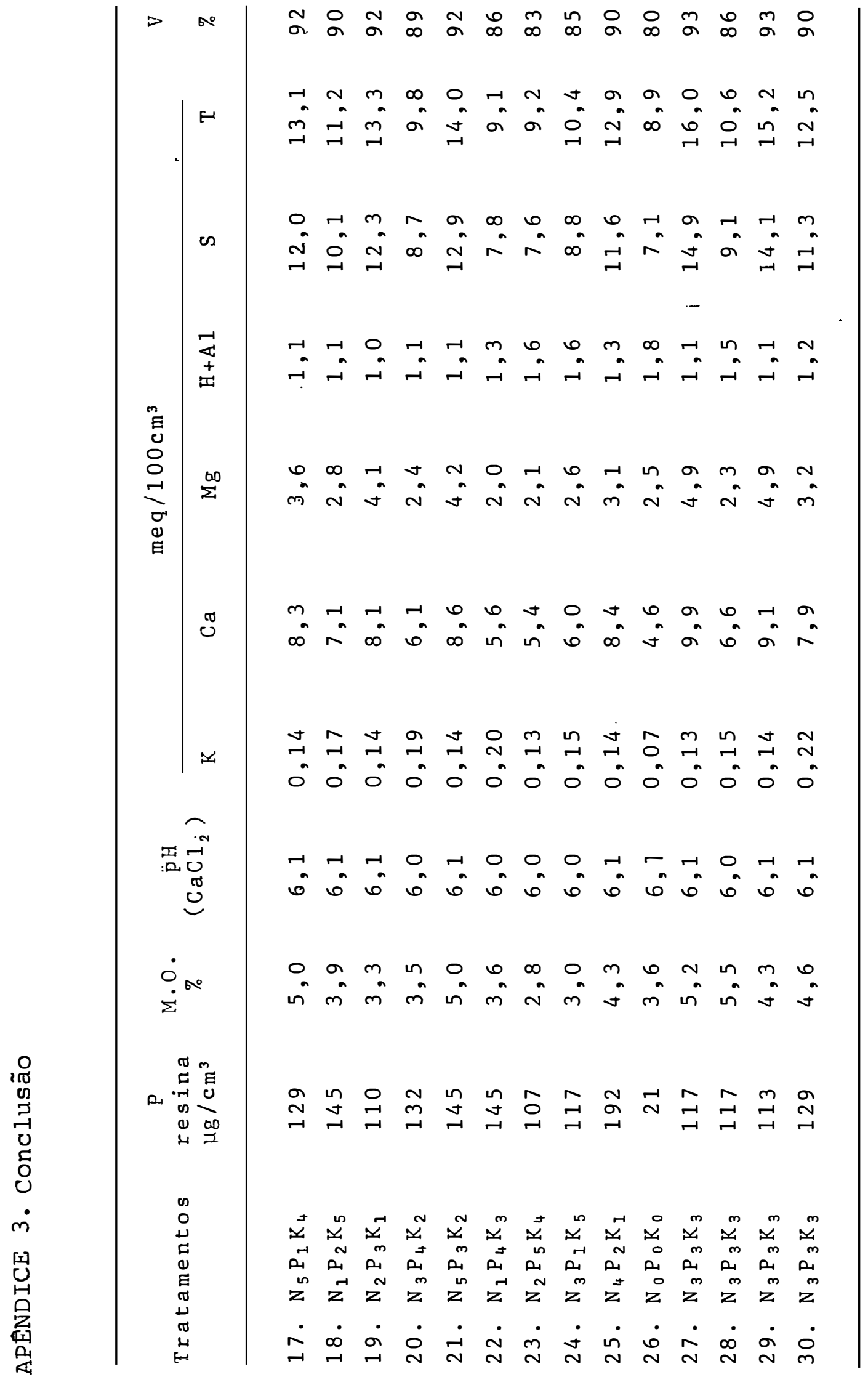




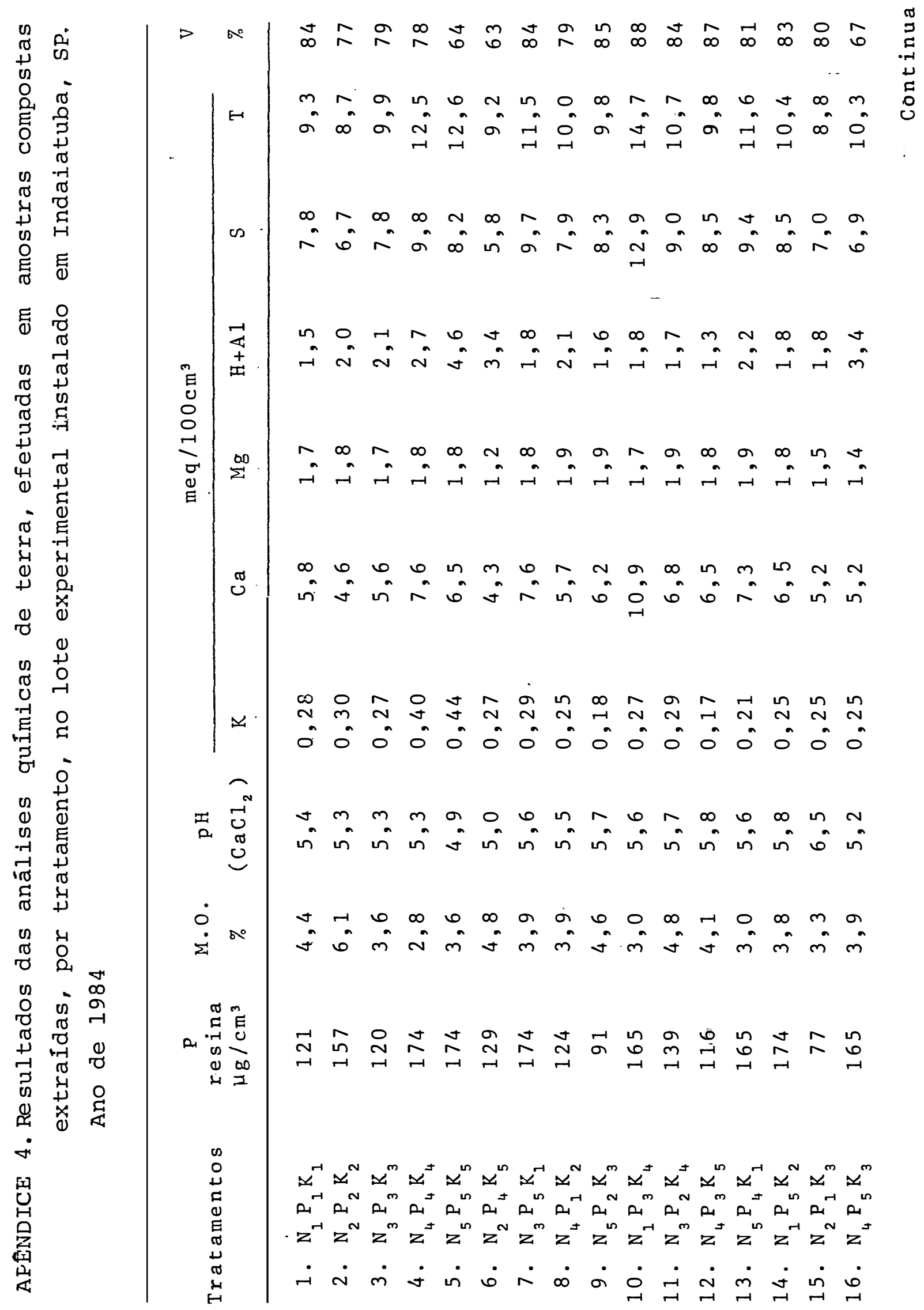




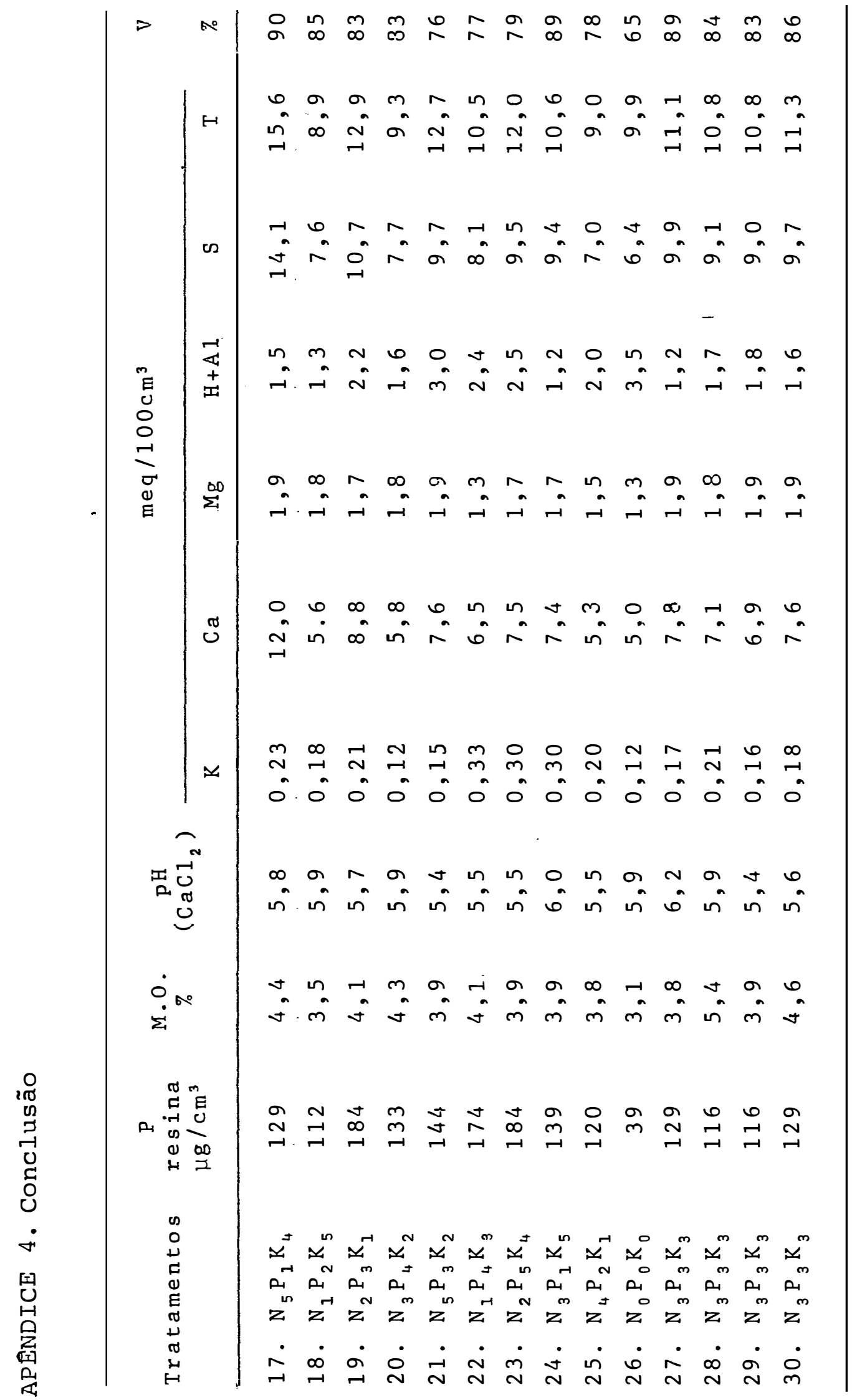




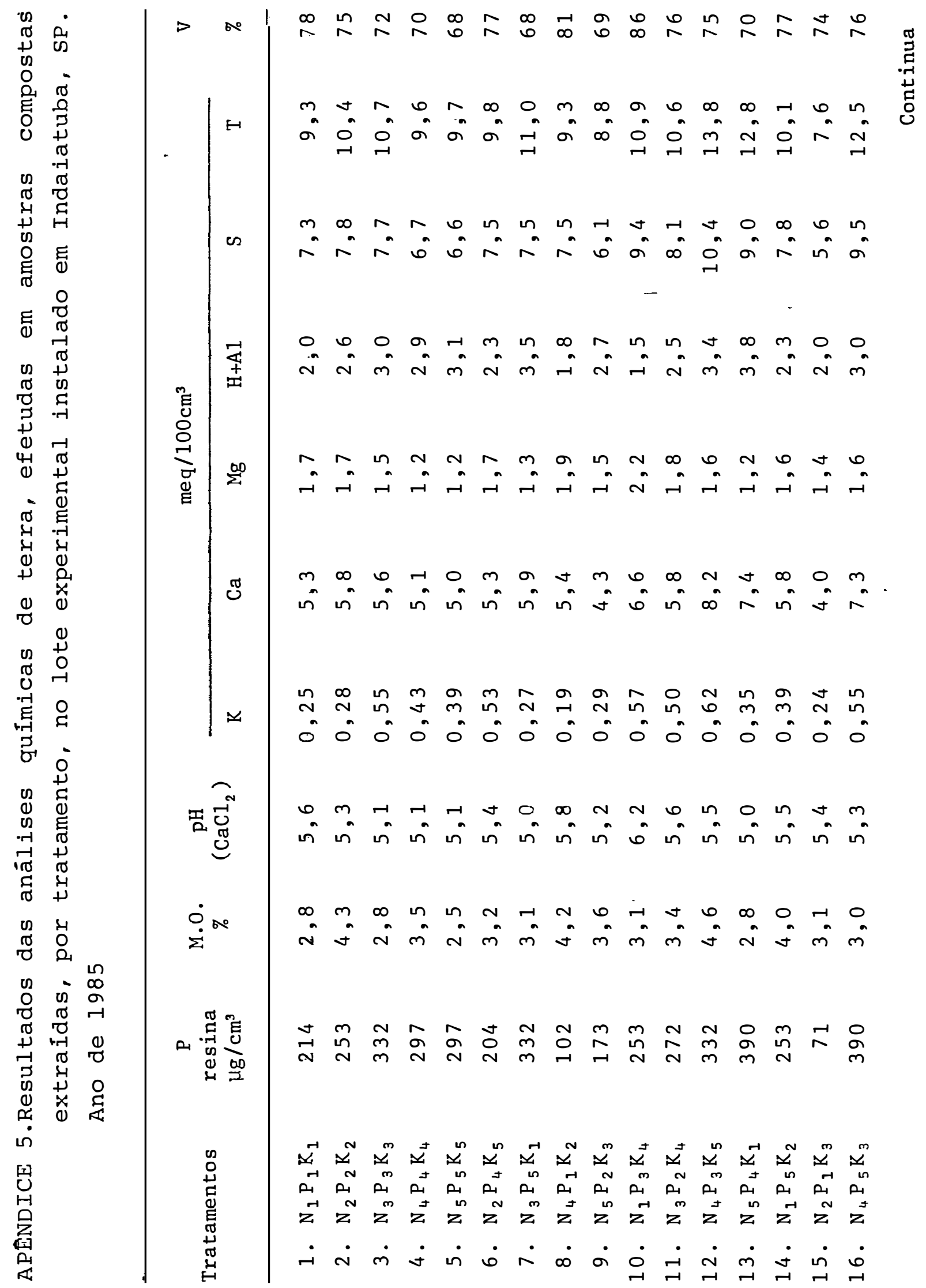




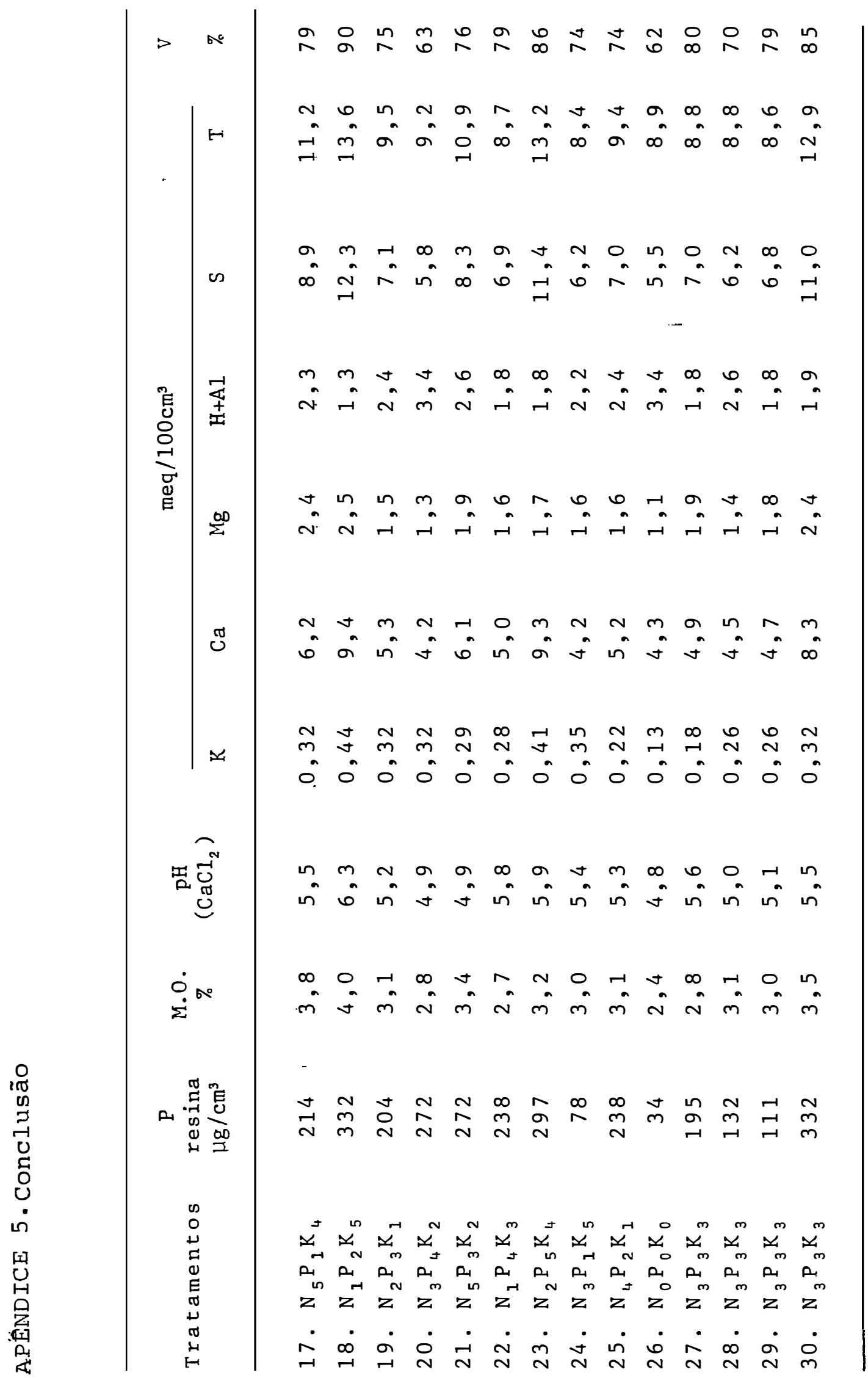

